\title{
CONSERVATION THROUGH LIMITED DEVELOPMENT: AN APPROACH FOR LAND CONSERVANCIES
}

\author{
A Professional Project \\ presented to \\ the Faculty of California Polytechnic State University, \\ San Luis Obispo \\ In Partial Fulfillment \\ of the Requirements for the Degree \\ Master of Planning in City and Regional Planning \\ By Catherine Joy Tarone
}

March 2015 
(C) 2015

Catherine Joy Tarone

ALL RIGHTS RESERVED 


\section{COMMITTEE MEMERSHIP}

TITLE:

Conservation Through Limited Development: An Approach for Land Conservancies

AUTHOR: Catherine Joy Tarone

DATE SUBMITTED: $\quad$ March 2015

COMMITTEE CHAIR: $\quad$ Chris William Clark, JD

Lecturer of City and Regional Planning

COMMITTEE MEMBER: Kelly D. Main, PhD

Associate Professor of City and Regional Planning

COMMITTEE MEMBER: Adrienne Greve, PhD

Associate Professor of City and Regional Planning 


\begin{abstract}
Conservation Through Limited Development: An Approach for Land Conservancies Catherine Tarone
\end{abstract}

The Land Conservancy of San Luis Obispo County is interested in determining the approach that it may take if it decides to pursue conservation and limited development as a strategy to preserve land. In using conservation and limited development, the Conservancy may put into practice its core values by employing this intenselycollaborative conservation tool and informing itself about development, conservation, collaboration and financing, in order to meet multiple community needs.

Information about the limited development process was collected from books, news articles and personal communications with professionals to determine its components. Each chapter of this report analyzes one component, putting authors' strategies into conversation, critiquing these and then offering conservancies several different approaches to accomplish each component. This report concludes that the most important decision that a conservancy must make when pursuing conservation and limited development, is determining the level of involvement appropriate for its conservation mission, resources, expertise, and role in realizing project goals. The final portion of the report provides two case studies that draw upon telephone interviews with professionals, and analyze the contrasting levels of involvement that each project's conservancy assumed. Since this report was requested by the Land Conservancy of San Luis Obispo County, it addresses some concerns and realities particular to the county; however, most recommendations are generally applicable to other land conservancies. 


\section{ACKNOWLEDGMENTS}

I would like to thank my Committee Chair and professor, Chris Clark, for his initial guidance in helping me to distill this very large topic into more manageable areas of discussion. I would also like to sincerely thank him as well as Professor Kelly Main for their patience and continued availability through this long process. I would like to thank Bob Hill, former Executive Director of the SLO County Land Conservancy, for directing me toward this topic and further developing my interest in conservation issues.

Additionally, I would like to sincerely thank Victor Montgomery and Ted Harrison for devoting their time to provide a real-world, practical perspective on the process of development and conservation through their in-person and phone interviews. Their in-depth discussions with me were crucial to the development of my paper and helpful to my own education and understanding.

Finally, I would like to thank my family and friends for their support and encouragement. 


\section{TABLE OF CONTENTS}

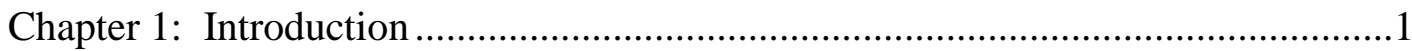

Challenges in Implementing Limited Development .............................................4

The Role of a Land Trust in a Limited Development Project...................................6

Chapter 2: Drafting a Mission Statement that Encourages Limited Development.....8

Chapter 3: Site Ecology .....................................................................................15

The Land Trust as Ecological Advocate ............................................................15

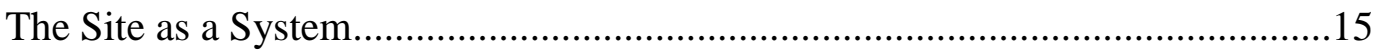

Balancing Human Impact with Human Access......................................................21

Chapter 4: The Site Plan .......................................................................................23

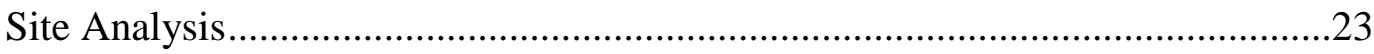

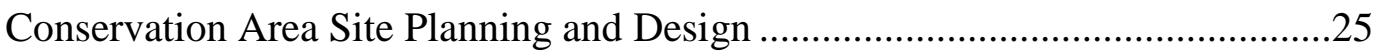

Development Area Site Planning and Design .....................................................29

Chapter 5: Development .......................................................................................

Defining the Direction of Development .............................................................

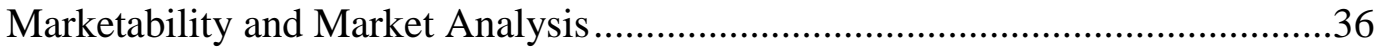

Chapter 6: Long-Term Project Management ............................................................41

Land Trust Involvement in Long-Term Land Management .................................41

Long-Term Adaptive Management ...................................................................

Composing an Easement Agreement …………………...................................50

Easement Costs vs. Landownership Costs ...........................................................52

Long-Term Maintenance Endowment Fund .......................................................56

Chapter 7: Limited Development Finance ...........................................................58

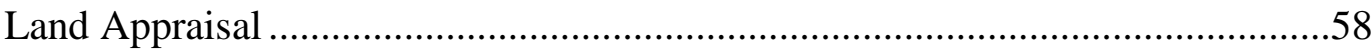

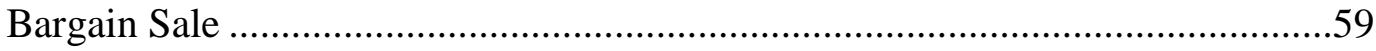

Full-Price Land Sale and Landowner Tax Deductions .........................................60

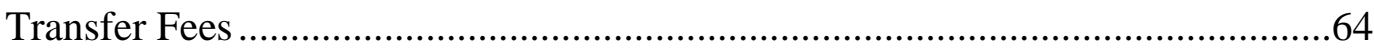

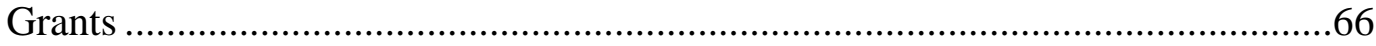

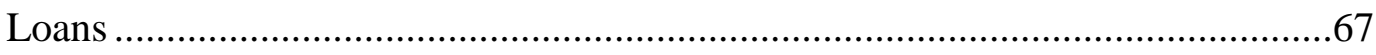

Minimizing Construction Costs .......................................................................68

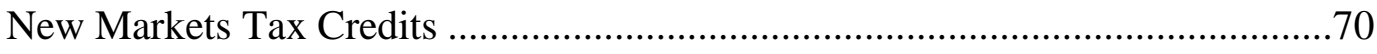




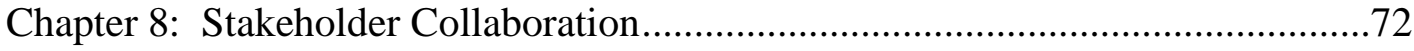

Determining the Desired Type of Partnership with Stakeholders .......................72

Valuable Stakeholder Behaviors and Roles .....................................................80

Stakeholder Collaboration Strategies ......................................................... 88

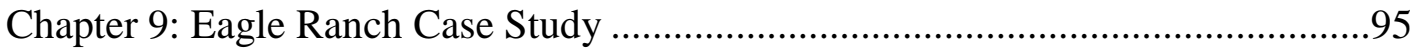

Eagle Ranch Project Description...................................................................96

The Role of the Land Trust in Project Design ..................................................97

Designing the Project Concurrently with the Environmental Impact Report .......98

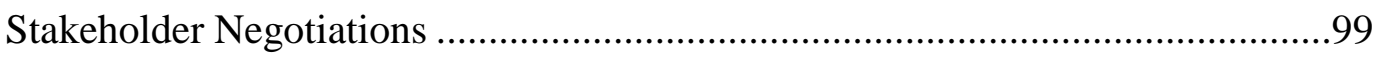

Chapter 10: Galisteo Basin Preserve Case Study .............................................. 107

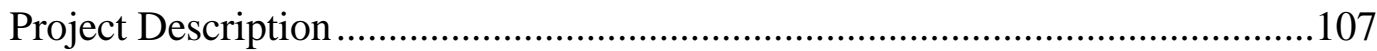

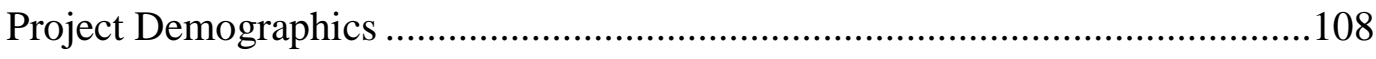

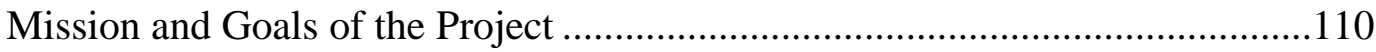

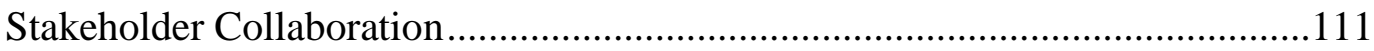

The Role of Amenities in Galisteo Basin Preserve .........................................116

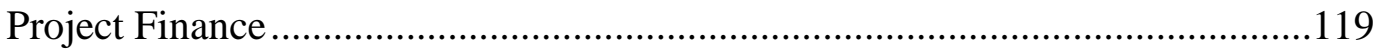

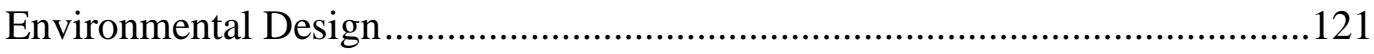

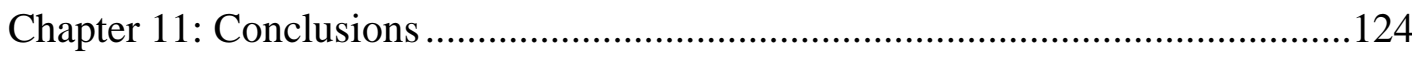

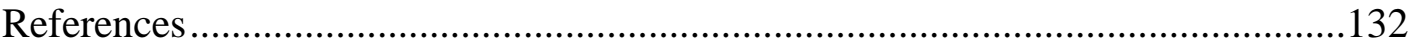

Appendices

Appendix A Interview Transcript: Victor Montgomery, RRM Design ..............138

Appendix B Interview Transcript: Ted Harrison, Commonweal Conservancy ..142

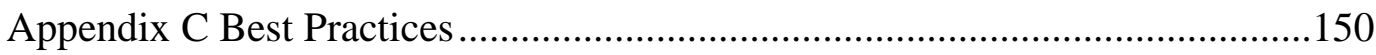




\section{Chapter 1: Introduction}

Conservation and limited development as a conservation tool has become useful for conservancies that must compete with developers for the conservation of land. By employing this tool, conservancies can cooperate, rather than compete, with developers by designating a small, less-critical, portion of a property as a development area in order to fund the preservation of the larger and more environmentally-sensitive portion. In many areas, decreasing open space, land prices, and landowners' reluctance to simply donate their entire property in exchange for a tax deduction, have become obstacles to conservancies attempting to piece together adequate conservation areas through the conservation of adjoining properties. Conservation and limited development makes land preservation more predictable by enabling conservancies to take the initiative, rather than waiting for others to approach them, and make competitive bids on conservation land.

This report details an approach for the Land Conservancy of San Luis Obispo County to implement conservation through the use of limited development. A locallyadapted approach to limited development may aid the conservancy in abiding by its mission statement to "utilize voluntary and collaborative measures" to achieve its vision of "distinct and thriving communities" surrounded by farms and public open space and its future goal of "funding voluntary easements on private lands" (LCSLO Strategic Plan, 2013). Conservation accomplished through limited development is also a worthwhile tool for land conservancies, in general, to utilize when the full conservation of a property is unlikely or entails too much risk. Limited development encourages collaboration rather than competition, enabling conservancies to pool their resources with other stakeholders in order to take part in larger, riskier projects. By using conservation and 
limited development, conservancies can adopt the developer's strategy of using the profits from the sale of homes to pay off its land-purchase and construction loans. By offering to purchase conservation land rather than asking for a donation, the conservancy eliminates the issue of landowner resistance to conservation since the landowner can recover all or, at least, a portion of the land's cost. According to Jeffrey C. Milder, author of numerous articles examining conservation and limited development, this method of conservation "can help land trusts move beyond opportunism to target highpriority lands in their service area" $(2006,14)$. Thus, limited development allows conservancies to initiate and actively pursue strategic properties by offering landowners a financially-appealing option that can compete with developers' proposals. At the same time, conservancies can ensure that development is situated in the least-impactful areas and can negotiate a property's size and quality.

According to Ted Harrison, the president and founder of Galisteo Basin Preserve, conservation and limited development provides a way to "reframe the conversation" between the developer and the conservation organization by "reassessing" the goals and priorities of standard development (McMahon, 2010, 137). In using limited development, all stakeholders involved must be willing to collaborate, negotiate and compromise as well as prioritize the site's unique ecological features, called conservation values. Despite limited development's prioritization of impact reduction and site ecology, these projects are, and must be, profitable for businesses and investors. Conservation accomplished through limited development generally results in improved property values, marketability and public appeal, which provides necessary encouragement for professionals in the industry to use this technique. 
The complexity of the limited development process can be both a boon and a hindrance for its participants. Limited development must reconcile several, seemingly opposite, considerations. For example, limited development must prioritize conservation yet maintain cost-effectiveness, employ collaboration strategies that are sensitive to stakeholder needs yet assert project goals, and lastly, adhere to environmental laws yet ensure that the project serves both the community and the developer. Land trusts that wish to embark on a limited development project must carefully balance preservation of sensitive habitat with community needs, while protecting their own financial resources. As a result, there is no universal strategy for conducting limited development projects due to the myriad of conditions under which they can take place.

Formulating an approach to limited development depends upon the professional role of the initiating organization, available funding, project goals, the land trust's own goals, habitat sensitivity, political climate and the stakeholders involved. However, there are numerous best practices that can aid land trusts in identifying the most appropriate and strategic method of conducting limited development projects. The purpose of this report is to provide the Land Conservancy of San Luis Obispo County with a strategic and functional approach to the limited development process. This report is divided into eleven main topic areas: an introductory discussion of limited development, drafting a mission statement and goals that encourage limited development, site ecology, the site plan, development, long-term project management, limited development finance, stakeholder collaboration, the Eagle Ranch case study, the Galisteo Basin Preserve case study and final conclusions. Appendix B contains a list of best practices for each subsection, excluding the case studies, consisting of the recommendations of other 
scholars, land conservancies and my own recommendations. Finally, Appendix C contains a distillation of the report's discussions and best practices, serving as a straightforward guide to limited development for conservancies.

\section{Challenges in Implementing Limited Development}

Challenges in limited development projects often arise due to incompatibility between development and conservation. For instance, the land trust must be careful not to lose its nonprofit status simply because it engages in profitable development. The Land Trust Alliance, the "national convener, strategist and representative of more than 1,700 land trusts across America," (landtrustalliance.org, 2012) asserts that land trusts are allowed to retain their nonprofit status, even if they purchase property solely to sell it for a profit (Land Trust Alliance, 2004). As a precaution, the Land Trust Alliance stipulates that a conservancy must notify the landowners of its intent to use the land in this way before purchasing it from them (2004). In a limited development project, the land trust uses the proceeds from the sale of properties like an endowment to pay off the land purchase loan and maintain the land long-term. Still, others may doubt that the land trust is using its profit appropriately and may feel the land trust is disregarding its commitment to conservation to gain a profit (Sullivan, 2005). Public and stakeholder criticism can cause obstacles for the project, costing it time, finances and even the risk of litigation.

Another challenge that comes with embarking on a limited development project is that despite the participation of stakeholders in the composition of project goals, there will always be individuals that think that the project's quality standards are not sufficient. Sullivan warns that if projects do not meet certain standards for habitat quality, 
appearance, visibility and character, residents may consider the project a nuisance (2005). A contentious project may be made less so if project designers gain an understanding of local politics and public needs by inviting public involvement to help define project goals and direction. Designers can then incorporate these needs into the very earliest stages of project planning. As will be seen, this report argues that early involvement of the public in the project is most often beneficial despite the expense and longer project timeline.

In addition, using an easement to accomplish conservation can be expensive and time consuming since easements require the conservancy to share land management with a homeowners' association or a landowner. This is a valid critique since the conservancy must assume responsibility for negotiating all land management decisions with a landowner or homeowners' association, monitoring whether easement terms are being adhered to and enforcing violations (Parker, 2002). For further discussion of the benefits and consequences of using easements to conserve land, see the Easement Costs vs. Landownership Costs section in Chapter 6 of this project.

Since limited development encourages unconventional priorities (McMahon, 2010), traditional priorities such as cost-effective building strategies may become subordinate to ecological or community issues. When deviating from traditional development, risk-reduction is crucial since there is a greater likelihood that each stakeholder will feel a degree of strain in their finances, staffing or level of expertise and must be able to negotiate among themselves to ensure that the project's priorities are possible for all stakeholders. Risk reduction strategies can include: trust-building strategies (New England EFC, 2003), early involvement of the public in project design, investment of time and finances in project quality or the use of an easement to share the 
cost burden with a landowner. Despite the numerous challenges that can arise when attempting conservation and limited development, if the conservancy takes the necessary steps to prepare for possible issues, many can be mitigated.

\section{The Role of a Land Trust in a Limited Development Project}

Since a land trust's core responsibility is to protect open space and habitat, it should ensure that a limited development project's mission and goals address ecological needs and prioritize conservation. Engaging in limited development opens to the conservancy numerous avenues for involvement in the development process including roles such as project initiator, designer, ecological consultant, mediator or community collaborator. The land trust is well-suited to engage in the development process since, according to Sullivan, "land trusts can mobilize and advocate for resources" $(2005,93)$. He states, "They are more free (sic.) from political limitations and so can demand public offsets from developers and can pursue their mission" (Sullivan, 2005, 93). Land trusts often have local credibility since they are nonprofit, public servants that possess unique influence in the community. To facilitate conservation through limited development, the conservancy may provide developers with access to ecological grants, advocate for certain projects and removes barriers for stakeholders. Since the roles the land trust can take depend upon its flexibility, the conservancy should be prepared to assume any role that must be filled in order to make these multi-faceted projects feasible.

The Land Trust Alliance acknowledges the need for greater expertise and different approaches to land conservation and thus it supports conservancies in assuming roles in limited development projects. A policy in the Land Trust Alliance's Standards and Practices, titled "Evaluating Partnerships," states "the land trust evaluates whether it 
has the skills and resources to protect the important conservation values on the property effectively, or whether it should refer the project to, or engage in a partnership with, another qualified conservation organization" $(2004,8)$. Thus, this statement frees the conservancy to pursue the most effective means of conserving a property, including forming partnerships with those that have similar goals. While some may argue that limited development should only be used if a conservancy lacks the resources to preserve the entire property (Milder, 2006), I argue that if a conservancy assumes a collaborative role in such a project, it can serve a greater number of people, encounter fewer barriers and be better able to maintain the project long-term. Thus, this report argues that conservation and development can be made to complement one another and conservancies have a legitimate, valuable contribution to make to local development. 


\section{Chapter 2: Drafting a Mission Statement that Encourages Limited Development}

Since incorporating development into a conservation project can negatively impact ecology, attract public and investor criticism and even endanger a conservancy's nonprofit status, it is important that a conservancy's mission statement and goals delineate acceptable uses of limited development. According to Sullivan, an effective mission statement and goals should make clear a land trust's priorities, reinforce its decisions in the face of criticism, and specify the type of expertise that will be needed by staff (2005). Sullivan recommends that a conservancy's mission and goals contain several requirements: First, procedures to ensure all stakeholders are treated ethically, second, a requirement for staff training in sustainable design and habitat rehabilitation, third, the prioritization resource preservation, fourth, cooperation with community groups' existing initiatives, and fifth, an objective to apply for grants and assistance programs $(2005,96)$. Even if the conservancy's existing mission and goals contain these provisions, it is important that they are revised to enable the conservancy to manage more intensive stakeholder collaboration, mitigate project impacts, advocate for conservation despite opposition, serve local needs, and piece together funding sources. This report argues that a conservancy's mission and goals must play the broad role of helping it to balance ecological needs with stakeholder needs and anticipate and mitigate likely issues.

A conservancy should also use its mission and goals to protect its reputation, and identify its desired level of involvement in a project. According to the Land Trust Alliance's Standards and Practices, a conservancy's mission and goals should set "parameters" for limited development projects that enumerate "specific natural resources or geographic areas where it will focus its work" (2004). Sullivan recommends that these 
strictures also specify the conservancy's minimum quality standards for both the developed and conserved portions (2005). According to Noss, conservancies, and even biologists, sometimes do not know the appropriate means of protecting a specific species and must rely on site observation and "general principles" to advise minimum quality standards for the site $(1997,220)$. According to McMahon, these standards should specify habitat design requirements, require that land management change in light of habitat health (adaptive land management), and specify the degree of involvement that the conservancy wishes to have in protecting key areas or determining appropriate development (2010). In addition, the Land Trust Alliance's Standards and Practices recommend that a land trust's mission protect the organization's nonprofit status by stating the role that the organization will play in serving the public interest (2004). Finally, as previously mentioned, the Land Trust Alliance recommends that a land trust's mission or goals place the conservancy in an advisory role by requiring it to analyze the site, identify all valuable habitat and conservation features and compose the property's protection agreement and site plan $(2004,8)$. These entities' recommendations should be heeded because they give greater authority to the land trust and ensure that ecological quality remains a priority in limited development.

Practical examples of mission statements that encourage limited development are provided by Commonweal Conservancy in Santa Fe, New Mexico, Santa Lucia Conservancy in Carmel, California and Franklin Land Trust in Massachusetts. Commonweal Conservancy's mission statement encourages comprehensive and direct involvement in limited development projects. This conservancy's mission reassures stakeholders that it will actively pursue a balance between community need and 
environmental stability, stating, “...we acquire signature landscapes that define a community's sense of place and spearhead the planning, entitlement and development processes associated with inclusive and engaging place-making" (Commonweal website, 2012). By using the words "acquire," "spearhead" and "engaging" the conservancy is committing to active involvement since these imply assuming risk, leading projects, solving problems and negotiating with stakeholders. Commonweal's mission states the situations in which it is willing to use limited development: to preserve signature landscapes and properties that "define a community's sense of place" (Commonwealconservancy.org, 2012). This conservancy thus wishes to lead and manage very visible and publicly important projects. Commonweal Conservancy was able to assume the burden of these tasks because it was established solely to manage the Galisteo Basin Preserve. However, many conservancies lack the resources to assume this level of involvement because they have additional land holdings that must also be monitored and maintained. In addition, limited development projects are risky, on-going, expensive, controversial, and require extensive expertise and professional connections. A conservancy should assess the level of involvement that it can realistically pursue and draft objectives and goals that will achieve it.

Santa Lucia Conservancy's mission statement enables limited development by emphasizing less-direct involvement in the development process and greater participation in land stewardship, education and impact mitigation. Santa Lucia Conservancy's mission states: "We work collaboratively on resource management, education and research to support and test...environmentally compatible human settlement" (2012, slconservancy.org). Rather than using its mission statement to position itself as a leader 
of its projects, the conservancy asserts its desire to become involved in smaller components of limited development. Its mission statement states: "it is our goal to advance understanding of the interfaces between human residences and natural environments" (slconservancy.org, 2012). Thus, the conservancy directs its efforts to understanding how the developed and the conserved portions impact one another, which is strategic since it allows the conservancy to anticipate, and then resolve, problems.

Santa Lucia Conservancy's mission and goals, allow it to pursue limited development: to further stewardship or promote ecologically-sensitive settlements. It also specifies the conservancy's priorities focusing on long-term management, stewardship, education and research. It protects its nonprofit status by setting minimum quality standards such as "integrity and transparency," "credibility and independence," "sound science" and "strategic partnerships" (slconservancy.org, 2013). While it does not identify particular partnering stakeholders, it states its commitment to strategic partnerships. To achieve even greater specificity, this conservancy would have to set requirements to achieve particular initiatives such as water conservation.

While Franklin Land Trust's mission statement does not specifically support limited development, it does, however, leave room for the land trust to support initiatives other than conservation, such as bolstering the local economy through protecting farms. The trust's mission states that it "works with landowners and communities to protect their farms, forests, and other natural resources significant to the environmental quality, economy and rural character of our region" (franklinlandtrust.org, 2012). By designating farmland preservation as an objective, the land trust must deviate from strict preservation. 
Thus, the inclusion of agricultural goals in Franklin Land Trust's mission statement required the trust to become involved in profitable sales in order to arrange for the farmland's long-term maintenance. In fact, Franklin Land Trust sold the development rights of a property with an agricultural easement to the state of Massachusetts and the protected farmland of that same property to a dairy owner (McMahon, 2010). However, Franklin Land Trust's mission constrains it to protecting, but not constructing, small projects, such as farms, in order to fulfill very specific purposes. Thus, Franklin Land Trust chose to use its mission and goals to allow the most basic of limited development functions-the ability to purchase, and profit from, the sale of developed land in order to fund the purchase of the conserved portion. Such a mission statement is particularly useful when a conservancy would rather fund the maintenance of a small, existing property, rather than embarking on new development.

In San Luis Obispo County, the conservancy should consult localities’ Area Plans before finalizing revisions to its mission and goals since they discuss Coastal Zone requirements, circulation regulations and the acceptable types, density and intensity of development. For instance, the San Luis Bay Area Plan states that "careful reading of the planning area standards will assist in creating projects that are consistent with adopted policies and regulations" (2009, 1-1). Furthermore, Specific Plans and Community Plans outline the visions of local residents and businesses and propose policies and programs that incorporate community suggestions (Shandon Community Plan, 2012). Because some of these documents are outdated, the Conservancy of San Luis Obispo County should also consult county planners when composing its mission and goals to accommodate limited development. 
The Land Conservancy of San Luis Obispo County's mission states: “through voluntary and collaborative measures (the Conservancy) works to permanently protect and enhance lands having important scenic, agricultural, habitat and cultural values for the benefit of people and wildlife" (Strategic Plan, 2013-2018, 3, parentheses mine). This mission statement clearly articulates the Conservancy's dedication to preservation and its priorities, and while it does not specifically address limited development, this conservation tool is both voluntary and highly collaborative. If the Land Conservancy of San Luis Obispo County does not wish to make limited development its primary function, it need not mention it in its broad mission statement.

In future updates of its Strategic Plan, the Land Conservancy of San Luis Obispo County may consider specifically mentioning the use of conservation and limited development in one of its goals since, I argue, this strategy would complement its existing vision and several of its goals. This vision is to achieve "distinct and thriving communities" surrounded by farms and public open space and its future goal of "funding voluntary easements on private lands" (LCSLO Strategic Plan, 2013). In addition, Goal 17 of the Conservancy’s 2013-2018 Strategic Plan states that it will prioritize projects that accomplish goals in all three of its Conserve, Care and Connect programs. Within the Conserve program, limited development enables the Conservancy to fulfill Goal 1: increase the land under its protection to 20,000 acres and Goal 2: insure that all conservation projects are self-sustaining since these projects prioritize conservation and provide numerous collaborative long-term funding options including full-price land sales, landowner easement pledges and homeowner's association maintenance (LCSLO Strategic Plan, 2013). Within the Care program, limited development helps accomplish 
Goal 4: raise an endowment by 2020 and Goal 9: participate in the development of conservation planning documents, due to the previously-mentioned funding options and land trust participation in composing and advising the project's easement and development agreements (LCSLO Strategic Plan, 2013). Finally, within the Connect program, a limited development project may help accomplish Goal 10: increase private philanthropy and Goal 13: provide meaningful and sustainable education and service opportunities for the community, since these projects encourage philanthropy such as bargain sales and landowner easement pledges and depend upon stewardship by residents (LCSLO Strategic Plan, 2013).

While the Land Conservancy of San Luis Obispo County's goals do not specifically mention conservation and limited development, they leave room for the conservancy to pursue this conservation tool. The land conservancy should incorporate these goals into future updates of the Strategic Plan. In making their mission and goals more oriented toward accomplishing conservation using limited development, the Conservancy may consider specifically mentioning limited development, or incorporating strategies that empower it to assume any role it desires in projects rather than one assigned to it by stakeholders. Thus, the Land Conservancy of San Luis Obispo County’s mission statement and goals should increase its public visibility, explicitly state its support for, and desired role in, limited development and protect its reputation and nonprofit status. They should define minimum quality standards, encourage urban and ecological compatibility, specify resources for protection, refer to jurisdictions' plans, propose funding sources and designate its responsibility for composing the site plan. 


\section{Chapter 3: Site Ecology}

\section{The Land Trust as Ecological Advocate}

When shouldering the role of ecological advocate among project stakeholders, a land trust should have an understanding of the site's natural processes. The Land Trust Alliance's document, Standards and Practices, recommends that when a land trust sells a property, it should, at minimum, compose a preservation agreement and a site plan indicating the location of sensitive or important areas for preservation (2004). In this role, the land trust acts as an advisor to stakeholders and must, therefore, be an authority on green design and preservation. A land trust should have a realistic grasp of the feasibility of project features and approaches proposed by stakeholders. A land trust should also anticipate potential conflicts and problems and suggest preventative solutions and mitigation. The following discussion outlines ecological principles that are key concepts for land trusts when negotiating with project stakeholders about site design.

This report agrees with the Land Trust Alliance (2004) and Perlman and Milder (2005) that a conservancy should assume responsibility for the composition of the site plan for both the developed and conserved portions. In creating a site plan, the conservancy has the burden of predicting and mitigating likely impacts, preserving beneficial flows and preventing the depletion of the site's stabilizing resources.

\section{The Site as a System}

When a land trust begins to evaluate the feasibility of a proposed limited development project, it should first understand how the site functions naturally, without development, so that it may accurately evaluate how the site will function after the 
project is built. A key element of designing and locating a project is the management of disturbances that arise from the joining of two, initially incompatible, systems: the ecological system and the urban system. According to Donela Meadows, a system is a group of elements that are "interconnected in such a way that they produce their own pattern of behavior over time" $(2008,2)$. The "behavior patterns" of systems are shaped by the habitats and species within them which Meadows calls "structuring forces," stating that they make up a "feedback loop" that keeps the system stable (2008). A system can absorb more impacts without changing if it has "resilience," or, in other words, numerous feedback loops in the event that one fails (2008). Perlman and Milder provide an example of one of these structuring flows, stating that if there is a system in which a species of frog migrates from the water to the trees as it matures, the habitat it moves through is shaped because plants, predators and prey depend upon an annual migration of frogs from the wetland to the trees (2005). While the introduction of development will interrupt some flows, the land trust should protect those that stabilize the system.

According to Meadows, systems can coexist as long as the flow from one system does not disrupt the patterns of another system (2008). It is the land trust's duty to focus stakeholder attention on the compatibility of adjoining systems such that a surplus flow from one system satisfies a shortage in the other (Meadows, 2008). The land trust should also evaluate whether the project will allow the site's natural processes to continue. While there will inevitably be impacts between the urban and ecological systems, the land trust can suggest particular mitigation measures for impacts above a certain threshold and can advise the use of man-made design features in directing flows and maintaining system patterns. 
One issue with placing different systems in contact with one another is that unnatural flows are created. Harmful flows resulting from direct human access include: wildfires, poor vegetation management, trail widening, off-road vehicle use, poaching, plant collecting, littering, and destruction of core vegetation due to off-trail intrusion (Sauvajot et al., 1998). For example, according to Noss, birds that nested in trees near suburbs had a higher rate of predation than those that nested in more isolated forest, likely due to the presence of domestic animals (1997). A common point of conflict between urban and ecological systems is the incessant flow of urban impacts into protected areas due to the urban systems' numerous feedback loops. The urban system's feedback loops are much more resilient since in order to ensure human health, they are supported by sheer population size, mass production and importation of resources from outside systems (Meadows, 2008). Since ecological systems are less-resilient, this report argues that land trusts must advocate for the inclusion of additional feedback loops to strengthen ecosystems against harmful urban flows. Land trusts should also hire biologists to study local resource flows to tailor mitigation to the local landscape.

To better understand how negative flows change a habitat, Raymond Sauvajot et al., of the National Parks Service, published a case study analyzing the effects of disturbance on small animals and birds in a 6,700-hectare chaparral preservation area adjacent to development in the mountains of Santa Monica, California (1998). The study found a decrease in the area's native wildlife and an increase in disturbance species (Sauvajot et al., 1998). The only native species that could be found in the site were birds, which, the study speculates, have larger ranges and can fly between disturbed and undisturbed areas (Sauvajot et al., 1998). The study also found that disturbed areas 
contained vegetation that was lower to the ground and "less woody" than undisturbed vegetation, demonstrating that disturbance creates long-term impacts that actually alter habitat (Sauvajot et al., 1998). Thus, even after impacts have ceased, disturbed areas remain altered until succession gradually restores them.

Despite the Sauvajot's study's findings that nearby development caused impacts to the entire site, including the site's interior, this study may be used as evidence to support limited development since most disturbances occurred within 400-600 meters of an urban edge or road (1998). Sauvajot's study concludes that development causes fewer disturbances to habitat than roads, paths or other public access points (1998). Since the greatest impacts were the result of flows of people and domestic animals, Sauvajot recommends using buildings to prevent public access to habitat (1998). Thus, this report argues that limited development may be used strategically to control harmful flows.

Another issue with locating development in proximity to conservation areas is that human lives may be endangered by ecosystem fluctuations such as floods, wildfires and rock slides (Meadows, 2008). Historic hazards should be considered before locating homes in the development area. According to Meadows, since the likelihood of fires or floods changes seasonally, safety ordinances must be flexible to control these hazards depending upon site conditions (2008). Often, it is part of a landscape's natural process to burn or flood periodically. According to Perlman and Milder, limited development should always incorporate fire-resistant buildings and designs since the developed portion will always be located in or near dry, grassy areas (2005). I recommend using barriers such as watered sports fields, gardens with native plants, ponds or watered farmland to 
buffer residences from natural areas at risk for flood or fire. Further discussion of fire safety is provided in the Development Area Site Plan section of this report.

One example of a nutrient flow that the Land Conservancy of San Luis Obispo County will have to control for is erosion and runoff which can deplete or add excess nutrients to a system. An undated soil survey conducted in the Paso Robles area of San Luis Obispo County lists erosion as a problem and advises minimizing erosion by placing crop rows perpendicular to hill slopes, planting annual or permanent cover crops, rotating crops, leaving plant residue in the ground during the rainy season or using a drip watering system (U.S. Department of Agriculture). This soil survey also suggests constructing a water retention basin to replenish the underground aquifer and planting "important forage species" in the county such as "soft chess, wild oats, and burclover" (U.S. Department of Agriculture, undated). While the findings of this soil survey apply only to the specific property that it was conducted for, erosion is a common issue in San Luis Obispo County as well as in most limited development projects. To combat erosion, McMahon encourages using pervious cement, pavers or gravel for roads and parking lots (2010). According to Perlman and Milder, erosion from construction sites is 2,000 times greater than on forested land and 200 times greater than on paved land $(2005,208)$. Since project construction can cause heavy flows of soil and pollution, anti-erosion measures should be implemented in all limited development projects to prevent permanent alteration of nearby habitat areas.

It is also important that the conservancy analyze a project's likely impacts on larger regional systems. For instance, if it is unclear why a site cannot support sensitive species, Perlman and Milder suggest referring to the problems faced by neighboring 
regions such as air pollution or water shortages to determine what issues the site might face (2005). For instance, an article in the Modesto Bee discusses a regional system imbalance in the Central Valley of California, in which water-intensive, permanent, crops such as orchards and grape vineyards, are consuming an excess of Merced County's groundwater (Sbranti, 2013). This system imbalance is causing 1,200 square miles of the county to sink one foot per year, and is eroding the clay layer of the underground aquifer, which will eventually prevent it from ever refilling (Sbranti, 2013). The article cites one farmer who says, "I question the wisdom of growers who plant permanent crops...on land that has no access to river or canal water" (Sbranti, 2013, par. 26). Thus, by deviating from the historic use of the land, this area's farmers contribute significantly to land subsidence, property damage, the draining of wetlands, and even, the sinking of the region's water transport system which relies on the land's natural slope (Sbranti, 2013). If a land trust discovers that neighboring jurisdictions are struggling with problems such as subsidence, the land trust should ensure that site uses complement the historic use and ecology of the system. To address subsidence specifically, use restrictions or even crop restrictions can be included in the easement agreement. If water-intensive uses will be included, as recommended by the soil survey, water retention areas should also be planned to allow rainfall and water use by residents to remain on-site and replenish the underground aquifer. A limited development project called Inspiration in Bayport, Minnesota opted to filter the site's water naturally using fifteen reservoirs that direct water into wetlands and rain gardens in the urban area (McMahon, 2010). Water retention basins also act as wetland habitats and scenic duck ponds around which residents may walk or fish. 
However, since Arendt argues that drainage ponds are not a good solution because they collect garbage and breed mosquitoes, he recommends installing drainage pipes that lead to running water such as streams (1994). This report differs with Arendt's recommendation since storm water runoff may need to be filtered before being released into a natural creek or pond in order to protect wildlife and comply with water quality laws. In addition, drainage pipes are usually metal and so transport water very quickly and do not allow slow seepage into the ground via streams. This report argues that state, federal and county water quality laws should be consulted before designing the water delivery system in a limited development project. This report also argues that if drainage ponds cannot be filled with water, stocked with fish to control mosquitoes and maintained to be an attractive feature of the community, then bioswales, permeable pavement, and planters with native vegetation are better alternatives because they clash less with the natural balance of the ecosystem. Finally, drought-tolerant native species should be used to decrease the need for water and to showcase the features that make the community unique. Often, mimicking the site's historic inputs and outputs is necessary.

\section{Balancing Human Impact with Human Access}

While human intrusion can disturb ecosystems, it is important to allow the public to access open space. Perlman and Milder agree that it is desirable for residents to use open space for recreation since it deepens their connection to the land and since their homeowner's association fees pay for the land's maintenance (2005). Land trusts should ensure that site access is balanced with preservation. 
To limit the impact of foot traffic, trails for people may be constructed along a less-sensitive route. This report argues that trails should be located to suit the site's existing flows. Land trusts should prioritize the land's protection and locate trails in large, common or resilient environments (Perlman \& Milder, 2005). However, since, according to Milder, the purpose of hiking trails is to provide residents with a change of scenery, the conservancy should also consider which areas would be desirable hiking destinations and allow access to scenic or even riparian areas (Perlman \& Milder, 2005). In sensitive areas, trails can take the form of a bridge built over sensitive habitat, preventing hikers from wandering (Perlman \& Milder, 2005). Since the land trust should prioritize the land's protection, vital feeding or nesting areas should be entirely avoided.

According to McMahon, parcels that have already been disturbed should be used for agriculture, development or public recreation since only disturbance species will use them as habitat (2010). When a site hosts gas stations, agriculture or mining, these can leave "nutrients, sediments or toxins" in the soil (Perlman \& Milder, 2005, 121). Perlman and Milder state that the stability of habitats depends upon key resources such as phosphorous, nitrogen, potassium, food sources, predators and habitat size $(2005,84)$. If disturbance changes these key resources, the land cannot sustain sensitive species often for many years; however, it can still serve as a feeding ground for birds and disturbance species and a recreation area for people (Sauvajot, et al., 1998). Thus, McMahon and Sauvajot agree that a disturbed parcel should be used for community recreation and as habitat for disturbance species since these species can substitute as a food source for native species (Sauvajot, et. al., 1998). 


\section{Chapter 4: The Site Plan}

\section{Site Analysis}

After gaining an understanding about how sites function as systems and ways to balance human impact with human access, the land trust should then conduct a site analysis. The conservancy may choose to hire its own ecologists or biologists, or it may use the Initial Study of the project's Environmental Impact Report as a substitute provided it is "an assessment of pre-development levels of productivity, biodiversity, and soil and water" quality (Perlman \& Milder, 2005, 126). The landscape analysis should also record how people and animals use and traverse a site. Biologists provide advice about specific species' needs, while ecologists provide advice about the ways that different species or systems interact. The landscape analysis should inform the composition of the site plan and help determine the location and type of development that will complement the landscape's habitats and ecological processes. Having this information as a baseline enables the land trust to substantiate its environmental design requests and gauge and mitigate impacts as they are discovered as seen in the Eagle Ranch project case study in this report (theeagleranch.com, 2014).

The site analysis should also identify whether a habitat serves as a source of population for a species or whether the habitat is a population sink that cannot support species long-term (Perlman \& Milder, 2005). Source and sink areas are both needed and should be connected in order to replenish depleted populations with excess population (Perlman \& Milder, 2005). According to Perlman and Milder, identifying source and sink populations requires field research, tagging individuals from different populations and tracking their movements over several years $(2005,77)$. This field research requires 
many staff hours, specialized equipment, and is best carried out by the forest service or an ecologist since it requires long-term analysis (Perlman \& Milder, 2005, 77). Thus, it is likely that, initially, project partners will not know whether a habitat area is a sink or a source, unless this has been intensively studied. The intent of this research is to find the "minimum viable population" of a certain species, or "the number of individuals required for the population to have a specific probability of surviving a specified number of years" (Perlman \& Milder, 2005, 146-147). The Conservation Area Site Plan section of this report discusses habitat design alternatives if sources and sinks cannot be identified.

While the site analysis provides the conservancy with a snapshot of conditions in the site, to gain an understanding of the site's less-visible long-term processes, the conservancy should consult a county's or city's GIS data. For instance, the County of San Luis Obispo's Department of Planning and Building, offers publicly-accessible GIS maps illustrating flood plains, fire danger, rock slide danger, soil richness and a myriad of other geological data that is very useful in gauging project feasibility (Permit View, sloplanning.org, 2014). These Permit View maps are convenient since they show individual property information for the entire county and do not require the use of GIS since they operate in the site's browser. Additionally, shape files for use in GIS are also available to the public at Cal Poly's SLO Data Finder website (2010). If applicable, data about the land held by the forest service or contained in a city's Local Coastal Program may also be consulted. Additionally, the Northern Prairie Wildlife Research Center's (NPWRC) Species Distribution Maps provide case studies and site observations of a few specific bird species discussing their preferred home range, prey habitat requirements and 
response to land disturbance (Dechant, 1998). Using data from all of these sources, the land trust may design the project to be compatible with the site's natural processes.

\section{Conservation Area Site Planning and Design}

After the site analysis is completed, the land trust should use it to compose the project's site plan. In limited development projects, the site's ecology should always be prioritized and the ecological resources and processes of the entire site should first be identified and protected with a conservation easement. After identifying the area to be conserved, this report argues that an effective conservation and limited development project carefully plans the development area and evaluates whether some areas require rehabilitation, mitigation or the construction of animal migration corridors.

The land trust should choose preservation areas in the site based on source and sink data, mentioned previously in the Landscape Analysis section, to determine how populations of animals are using the site. If a conservancy is not certain how animals are migrating through the site, according to Perlman and Milder, a good strategy might be to conserve one area of each particular habitat type (2005). In this way, the natural pattern of habitat types is preserved and, if they are connected by green migration corridors, animals can use them as they naturally would. If funding is available, redundant habitats are also advisable to ensure that if one population dies off, populations in other habitat areas will remain to migrate and replenish the species.

In order to determine the necessary size of habitat areas, whether connections are needed and how they should be designed, the land trust should determine the range size of target species. It also should also determine whether target species are willing to cross 
barriers such as roadways, trails, pastures or disturbed habitat. In a site study published by Raymond Sauvajot et al., small mammal species had smaller ranges than small bird species and thus were more affected by alteration of their native habitat (1998). Species' ranges determine the size of habitat and the connections needed to sustain populations.

If exact animal ranges are not known, Perlman and Milder (2005) offer a few guidelines for habitat size. Animal species that tolerate disturbance are often non-native and require 12 acres or less (2005). Birds that prefer undisturbed habitat may be willing to use areas of 15 to 25 acres if they can fly to undisturbed areas nearby, while some sensitive species require100 acres or more of core habitat (Perlman \& Milder, 2005). Thus, in order to be worth conserving, habitat areas should be larger than 12 acres and spacious enough to support a population larger than the average amount of population fluctuation resulting from illness, genetic drift or food and water availability (2005). When only small areas of habitat may be provided, the conservancy should pursue Jeffrey Milder's "Aggregate with Outliers" model which proposes that all major uses in the site, whether natural or urban, should be "aggregated" or connected and viewed as an entire system (2005). Population sources and sinks are connected using natural and man-made animal migration corridors to form a large, connected habitat that may sustain key species' migration patterns. These migration routes act as Meadows' (2008) feedback loops, stabilizing the system when natural fluctuations such as extinction or overcrowding occur. Species' migration and intermixing allows animal populations to repopulate areas and maintain a diverse gene pool resulting in new and disease resistances (Perlman \& Milder, 2005). 
The land trust should use the findings of the landscape analysis to tailor animal migration corridors to the range size and escape and nesting cover preferences of key species or groups of interdependent species (Sauvajot, 1998). For instance, culverts or metal pipes that are often a foot or two in diameter may be placed under streets, enabling streams and small animals to pass under roads (Perlman \& Milder, 2005). However, small holes for light and air must be included all along the culvert to encourage its use by fish and animals (Perlman \& Milder, 2005). Specific types of migration corridors include riparian areas, ridges or foothills, bioswales in property owners' yards, hiking trails or small patches of native vegetation on public land (McMahon, 2012). Other more costly connections include overpasses covered with greenery and animal migration corridors built as tunnels below the street (Perlman \& Milder, 2005). For all migration routes, Perlman and Milder advise using the contour of the habitat or hard barriers such as fencing to direct animals toward green corridors and away from urban conflicts (Perlman \& Milder, 2005). Since the maintenance of green corridors can be costly, nearby jurisdictions may be willing to pay for their maintenance if the project serves a need of theirs (Perlman \& Milder, 2005).

An example of another use of Perlman and Milder's Aggregate with Outliers model is the integration of habitat patches with the project's developed portion (2005). To accomplish this integration of development and habitat, the land trust can encourage residents to plant native vegetation in their yards, creating miniature habitat areas. McMahon recommends that the land trust consider certifying gardens that meet their ecological standards (McMahon, 2010). For example, the City of Trumbull, Connecticut offers a Certified Backyard Habitat Program in which yards may only use native plants, 
and must refrain from using chemicals, turf grass or the practice of growing only one species of plant, also called monoculture (Perlman \& Milder, 2005, 117). Certifying garden habitats boosts the quality and popularity of this effort to connect the urban and rural and provides places for wildlife to feed as they migrate.

In regard to habitat shape, McMahon recommends designing patches with uneven, rather than straight, borders because, in studies, animals were more likely to migrate across a natural, uneven boundary than a straight boundary (McMahon, 2010, 93). Perlman and Milder echo this theory in their book stating that curved habitat edges encourage animals to cross while straight boundaries encourage animals to follow along them $(2005,101)$. I argue that this concept might be applied to the edges of habitat areas as well as to green corridors to passively guide animal migration, helping them avoid dangerous urban areas. According to Sauvajot, while "edge" habitat, with its disturbance vegetation and sparse native species, can extend several hundred meters into the preserved site, tapered habitat boundaries extend the edge even further since the uneven boundary dips into core habitat (1998). This report recommends beginning with a border that juts or dips just ten or twelve feet to avoid adding significantly to the edge.

Once the site plan has outlined the general locations, sizes and shapes of migration routes and habitat areas, the land trust may compose a green print to provide more-detailed guidance on the exact layout, number and species of native plants that will be included in each habitat area (Perlman \& Milder, 2005). Green prints are a site design tool that apply the findings of the site analysis to propose locations for habitat, trees, plants, water sources, parks and even planters in the urban area (Perlman \& Milder, 2005). Perlman and Milder give the example of Washington Elementary School in 
Berkeley, California which incorporates redwood groves into its play area (2005). It is important that the green print include several types of vegetation, for instance, "escape cover," or grasses and shrubs for small animals, as well as understory, mid-story and canopy trees for birds (Perlman \& Milder, 2005, 162-163). According to Perlman and Milder, the amount and type of vegetation included should be comparable to undisturbed habitat in the region (2005). Native plants are important to include in a site since these are the species that can survive in the landscape without the need for costly additional nutrients or water (McMahon, 2010).

\section{Development Area Site Planning and Design}

In planning the location, type and density of development, the land trust should utilize existing data about the site. This means using the county's GIS data detailing flood plains, geography, the slope of land and zoning in the site. As previously stated, the existing, proposed and past uses of the parcel and adjacent parcels should also be considered (McMahon, 2010). In addition, the project's vision and goals are very important to consult in order to incorporate the community's input into site design. For instance, if the goals and objectives identify sustainability as important, roofs will need to be positioned for the installation of solar panels or buildings installed with piping to carry grey water (McMahon, 2010). The developer and the conservancy should collaborate to locate development so that it is feasible, marketable and ecologically-beneficial.

One challenge in designing the site plan of a limited development project is that residents and business owners often want the seclusion of rural living, but the convenience of nearby grocery stores, gas stations, hospitals, schools and retail 
(McMahon, 2010). According to McMahon, this can be accomplished by locating the developed portion near to existing development so that roads, utilities and school routes will not mar the conservation area (2010). The issue with McMahon's approach of locating project residences near existing communities is that rural residents may object to the project if it is visible from their property or if it changes their property's ambiance or monetary value. This report argues that the project's land uses and amenities should serve the project's target market. If retail, restaurants and outdoor recreation offered by the project can compete with those in nearby cities, residents, and even tourists, will be encouraged to spend their time and money in the project. I argue that a communityoriented culture is only feasible if the project's land uses and designs are used to build community relationships and celebrate, rather than compensate for, the rural nature of the project. Housing and business locations must be practical, viable and desirable.

In determining the parcel size and configuration of development, buildings should be located to minimize impacts to neighboring uses. According to Arendt, homeowners who purchase large, two-acre residential properties often have difficulty keeping their fields trimmed with only the few horses under their ownership (1994). The grasses, if left uncut, then disperse an excess of seeds, threatening the crops of nearby farmers who must, at their own expense, eliminate an influx of weeds with herbicide which then pollutes nearby ecosystems (1994). To address this, I recommend using buffers between incompatible uses as well as closely examining how site conditions such as wind direction, light reflection, and runoff will affect proposed development. Arendt advises limiting each property to one acre, and instead, devoting the space to a common green and five to ten acres of easement-protected communal open space (1994). Smaller lot 
size and increased density will likely need to be negotiated with both county officials and the project's developer. If the conservancy decides to allow some large properties or land uses that cause impacts, it must only do so if it has evaluated whether the proposed development will complement the health and long-term feasibility of the project.

Clustered development is a key component of limited development; however, it creates less space between homes and businesses and lessens private property in favor of larger communal open space. Site design must compensate for the proximity of homes by decreasing impacts, providing privacy, maintaining or improving home values, and fostering the rural character of the community. McMahon advises situating homes next to open space as well as in the "seams of the land next to forested areas or on knolls that offer views of ponds, meadows and fields" $(2010,81)$. Thus, even if homes are clustered, the view from each home is open space and each is separated by a natural feature of the site such as a hill or cluster of trees. However, building on uneven terrain or farther from existing development can be costly since utilities and roads must be extended, thus a balance is needed. In the Galisteo Basin Preserve limited development project in New Mexico, ecological processes were facilitated by allowing natural features, such as ridgelines, rock formations, streams and habitat to define the location and character of conservation neighborhoods (Galisteo Briefing Book, 2011). In addition, if homes or businesses are located to blend with and provide views of the scenery, the landscape can become a part of residents' lives (Arendt, 1994, McMahon, 2010). The more the project design celebrates the natural surroundings, the more the residents, themselves, will feel connected to their community and be willing to help maintain the landscape. 
Despite its challenges, there are numerous ecological and economic benefits that result from clustering development such as less soil disturbance since, according to Perlman and Milder, grading and construction disturb the soil's bacteria, mold and nutrients (2005). Clustered development requires $40 \%$ less road paving than standard development (Perlman \& Milder, 2005). To decrease the site's paved area, a local jurisdiction's design guidelines may need to be altered to construct smaller parking lots or garages or narrower streets (Perlman \& Milder, 2005). If more affordable properties are desired, and if site runoff is predicted to be insignificant, Arendt recommends decreasing construction costs and, consequently, the cost of homes, by refraining from installing curbs (1994). The land trust should ensure that design minimizes construction costs and decreases the paved area; however, since curbs, low density and road width may be required by a jurisdiction's General Plan, additional negotiation may be required.

Negotiation with jurisdictions is a major task for a land trust in a limited development project since it must advocate for the land's ecology in spite of local building standards. For instance, McMahon, Perlman and Milder recommend reducing the width and length of roads in limited development projects $(2010,2005)$; however, certain roads must be wide enough to accommodate emergency vehicles. Arendt states that road widths of 18 to 19 feet can serve lower levels of traffic, for instance, 20 or fewer homes in a neighborhood $(1994,181)$. However, the Cal Fire standard for residential road width in San Luis Obispo County is 24 feet (Cal Fire, 2011). This standard does, however, allow access roads for one-way traffic to be 10 feet wide "in limited circumstances" (Cal Fire, 2011). Since San Luis Obispo County has abundant grassland, the high danger of fire and the need for fire vehicle access must be weighed against the 
need to reduce paved surfaces and maximize green space. Perhaps roads with high volumes of traffic could use the standard-sized road, while designers can negotiate with Cal Fire to allow 18 to 19 -foot road widths on smaller streets. In residential areas, Arendt recommends constructing roads that are even narrower, with a width of 16 feet if street parking is not needed, 26-28 feet if parking is needed on one side of the street, or 32-36 feet if parking is needed on both sides (Arendt, 1994, 181). This report recommends that all roads should carefully balance impact, access and safety and all site planning should be negotiated with relevant stakeholders and informed by current research.

To convince municipalities to make allowances for limited development, the land conservancy must demonstrate that clustered development provides public open space while maintaining the amount of development originally planned for the area. Although a jurisdiction's building and zoning standards are intended to protect rural land from dense development, they can, ironically, inhibit environmentally-friendly clustered development. If a municipality is concerned about the project's impacts or quality, performance zoning may be used to require mitigation if limits on traffic, pollution or runoff are exceeded (McMahon, 2010). A yield plan allows city officials to see an illustration of the size and configuration of the proposal and upon which lots development is feasible based on the lot's size, utility connections, setbacks and vegetation (Arendt, 1996). It is used to ensure that lots in the project are not too steeply graded, flood-prone or densely-clustered to support homes, septic systems or roads (Arendt, 1996). Composing a yield plan enables compromise since the land trust can suggest altering the area's zoning requirements in light of what is feasible while also illustrating the project's compliance with non-problematic design guidelines. 


\section{Chapter 5: Development}

\section{Defining the Direction of Development}

The project's developed area is perhaps the most complex portion and must be negotiated with care. Since the developer depends on the sale of a certain number of properties to produce an acceptable profit margin, the land trust should be aware that limited development projects are only viable if they are feasible, marketable and comply with all county and state requirements. Since the land trust may need stakeholder assistance in making the project feasible as well as ecologically valuable, all relevant stakeholders should meet and determine development goals.

At the beginning of the development process, land conservancies must decide whether tasks can be conducted by staff or whether contractors such as hydrologists or geologists should be hired if staff lacks the necessary specialized knowledge. The conservancy should refer to its overall goals and mission in deciding the services its staff can provide. If the land trust's mission is to protect a certain species, a biologist or ecologist, on-staff, could advise the land trust's management plan long-term.

Often, the development of the project is not under the direct control of the conservancy. If a conservancy wishes a greater degree of involvement in project design, the conservancy may, at the first meeting, negotiate designs with the developer as a condition for holding the easement. The conservancy may also consider initiating the project, hiring the developer or even assuming the central role of project manager. If the land trust manages the project, it must coordinate the project's design, construction and mitigation and ensure that these satisfy project goals. When the project is completed, the project manager often passes its long-term management to a homeowner's association. 
For an in-depth analysis of a conservancy that assumed a leadership role in a limited development project, see the Galisteo Basin Preserve case study in this report.

If a conservancy lacks the finances, time or staff to serve as the project manager, it can still have an involved role by designing the conservation area's site plan, green print, and easement conditions. This requires it to specify the location and type of development that can be built without disturbing habitat (Perlman \& Milder, 2005). In this way, the conservancy can offer its recommendations to project partners without additional meetings or negotiation. I advise that, while the developer conducts feasibility studies, the conservancy should develop the site plan, perhaps consulting with city biologists to ascertain the specific characteristics of the site. While developers can choose not to heed the conservancy's recommendations, if these recommendations use sound data and accommodate the developer's needs, they are more likely to be utilized.

Entrusting the project's development to a developer offers the conservancy the advantage of this entity's experience navigating the construction process. According to Sullivan, limited development can be employed for the purpose of "stimulating economic development in once-abandoned areas, guiding additional development dollars toward designated growth areas, protecting areas appropriate for conservation, and providing local residents as well as visitors with valuable civic and recreational amenities" (2005, 106). Thus, putting a project to these purposes may depend upon: the project's market, competition with other developers, project applicants' level of expertise, the local cost of utilities or even the climate, a developer's expertise is vital (Miles et al., 2007). Using its expertise as well as a market evaluation, site analysis and an analysis of comparable projects, the developer will have a sense of what is financially or politically feasible 
before beginning the project (McMahon, 2010). It is important that the conservancy respect developers' concerns and project critiques in light of its findings.

\section{Marketability and Market Analysis}

While the conservancy composes the site plan, the developer will meet with buyers, coordinate loans and grants, conduct a site analysis and conduct a market analysis to assess the project's potential demand, profitability, costs and feasibility. In conducting the market analysis, the developer will assess the rate at which buildings are selling and the price of homes in similar projects (Miles et. al, 2007). The developer will then analyze comparable projects with a vision similar to the proposed project so that the successes and failures of these projects can inform the proposed project (McMahon, 2010). The developer or conservancy should next determine whether the local jurisdiction has implemented zoning policies that concern limited development which will indicate the locality's attitude toward limited development (McMahon, 2010). Next, the developer will conduct a feasibility study which compares the project's profits and costs (Miles et al., 2007). Finally, the developer presents to project partners its findings regarding the project's legal, financial and geographic feasibility.

In order to construct a project that will result in a promising market analysis, the project must not only address community and ecological goals, it must also be marketable. Limited development projects tend to be very marketable since they seek to preserve ecologically, culturally, historically important features. According to McMahon, research indicates that people value authenticity in their surroundings (2010). Thus, the natural features in a site that benefit ecological health also make the location 
both scenic and marketable. In addition, homes should help accomplish the project's vision, lessen negative impacts and aid in reconciling the natural and urban landscapes. McMahon recommends a built environment that complements a "total lifestyle" for residents, including both conservation and outdoor recreation (2010). Fostering a "total lifestyle" in a project is dependent upon the flexibility of city development standards. For instance, limited development projects can require increased density, public transit options and green infrastructure such as drought-resistant landscaping, bioswales, piping for grey water and roofs that are oriented and wired for solar panels. The "total lifestyle" development concept works best when homes are clustered such that green amenities can be easily extended from one house to another (McMahon, 2010). Cities must be willing to allow such designs for rural development.

According to McMahon, potential home buyers are often "highly value-driven," and since limited development often takes the form of luxury communities, they must compete with standard-development luxury communities that offer larger lot sizes or amenities such as golf courses (2010). To compete with projects that offer more amenities, McMahon advises emphasizing the project's total green lifestyle which focuses on enjoyment of the natural surroundings and local community (2010). Retired members of the baby-boomer generation are likely to be interested in such selling points since this generation's values typically support environmental initiatives and since they often have surplus income with which to purchase homes (McMahon, 2010). A broader market may be pursued by including businesses, schools and affordable housing. However, these require additional coordination with the city and county, a larger investment and compatibility with project goals. It is important to prioritize 
conservation, but also consider what the most likely target market will be and then tailor the design to accommodate these needs.

At Tryon Farm in Indiana, homebuyers do not purchase the rights to the land under their home; instead, they buy a share of the ownership of the entire project (McMahon, 2010). This marketing strategy allows residents to have a financial investment in the project and reinforces the concept that all property outside of their house is communal, rather than privately-owned. These communal spaces and activities constitute the project's unique and marketable attributes, such that, as recommended by McMahon, a golf course may be replaced by organic community orchards or a scenic duck pond that also benefits local aquifer recharge (2010). Alternatively, the Balsam Mountain Preserve, located in the Blue Ridge Mountains of North Carolina, includes amenities found in standard development projects such as a community center and a recreation center with a pool, tennis courts, a gym and a horse stable (McMahon, 2010). These community amenities are much more compact than a golf course and do not require excessive water use to maintain them. A conservancy including these amenities would have to ensure that these amenities do not interrupt interpersonal interactions, preserve the rural atmosphere and focus on ecological preservation.

A land trust should understand that the inclusion of project amenities must also correspond with an increase in development to offset the costs. According to Victor Montgomery, in the Eagle Ranch limited development project in California, RRM Design requested to construct more homes on smaller lots to meet demand for more numerous, free-to-use but costly-to-install, public amenities (personal communication, May 22, 
2012). Project partners must ensure that amenities, such as public trails or stables, do not decrease the profitability of the project so much that it offsets financial stability.

A project's amenities are important and should be used to attract the desired demographic. Appealing to a specific demographic is necessary to convince banks that the project is marketable and stable enough to be entrusted with a loan. However, identifying the most effective market for the project may be difficult. For instance, the market research conducted for the Santa Lucia Preserve in Carmel determined that almost one-third of potential buyers would not consider buying a property unless the project had a golf course, while one-tenth stated that they would only consider buying a property if no golf course was included (McMahon, 2010). Potential buyers clearly had two different visions for the project, and catering to the largest market is a very different strategy than designing the project to satisfy the needs of a particular, narrow market. Project partners should prioritize the amenities that are most crucial to the overall vision. After designing the project to appeal to a certain demographic, it is important to advertise to that demographic. Advertising can include individual invites to a formal tour of the property or a general open house. This strategy of using an open house to market the project both attracts buyers and quells public criticism by giving the public an idea of the project's quality. For instance, the development team of the Bundoran Farms marketed this limited development project by meeting, individually, with carefullyselected buyers, spending about 10 hours with each of them, to explain the project's philosophy and vision (2010). This report argues that only projects with a luxury atmosphere and market should use this expensive and labor-intensive approach. The priorities of potential buyers should determine the method of project marketing. 
If project partners have difficulty securing a development loan from a bank, they should consider pre-selling the lots to prove its marketability. This strategy was used in the Dewees Island limited development project in South Carolina. The developer, Chaffin/Light Associates, after being denied project financing by its bank, then purchased an option on Dewees Island and pre-sold 35 undeveloped lot for $\$ 300,000$ each earning $\$ 10$ million which was then reinvested to construct a bridge from the island to the mainland (McMahon, 2010). These pre-sales demonstrated the project's marketability and, coupled with Chaffin/Light's reliable loan repayment and long-term business partnership with NationsBank, it secured a \$17 million loan and a \$20 million venture capital loan (McMahon, 2010, 65). When using this approach, Chaffin/Light advises conducting a proforma to gauge the likelihood of success as well as using equity financing granting ownership of a portion of the project in exchange for investments (McMahon, 2010). While this financing method provides the capital to begin building the project, it is very high risk and requires maintaining a good reputation and demonstrating for investors why the project is a good long-term investment.

Finally, if it is anticipated that the project will generate substantial public interest or critique, it is advisable to establish a website for the project containing individual pages for each stakeholder to articulate the goals and public outreach that guided their portion of the project (McMahon, 2010). A website should be used to familiarize the public with the project by providing a detailed description, an overview of project outreach, a summary of the ways that community input shaped the project's vision, and visual evidence of the project's quality. 


\section{Chapter 6: Long-Term Project Management}

\section{Land Trust Involvement in Long-Term Land Management}

When the construction of a limited development project is completed, developers will usually transfer the responsibility of holding and enforcing the easement to a land trust in order to pursue other projects. The land trust can either take a limited role or a more involved, long-term role in the management and maintenance of a limited development project once it has been completed. I argue that regardless of the land trust's desired level of involvement, it should seek input from other managing entities and craft at least the initial management strategies of the project's long-term land management plan. It is the land trust's role to ensure that management practices accommodate local needs, cultural values (McMahon, 2010) and the environmental goals of all stakeholders that will be impacted by the project.

One tool a land trust may use to help it draft the project's long-term management approach is the Northern Prairie Wildlife Research Center's (NPWRC) Species Distribution maps which provide recommendations for managing land to accommodate select threatened species of birds. They also provide a discussion of bird species' preferences, behavior and response to site-management based on case studies and site observations from around the country (Dechant, 1998). For instance, the website's recommendations for the Northern Harrier raptor, a threatened species native to California, are that the bird will not nest in areas that are burned or mowed more than once per year (Dechant, 1998). The website instead, recommends "haying" the site every three to five years to avoid disrupting either the raptor or its prey (Dechant, 1998). A 
land trust may use the NPWRC's recommendations to evaluate the expense, frequency and feasibility of long-term maintenance that will be required.

As stated previously, land trusts may become involved in the management of projects to any degree they wish. However, since land trusts are nonprofit organizations, they often must rely on other entities to handle expensive vegetation management, impact mitigation and resident complaints. One way to share the maintenance burden is to establish a cooperative agreement with a city or county. In such an agreement, parties that will mutually benefit from a project can purchase ownership over the beneficial portions and assume responsibility for their maintenance (Sullivan, 2005). For instance, if the project preserves wetlands which filter the local water supply, a nearby city may be willing to fund that part of the project's long-term maintenance. For example, a land conservancy called Scenic Hudson, reduced its long-term costs by selling the National Park Service a historic carriage road located on one of its properties, entrusting the Park Service with the road's long-term maintenance (Sullivan, 2005). If a city is hesitant to undertake such a long-term commitment, the land trust may want to demonstrate how the project satisfies the jurisdiction's General Plan goals. The land trust may even wish to calculate the financial benefits that the city will receive from its long-term maintenance of the site (McMahon, 2010). Thus, a cooperative agreement enables a land trust to alleviate its maintenance burden by tailoring the project to meet another entity's needs.

Another option for the long-term maintenance of a property is for the land trust to hold the development rights and lease the land to private owners who have the expertise to put it to additional uses such as farming or logging (Parker, 2002). The land is thus protected from development, yet the landowner may continue to profit from the land. In 
this arrangement, the land trust collects rent from each tenant in order to pay for the maintenance of the entire property (McMahon, 2010). Lots available for lease must be located on land that is desirable for farming, lumber harvesting or other uses so that it will be marketable to tenants (McMahon, 2010). Thus, development is not the only means of deriving a profit from conservation land.

Another long-term management option for a land trust is to sell a property to a larger conservation organization such as the Trust for Public Land or the Nature Conservancy (McMahon, 2010). It is important to consider that when a national conservation organization purchases the land, they may require an endowment to be provided to pay for land management and maintenance (McMahon, 2010). The primary advantage to partnering with a national organization is that it has a more extensive network and access to greater financial resources that it may devote to maintaining the property. However, for a national conservation organization to be interested in preserving a project, the land usually must host a rare species (McMahon, 2010).

The establishment of a homeowner's association by the conservancy or developer is the most common and most convenient option for the long-term management of a property because, in addition to handling ecological management, it more effectively handles residential issues. If a land trust is not the developer or manager of the project, it cannot establish a homeowners' association; however, it can petition the developer to incorporate certain requirements into the codes, covenants and restrictions of the homeowners' association (McMahon, 2010). Additionally, establishing a homeowner's association decreases the managing entity's long-term maintenance costs which are, instead, paid for by resident fees. For example, the San Creek Ranch limited 
development project in Buffalo, Wyoming established a homeowners' association that relies on resident fees to monitor wildlife health, hire a security guard and ranch hands to manage maintenance, irrigation and vegetation removal (McMahon, 2010, 116). Produce and livestock from the project's community-operated ranch is sold and the (taxed) profits decrease residents' collective homeowners' association fees (McMahon, 2010).

Residents are also encouraged to conduct site maintenance and harvest crops in exchange for a reduction of their homeowner's association fees. This homeowner's association also educates residents about the project's successes, green design and ecosystem (McMahon, 2010). Thus, the establishment of a homeowners' association ensures that the conservancy need not involve itself with the daily management of the site.

When a homeowner's association manages the land, the land trust can continue to influence management using a "restrictive conveyance" which dictates the type of project features permitted including house size, building density, land use, building design or type of vegetation (McMahon, 2010, 100). The conservancy then monitors the site to ensure that provisions are followed, and if numerous violations are discovered, the homeowners' association can initiate a lawsuit or evict a homeowner (McMahon, 2010). These provisions allow the conservancy and homeowner's association to enforce the project's initial mission and objectives. McMahon cautions that restrictions must carry out conservation goals and remain flexible enough to adapt as the project's circumstances change (2010). Thus, a homeowner's association ensures that the project's initial goals will be enforced even without constant supervision by the land trust.

A combination of several managing entities may be necessary in limited development projects if multiple objectives are pursued. McMahon provides the example 
of Bundoran Farms, in Albemarle County, Virginia which is managed by a homeowners' association, a sustainability manager, a farm management committee and the Baldwin Center for Preservation Development which shares information about limited development and farming with professionals (2010). The homeowner's association has authority over the farm management committee, but it can only change the farm's management if more than a majority of its board votes in favor (McMahon, 2010). Thus, establishing multiple managing entities may be necessary when a project must accomplish numerous objectives. In this way, each entity has the freedom to pursue different priorities, yet each possesses expertise over one aspect of the project that it can share when collaboratively evaluating and adapting management policies.

If the land trust, itself, decides that it has the necessary resources and would be the most effective manager of the project, it may choose to assume this challenging role. As previously stated, it may serve in a limited, moderate or full capacity. For example, limited involvement in land management might entail providing initial and occasional land management advice to the managing homeowner's association. A moderate to high level of involvement in land management might entail involvement in site monitoring, adapting land management, educating the public or serving as an ecological advisor. McMahon encourages land trusts to research solutions to problems, for example, the costeffectiveness of a farmer leaving an area of his field undisturbed so that birds may keep insects under control in lieu of expensive pesticides (2010). However, if a conservancy desires greater involvement in maintenance, the conservancy must be able to divide its time between existing projects and the maintenance of the limited development project. 
A high degree of involvement in public education, which can be an important component of land management, might entail coordinating conservation activities, workshops and site maintenance events for residents. According to McMahon, the land trust should promote the landscape as a central gathering area for residents and coordinate trail walks, horseback riding, species counts, public lectures and school field trips (2010). McMahon recommends encouraging environmentally-focused activities and clubs such as 4-H, summer camps, Boy and Girl Scout troops, a visitor's center or kayak rental facilities (McMahon, 2010, 117). The land trust's role may range from offering comprehensive education and outreach, to implementing a few programs as necessary (McMahon, 2010). This report argues that community activities should complement project goals and should be informed by community feedback.

Even if the conservancy only wishes to fulfill a minimal role in long-term land management, it can still facilitate the limited development process. For instance, the conservation manager in the Bundoran Farms limited development project in Albemarle County publishes a document called The Green Book which describes how the local ecosystem functions and how to use green design, waste disposal, water efficiency, energy efficiency and sustainable site management (McMahon, 2010). Informing the public about the proper maintenance of the landscape decreases the land manager's maintenance costs if each resident spends money and time caring for private and communal property. Thus, by assuming even a limited role, a land trust can help adapt management to the needs of the landscape and community - a responsibility that the fulltime manager does not have the time or funding to undertake. 


\section{Long-Term Adaptive Management}

Adaptive management can be used by the land trust to ensure that development does not affect the conservation area over time. This type of management requires the land trust to use the site analysis and the project's goals to set management objectives, monitor the system for the achievement of these objectives and change the landscape's management if certain indicators or missing organisms illustrate that objectives are not being met (Perlman \& Milder, 2005). For instance, if disturbance causes an absence of predators, herbivores can become too numerous and can deplete vegetation and cause disease-carrying ticks and fleas to proliferate; however, the introduction of predators to control herbivore populations can be dangerous for residents (Perlman \& Milder, 2005). Monitoring and using available population control measures, such as allowing hunting in certain areas or changing the site's vegetation to suit native rather than invasive species can restore balance to the ecosystem (Perlman \& Milder, 2005). Thus, adaptive management is often less-invasive and requires careful seasonal monitoring by the land trust to ensure the compatibility of the conserved and developed portions.

In regard to specific land management for San Luis Obispo County, as previously mentioned in the Balancing Site Flows section, fire danger in the county's chaparral environment is high, making the decrease of fire danger an important long-term maintenance goal. According to Dr. Jutta C. Burger, if a wildfire occurs, a good management practice is to restrict public access for one season to the burned area and adjacent areas to protect habitat for animals that migrate away from the fire (no date, 101). Since complete fire prevention causes a build-up of brush that can result in larger fires (Perlman \& Milder, 2005), long-term maintenance must involve vegetation 
management. Vegetation management options such as controlled burns, mowing and grazing impact native species to varying levels. For instance, according to a master's thesis by Appelbaum et al., in the Tejon Ranch limited development project, cattle grazing resulted in compaction of the soil, invasive species, a decrease in species diversity and the contamination of nearby water sources and riparian habitat with runoff and cow manure (2010). Adaptive management techniques should be selected based on the site analysis and other sources that discus the tolerances of key species, such as the Northern Prairie Wildlife Research Center's Species Distribution maps. The land trust should ensure that the management plan establishes which practices are appropriate given the site's processes, the tolerances of native species and the proximity to residences.

When adaptive management was used to control fires in the Prairie Crossing limited development project, the project's stakeholders contacted homeowners and explained the importance of conducting regular controlled burns despite the proximity of homes (McMahon, 2010). Project stakeholders then consulted with experts and, with input from the community, composed a strategy for carrying out yearly controlled burns (McMahon, 2010). Such changes in land management are thus processes that require consultation with numerous groups, including professionals, cities and homeowners, in order to address all needs and decide upon an appropriate course of action.

When seeking feedback, this report argues that the site's manager must be careful not to alter initial project goals and habitat quality standards. Adherence to existing project goals preserves the values, purpose and sense of community that the project was intended to foster and prevents a conservation goal from being changed to, for instance, a recreation-focused goal. The Bundoran Farms conservation community addressed this 
issue by requiring that small changes in the land's management, such as permitted crop types, be proposed by its farm management committee and homeowner's association based on resident feedback (McMahon, 2010). However, if a major change in the project's goals was proposed, a "super majority" vote of all property owners must approve the proposal (McMahon, 2010, 100). Thus, adaptive management means altering management goals to better achieve key project goals, but adhering, without compromise, to these key project goals unless strong criteria for changing them is met.

Additionally, adaptive management strategies should not be overly-complicated or time-consuming to implement (Parker, 2002). According to Noss, the purpose of adaptive management is not to introduce restrictive rules, but to emphasize monitoring and problem-solving in addressing constantly-varying impacts (1997). Additionally, Parker warns that when adaptive management is incorporated into a land management agreement, it may prevent a conservancy from solving problems quickly (2002). This report agrees with these perspectives and adds that it will likely be a homeowners' association that manages the land's long-term maintenance and so land management terms should be basic enough for the general populace to act upon.

Thus, to ensure that management strategies remain flexible and that original project goals are maintained, the land trust must make changes to the land management agreement only when necessary. Dr. Jutta C. Burger, the Project Director of the Irvine Ranch Conservancy, recommends monitoring the site and establishing threshold “triggers" for altering land management (California Dept. of Fish and Wildlife, undated, 102, 105). To identify these triggers for adapting land management, Irvine Ranch uses "quarterly wildlife camera surveys" to estimate the number of species in a site and 
monitor particular species' declines or increases (Burger, n.d., 102). Additional indicators for needed management changes may include the presence of raptors, evidence of erosion, or species' breeding behaviors or seasons (Burger, n.d., 103). When these indicators are observed, the report recommends limiting public open space access to: areas with resilient species, a particular number of users, specific hours of the day, or certain days with at least three days between to allow animals to repopulate (Burger, n.d., 101). Noss, however, states that initiating the alteration of land management should not depend upon a species' population decrease since, by that time, it is likely to be too late to revive the population (1997). Clearly, adaptive management requires a higher degree of involvement from the land trust since it requires more frequent and comprehensive monitoring, expensive monitoring equipment, regular analysis of ecological indicators, negotiation with a homeowners' association, and the expensive installation of mitigation. This report argues, however, that adaptive management is very necessary to protect the legitimacy of the conservation initiative in limited development projects.

\section{Composing an Easement Agreement}

The easement agreement is the primary means of protecting land in a limited development project, allowing the land trust to preserve exactly the habitat features it wishes, manage flows and locate land uses so they do not mar the landscape. Typically, when a conservancy engages in a limited development project, it will place an easement on the portion of the property that it wishes to protect and then will either allow the landowner to develop the remainder or will sell the developable portion to a developer. It 
is the land trust's duty, regardless of its preferred level of involvement, to hold and enforce easement provisions by visiting the site to check for compliance.

Parker states that a basic conservation easement should contain: "a statement of the property's 'conservation' values," "reference to supporting documentation of the property's legal description and present "baseline" condition," and a general or specific Statement of Purpose (2002, 6-7). The Statement of Purpose should be general unless the project's goal is to preserve specific habitat types or species which requires specifically naming these resources. Next, the site's baseline conditions should be recorded including critical species and processes (Parker, 2002) and, I argue, how these processes and species interact to form the system's sustaining processes such as water cycling or fire processes, both regionally and locally.

Next, the land trust must include the land's management plan in the easement agreement which, as previously stated, outlines quality standards and indicators that trigger management changes. In addition, the easement should state the maximum number of acres that may be developed (McMahon, 2010). Parker also advises specifying the level of maintenance required for each portion of the site and clearly defining each stakeholder's short and long-term responsibilities to avoid confusion and conflict (2002). Finally, Parker states that easement contracts should contain "enforcement or dispute remedies; indemnity and liability disclaimers; procedural directions for notices and approvals; and amendment and extinguishment clauses" (2002, 6). Clearly, the easement agreement must act as the guiding master document for the land's quality and maintenance. It must set standards and procedures for a variety of issues ranging from ecological to collaborative. 


\section{Easement Costs vs. Landownership Costs}

Next, the financial implications of purchasing a property will be evaluated in comparison to the costs of placing an easement on a property and allowing a landowner or homeowner's association to maintain it. Since ownership of a property presents different challenges than does holding an easement, a land trust should prepare before embarking on either form of land ownership.

Both land ownership and easement placement have numerous costs in common. Both require land trust staff to assess the condition of the property, determine if the property will fulfill land trust goals and record baseline data about the site, its zoning, land value and owner (Parker, 2002). In easement ownership, the terms of the initial easement must be negotiated with the donor and all future adaptations of the land's management must be negotiated with the homeowners' association. For land and easement ownership, the land trust must hire its own appraiser to determine the value of the land, before and after the placement of the easement (Parker, 2002). Additionally, under either type of ownership, the more amenities offered, the greater the project's maintenance costs and, consequently, the larger the project and its homeowner's association fees must be. For example, in the Serenebe limited development project in Georgia, the average homeowner's association fee was between $\$ 600$ and $\$ 900$, in order to support a 25-acre organic farm, trails and the project's chemical-free wastewater treatment system (McMahon, 2010, 206). This report argues that residents must decide whether an amenity is worth maintenance costs or an increase in project density. Thus, both easement conservation and land purchase incur unavoidable expenses. 
However, there are additional costs associated with maintaining an easement. The primary source of these costs is the conservancy's need to negotiate with another managing entity, monitor the easement and adapt management as needed. Guenzler states that the land trust must document the condition of the property with reports and photographs, visit the property, collect aerial photographs and mark the location and types of vegetation (Parker, 2002). Finally, enforcing the easement may also consume funding if the land trust must hire a mediator or a lawyer to resolve disagreements, buy materials to restore habitat, or send notices to landowners (Parker, 2002).

Since easements are the primary conservation tool in the limited development process, this report asserts that it is important to examine the negative impacts that may arise from their use. Dominic Parker argues that easements should not be used for pure conservation, arguing that sharing the management of the land with a homeowners' association or landowner and monitoring and enforcing the easement can result in contention long-term (2002). Parker provides the example that the land trust and homeowners' association might disagree about how near to the habitat the landowner's cattle may graze, the kinds of plants that may be grown or how often the land trust should monitor or maintain the property (Parker, 2002).

In addition, Parker critiques the ability of easements to adequately protect habitat quality. Parker states that when site management is shared with multiple users, easement restrictions are more likely to be opposed or violated and that easements protecting habitat areas are more likely to be violated than those that preserve community open space due to hikers wandering off-trail $(2002,18)$. He finds that conservation easements were not often used when preserving woodlands, underground aquifers or habitat areas 
since complex easement provisions are more difficult to specify, monitor and enforce and recommends direct ownership for these uses $(2002,14,22)$. Parker goes so far as to argue that easements should only be used to accomplish conservation if additional value may be extracted from sharing ownership with an individual such as a farmer that can grow crops on the land (2002). Finally, he asserts that easements require substantial work and resources to maintain resulting from the joint ownership of the land (2002).

While this report agrees with Parker that easement provisions should be simple and that the need to negotiate with another entity raises costs, this report argues that the use of easements is necessary in limited development to ensure that stakeholders are all working toward the same conservation goals. One main function of easements in limited development is that they enable land trusts to achieve much more precise conservation of ecologically-important natural features while developing the remainder to afford properties that are out of its price range. A second main function of easements in limited development is that they allow the land trust to provide the safeguards and restrictions necessary to place development next to conservation land with minimal impact and no risk of encroachment. A third main function is that easements help realize a more diverse use of a property than would have been realized through more rigid and single-use traditional development. A fourth main function of easements in limited development is that they make conservation attractive to potential donors by allowing them to sell their land and make a profit and by offering tax incentives for placing an easement on the property. Finally, a fifth main function is that easements grant the land trust freedom from long-term maintenance costs which, instead, fall to the homeowners' association, helping to mitigate the cost of negotiation. 
To address Parker's other critique regarding conflict when negotiating, this report recommends avoiding conflict by specifying both in the easement agreement and, verbally, that the management of the land will change. The land trust should be sensitive to the needs of homeowners' association and they should solve problems jointly. If the landowners contributed to project goals at the beginning of the project, the homeowners' association will be more committed to upholding them. If the longer, more collaborative negotiation process required in limited development projects is successful, it often results in the creation of easement standards that meet a diverse range of needs.

Parker is correct in his statement that complex easements may be difficult to implement and monitor (2002). This is because the proximity of development and open space causes more frequent impacts that must be monitored, mitigated, and enforced (Parker, 2002). However, Parker gives a good recommendation that when a property requires complex conservation standards, the land trust should acquire just this portion of the property so that it may maintain it according to its own standards (2002). Parker also recommends that land conservancies refuse to hold easements for land that they predict will fall short of its standards for long-term affordability, quality or monitoring (2002).

This report argues that, while easements can be costly to maintain and monitor as Parker describes, full ownership of land is also often very expensive and time-consuming due to the high cost of land and long-term maintenance. The land trust must be equipped to assume a very large initial risk when purchasing the property. It must depend on the marketability of the portion that it will develop in order to pay back its land purchase loan. The risk is high because if lots in the developable portion don't sell as fast as anticipated, the land trust must still continue to pay back its land purchase loan at a 
steady rate. The strategy of selling subdivided land at full-price to fund the purchase of the entire property is discussed further in the Finance Section of this report. In addition to the initial land purchase risk, the land trust must develop the property or coordinate a developer, contractors, architects and many others on its own. As was the case with the Galisteo Basin Preserve, discussed by Ted Harrison in the Case Studies section, the conservancy had planned to purchase the land and then hire a developer to coordinate construction; however, all developers approached declined involvement in the project stating that they lacked experience with ecologically-sensitive limited development projects (personal communication, May 5, 2012). Before pursuing a property, a land trust should ensure that a developer is willing to complete the project to the land trust's standards. Finally, after the project's completion, if a conservancy owns the property, it must conduct all maintenance itself or establish a homeowners' association.

\section{Long-Term Maintenance Endowment Fund}

To maintain the easement-protected portion of the property, the land manager is usually given a long-term maintenance endowment by the land donor which may be the landowner or even the land trust. Since land trusts are 501 (c) (3) non-profit organizations, they cannot maintain a profit. However, as the long-term manager, they can receive an endowment for the long-term maintenance of easement land. If land trusts act as the land donor, they must provide the land's manager with funding for the endowment. The endowment should be of a sufficient amount that it may remain intact and accumulate enough interest to support the land's yearly maintenance (Doscher, 2011). A proforma should be used to estimate the average annual cost of maintaining the 
easement and thus, the amount of the endowment. Doscher states that the Forest Society requires $\$ 500$ per year (or a principle endowment of $\$ 10,000$ ) to maintain its easements (2011). Another example is the 18,000-acre Santa Lucia Preserve limited development project, near Carmel by the Sea, in California, whose development agreement required the developer to contribute to the conservancy's endowment fund $\$ 85,000$ for each of the site’s 249 lots, which totaled $\$ 25$ million by 2008 (Sullivan, 2005, 105). This amount was based on anticipated development profits and the yearly cost of maintaining the conservation area (Sullivan, 2005). Since the developer established the land trust, it also paid for its property taxes, property assessments, liability insurance and employee insurance until the endowment was fully-paid in 2008 (Sullivan, 2005, 105). Thus, the land trust must ensure that it can provide a sufficient endowment to achieve the level of maintenance that it specifies in the easement agreement.

If the land's donor cannot afford to provide the entire endowment, the long-term manager can provide the remainder using grants and loans (Sullivan, 2005). The project's developer may also be willing to contribute to the endowment by donating a percentage of its profits from property sales (Sullivan, 2005). If this occurs, the development agreement must include the percentage of the project's proceeds that will be given to the land manager to refund its purchase of the land. The land trust can even sell the subdivided, developable portion to the developer to fund its own endowment; however, it should use caution when directly profiting from the development project since this decision ties its reputation to the developer and the community can begin to question its conservation purpose. 


\section{Chapter 7: Limited Development Finance}

Limited development can be difficult to finance since banks are often reluctant to provide loans to a project that deviates from standard development in regard to its target market and the flexibility of its cost and design. Limited development often requires the buyer to hold a debt while the project is negotiated between several parties, designed and built. Financing can also be difficult since nonprofit land conservancies must be sure to reinvest any income in the conservation project to avoid threatening its nonprofit status. However, a land conservancy's nonprofit status also gives it access to grants and other finance strategies that are reserved for charities. A discussion of the benefits and requirements of each finance method follows.

\section{Land Appraisal}

Before a property can be sold or purchased, it must be appraised. The conservancy is usually responsible for the initial appraisal after the land's donation unless the developer purchased the land and subdivided the portion to be developed; in which case, the conservancy must still hire an appraiser for the portion with an easement. Land appraisals should use different criteria than simply assessing value based on the percentage of the land that is developable or the square footage of the property (McMahon, 2010). Instead, appraisals should be based on the value of the land's scenery, public amenities and habitat quality (McMahon, 2010). It is important that conservancies ensure that, during appraisals, the land's value will be judged differently than standard development projects. There is a high monetary value in creating quality habitat areas, enhancing project atmosphere and serving the target market. 


\section{Bargain Sale}

One limited development finance method is termed a "bargain sale" by the IRS (Hoffman, 2012). According to the Planned Giving Design Center, it "occurs when a donor, who intends to make a charitable contribution, sells property to charity for less than its fair market value" (Hoffman, 2012). If the landowner agrees to grant a bargain sale to a land trust, the landowner can then qualify for tax deductions since it was not sold at full-market value. According to congressional laws, the amount that the landowner can gain "bears the same ratio to the gain that would have been realized if the entire property had been sold at its fair market value on the date of the bargain sale" (Hoffman, 2012). Land trusts should highlight this tax deduction when speaking to landowners about conservation options.

To fund the Galisteo Basin Preserve limited development project (see the Case Study chapter of this project for more detail), Commonweal Conservancy bought the land cheaply from the owners who agreed to pay $\$ 19,833,000$, (tens of millions of dollars less than the $\$ 40$ million the Smith family paid) in exchange for a tax write-off equal to the value of the donated portion (McMahon, 2010). The Conservancy benefitted as well since it only paid half of the cost of the property in five phases over eight years (McMahon, 2010). According to Ted Harrison in an interview, "you need a seller that is willing to make a significant concession and one that is conscious of his or her role in the larger community to advance the protective objective of the community" (personal communication, May 5, 2012). Harrison mentions that the landowner from whom the bulk of the 13,522 acres was purchased was sentimental about the landscape, having owned the property with his family for 70 years (personal communication, May 5, 2012). 
These family members were connected to their land and wished to see it preserved for others. According to Harrison, this bargain sale financing technique relies upon the presence of "people who are already in-place on the land" that form a community that "wants to put its wealth to good purposes" (personal communication, May 5, 2012). This model depends upon acquiring land at a bargain price. A passion for the landscape can motivate landowners to donate land to a conservancy and assume the risk of depending upon an income tax deduction to cover the donation.

Landowners that offer a bargain sale of their property are eligible to receive an income tax deduction provided that they do not profit in any other way than its sale. Landowners that offer a bargain sale must also follow Section 170(f) (8) of the Internal Revenue Code, which states that "all charitable gifts valued at $\$ 250$ or more must be substantiated by a letter acknowledging the gift and stating that the donor received no goods or services in return (or estimating the value of goods provided in the case of a bargain sale)" (Land Trust Alliance, 2013). Since the laws governing tax deduction qualification can be complicated, land conservancies may consider fostering a relationship with a particular tax consultant who can help landowners determine whether tax deductions are likely to offset the cost of the donation (LTA, 2013).

\section{Full-Price Land Sale and Landowner Tax Deductions}

The previous financing example of acquiring land at a reduced price and should be used with the next financing strategy which discusses easement placement and the conservancy's sale of portions of a donated property at full-market-value. If a land trust wishes to conserve the purchased property with an easement and then sell it, the 
easement's restrictions will lower the value of the land to half the price the conservancy paid for it (Parker, 2002). Since, in limited development, the conservancy depends upon the land's resale to recover its acquisition costs, it must protect the land's value.

In order to conserve a property and regain, at minimum, the land's purchase price, the conservancy must sell the land at full-market-value and encourage the buyer to voluntarily place an easement on it. Commonweal Conservancy used this strategy in its Galisteo Basin Preserve limited development project, combining a bargain sale purchase of 13,522 acres with the sale of subdivided ranchettes to buyers willing to pay full-price and place a conservation easement on their new property. The surplus money gained from the full-price sale of each subdivided property helped to offset the cost of the entire property and its long-term maintenance. Ted Harrison, the founder and president of Commonweal Conservancy, cautions that "most people underestimate the expense. It can take longer to sell lots. Ted Harrison states, "If the market goes away, we could be stuck with the land and with development costs" (personal communication, May 5, 2012). Parker cautions that surplus money should always be deposited into a fund that pays for land purchase loans, construction loans or land maintenance costs and should never be used to raise staff salaries (2002). Surplus money is thus necessary for nonprofit organizations to repay land purchase loans if property sales are slow.

Despite a property's reduction in value when easement restrictions are placed, the landowner may still profit from income, property and estate tax deductions and the property's placement in the lowest tax assessment category (McMahon, 2010; Forever Forests, 2010). According to the California Council of Land Trusts, the Protection Act of 2006 states that a land donor may receive income tax deductions for up to 50 percent of 
the donor's adjusted gross income and may continue to receive this deduction for up to 15 years (2013). Farmers that place an agricultural easement on their land "can shelter up to 100 percent of their income for up to 15 additional years” (Forever Forests, 2010). Under the Natural Heritage Preservation Tax Credit Act, reestablished in 2005, the state of California also offers tax credits, which provide deductions of up to 55 percent of the donor's adjusted gross income for 8 years and may be applied in addition to federal tax credits (LTA, 2013). As a result of the 1997 Tax Payer Relief Act, IRS tax regulations allow the "exclusion," from the calculation of estate taxes, of up to 40 percent of easement-protected land (Forever Forests, 2010). According to Parker, more easements are used for conservation in regions that offer tax incentives than are used in areas that do not (2002). To encourage land donations, conservancies should aid landowners in meeting tax deduction criteria.

To protect both the land's maintenance endowment and the landowners' tax deductions, the conservancy must assume greater risk, trusting that the buyer will place an easement on the land after its purchase. According to an article by the Pennsylvania Land Trust Association, "a charitable contribution must be voluntary in order to be deductible for federal tax purposes" $(2012,17)$. The conservancy cannot require, in writing, that a landowner put an easement on a property, accepting only the buyer's verbal pledge instead. Otherwise, states Ted Harrison, "it is not freely giving and thus does not merit a tax deduction because you're just performing to what you agreed to. As long as there is a risk that the easement won't be made, that period of risk is the donative intent" (personal communication, May 5, 2012). According to Milder, landowners and developers are not eligible to receive tax incentives in return for the donated easement if 
they also gain a profit from the sale or continued use of the portion they donated (2006). Tax incentives are intended to supplement the loss incurred from a donation.

The Land Trust Alliance highlights the difficulty of using this conservation method, stating that unless the donation fulfills "specific conservation purposes," tax deductions are often not granted for donations of the development rights but not the ownership of the land (LTA, 2013). Thus, some donated land is more likely to qualify than others and the amount of the deduction may vary or be threatened if a landowner continues to receive income from the property after its donation. According to Stephen Small in an article for the Private Landowner Network, "as a rule, the following generalization works: the more significant the land is, the more it adds to the public good, the more likely it is that you will qualify for the deduction" (2006). Most properties that meet conservancy criteria will also qualify for an income tax deduction since the property often contains important conservation features (Small, 2006). For more information about tax incentives, the requirements governing land donations or suggestions for further reading, consult the "Conservation Donation Rules" (2013) page of the Land Trust Alliance's website (see Bibliography).

If a conservancy decides to use this finance strategy, Harrison advises meeting with buyers to get to know them and ensure they are committed to conservation (personal communication, May 5, 2012). Harrison reports that all land buyers that have voluntarily agreed to place an easement on behalf of Commonweal Conservancy have followed through, but adds that the risk "is too much for some land trusts and is not an approach that works in all cases" (personal communication, May 5, 2012). This technique should be used with less-crucial habitat areas that will not jeopardize the landscape's health if 
the landowner reneges. Harrison advises ensuring that their clientele have enough financial resources to buy the, often expensive, subdivided properties at full-price (personal communication, May 5, 2012). Harrison advises locating homes near to already-established rural communities to ensure that a market exists and to entice potential buyers with membership in a small community (personal communication, May 5, 2012). To prevent objections from nearby community members or impacts to their property values, ensure that the project is located sufficiently far away. Harrison credits the marketability of the Galisteo Basin Preserve's properties to the scenery (canyons, rock formations and rolling hills) and mild climate, making the land seem "outside the norm" to potential buyers (personal communication, May 5, 2012). This model of conservation is highly trust-based and should only be pursued if the conservancy is reasonably sure of its success.

\section{Transfer Fees}

Up until 2012, transfer fees were another convenient way to fund the maintenance of limited development projects. Transfer fees are a mandatory fee that a buyer must pay each time the property is resold, and can be as much as $1 \%$ of the property's value (Rockwell Institute, 2012). In the past, the developer, investors and land conservancy involved in the project could use the money to fund other outside conservation projects (Rockwell Institute, 2012). However, the Federal Housing Finance Agency (FHFA) has banned the use of transfer fees for any project built after 2011, that can be sold on the secondary market, unless the transfer fee funds services that "directly and exclusively benefit the encumbered property" (LTA, 2012). The secondary market is when a 
property is resold after its initial sale. Transfer fees that were implemented before February 2011 are allowed to continue, but new projects built after 2011 may only impose transfer fees in the form of homeowner's association fees or a maintenance fund. While national FHFA standards allow transfer fees, some states do not, but according to the Pennsylvania Land Trust Association, “California’s statute permits private transfer fees that are properly recorded and contain certain disclosures" $(2012,11)$. The FHFA clarifies that a landowner or homeowners' association can use fees to 'directly benefit' the property by funding conservation, restoration or even "cultural, educational, charitable (or) recreational activities," either on or off of the property, provided that these activities are used frequently by the project's residents (LTA, 2012).

As a replacement for land transfer fees in states in which they are not allowed, the Pennsylvania Land Trust Association suggests requiring land-maintenance endowment payments from the project's home buyers, sellers or both (LTA, 2012). Easement maintenance payments are still allowed under this new rule since they are a loan rather than a fee and are more affordable and convenient for landowners and land trusts if the fee is broken into annual payments and not paid in a large, single amount by the landowner (LTA, 2012). While there is no guarantee that transfer fees can be deducted as a charitable donation, the Pennsylvania Land Trust Association states that if the property's original donor pays the maintenance funding to a land conservancy, it is possible for these payments to be deducted (LTA, 2012). However, any person that takes ownership of the property after the initial easement donor must assume the stewardship payments for the easement, yet the new owner cannot deduct these payments as charitable donations since it was not that person's charitable donation (PLTA, 2012). 
This report argues that transfer fees are thus risky and should only be used if homeowner's association fees or an endowment provided by the developer are not sufficient for maintenance.

\section{Grants}

Local, state and federal grants are another funding source that can aid in purchasing land and securing funding for project amenities. Grants can be difficult to secure because they often come with strict conditions specifying how the money is to be used and they sometimes require the applicant to match the funds. For limited development partners in California, the Funding Wizard section of CoolCalifornia.org, is a resource developed by public agencies such as the Governor's Office of Planning and Research, the California Natural Resources Agency and the Strategic Growth Council. This database allows applicants to search for California grants, cooperative agreements and local rebates according to specific criteria (2014). Before applying, each grant should be scrutinized since many have very specific conditions for the use of the money that could drastically change the project's goals or objectives. Due to the FHFA's new rules regarding transfer fees, if applying for a federal grant, a conservancy may have to demonstrate that any long-term fees derived from the buyers or sellers of its property will directly benefit only that property (LTA, 2012). Grants should only be pursued if their stipulations agree with the overall intent and goals of the project.

One state grant that is useful for conservation and limited development projects is the Natural Community Conservation Planning (NCCP) program. According to the Department of Fish and Wildlife's website, this program offers grants specifically for 
composing conservation plans in conservation development projects (2013). According to the website, the program "identifies and provides for the regional or areawide (sic.) protection of plants, animals, and their habitats, while allowing compatible and appropriate economic activity" (dfg.ca.gov, 2013). This grant requires that the project be started within 12 months of accepting the grant and that project partners work with NCCP officials or agencies such as the California Department of Fish and Game or the U.S. Fish and Wildlife Service which offer assistance and advice to grant recipients (dfg.ca.gov, 2013). Grants are awarded to conservation projects that serve various needs including those that are non-conventional, urgent or oriented toward acquiring habitat for threatened species (dfg.ca.gov, 2013). Some grants, such as the NCCP Local Assistance Grant, prohibit the use of any other funding sources. This can be problematic since many limited development projects require numerous funding sources. Project partners can try to solve this issue and make the project eligible for the grant by separating the project into individual components. For information about the restrictions, uses, and means of applying for each grant, please visit www.dfg.ca.gov/habcon/nccp/grants.html.

\section{Loans}

Bank loans are a temporary funding source that must be paid back, along with interest, over a certain period of time. Banks may resist providing loans to limited development projects since there is a risk that the project will not sell as readily due to its deviation from normal project density and design (McMahon, 2010). In order to secure a land purchase loan from a bank, a land trust should demonstrate that it has reliably repaid all loans for past projects (McMahon, 2010). A land trust must also assure the bank of 
the project's marketability using examples of successful comparable projects (McMahon, 2010). A land trust should also consider making alterations requested by banks.

In the Spring Islands development project in South Carolina, the bank objected to the site's protection agreement and lack of density, the proposal for which included only one-tenth of the allowed development (McMahon, 2010). The bank was skeptical that the project would not be profitable due to such limitations imposed by the developer (McMahon, 2010). To warrant a loan from a bank, the project must be presented as possessing numerous natural amenities and appealing to a particular target audience.

\section{Minimizing Construction Costs}

When green building techniques are used, such as lessening the width of roads, both the cost of construction and the project's environmental impacts are reduced (McMahon, 2010). The finances saved can then be allocated to reduce the expense of restoration, mitigation, grading or the maintenance of green infrastructure (McMahon, 2010). These expenses are an investment in the quality of the project and its conservation initiatives and it is the duty of stakeholders to help the developer feel equipped to make this investment. In addition to reducing project costs. The developer and stakeholders will value a project if it achieves conservation goals, attracts the target market or bolsters public support.

The inclusion of public amenities that appeal to the target market can help improve marketability (Sullivan, 2005). For instance, horse owners will want areas to ride, families will want child-friendly activities and retired individuals may want lowimpact activities. Amenities increase the marketability of the project because upscale 
limited development projects must compete with upscale standard development projects that offer tennis courts, a golf course or a public swimming pool (Sullivan, 2005). However, some publicly-accessible features can be very costly since they tend not to require user fees, and thus fail to refund the price of the materials used to build them. For example, the Long Dock Beacon project faced increased construction costs due to the inclusion of hiking trails (Sullivan, 2005). Sullivan calls this the "public value gap" which is the gap in income resulting from investing money in free public amenities rather than features that produce a profit (2005). To close the public value gap, home prices may need to be raised or fewer amenities included. The conservancy may hold a public workshop to decide the type of free-to-use public amenities that should be included. Public amenities can be an investment in the project's quality, but should be applied in an exact way to directly appeal to the project's target audience, fulfill a community goal or gain public support. Designers should seek a balance between public amenities, habitat areas and profitable, developed parcels.

To illustrate the reduction in costs that can result from limited development, McMahon provides the example of Dewes Island in South Carolina. This project avoided installing gutters and retention basins since fewer paved surfaces reduced runoff and infrastructure costs (McMahon, 2010). However, projects that use green infrastructure such as bioswales or permeable pavement will require maintenance to clean out the debris and pollutants that will accumulate in the ditches (McMahon, 2010). Construction costs can be reduced if roads are located on pre-existing trails in the site (McMahon, 2010). Building materials may also be reused to create new cement or reinforce river banks (2010). See the Conservation Area Site Planning and Design section of this report 
for more detail about this building technique. Lower construction costs benefit the developer, increase the likelihood of project success and enable more resources to be devoted to conservation.

\section{New Markets Tax Credits}

A final funding source is only available for the developer of the project in the form of New Markets Tax Credits granted by the IRS through the Treasury Department's Community Development Financial Institutions Fund (Sullivan, 2005, 100). This funding source can be difficult to procure for limited development projects because of the complexity of applying and the heavy competition for the grants. To fund the Long Dock Beacon project, the developer, Foss Group Beacon, pursued New Markets Tax Credits from which it earned $\$ 10$ million in equity (Sullivan, 2005). To be granted New Market Tax Credits, an organization must first submit an application to the IRS to become a "Certified Development Entity," thus it is mostly banks and community development organizations that apply (Sullivan, 2005). A conservancy cannot use the tax credits, itself, because it is a tax-exempt non-profit, but it can sell them to investors (Sullivan, 2005). To obtain them, a land trust can partner with a developer that is willing to become certified. Or, if a land conservancy wishes to add development to its mission and become a Certified Development Entity, the conservancy may apply for them as well.

These tax credits have many restrictions, for instance, they may only be used to fund development in low-income areas. Their purpose, according to Sullivan, is to "create economically and environmentally healthy communities in which all people, especially those with low incomes, can reach their full potential" $(2005,144)$. Qualifying 
for tax credits is highly competitive and the application process is expensive (Sullivan, 2005). According to the Community Development Financial Institutions website, in 2011, 99 organizations were selected to receive tax credits out of 250 applicants (CDFIF, 2011). The IRS requires that "substantially all of the equity" received by the developer be used for the project during the seven-year tax period (Sullivan, 2005, 101).

Once awarded, the Certified Development Entity can sell the credits to investors and use the money to fund development in approved census tracts only (Sullivan, 2005). Thus, the proposed project location is limited to must fall within an approved census tract. According to the Community Development Financial Institutions (CDFIF) website, investors are given credits for 39\% of their investment in the project (CDFIF, 2011). Overall, the highly-competitive and highly-regulated nature of New Market Tax Credits makes them less-convenient than other funding sources. Since the application process can drain resources, they should only be pursued if the project easily meets all criteria and if there are financial, staff and time resources to spare. 


\section{Chapter 8: Stakeholder Collaboration}

\section{Determining the Desired Type of Partnership with Stakeholders}

The land trust, as a nonprofit, public-serving entity, is an ideal stakeholder to coordinate public and professional partnerships since it has multiple connections to the community (Sullivan, 2005). A conservancy must be confident in the project's stakeholders since there is some risk in partnering with them in regard to their priorities, dependability or the financial limitations of each. As was discussed in the chapter of this report titled "Drafting a Mission Statement that Enables Limited Development," the land trust should have developed minimum quality standards with which to evaluate projects in which they are considering involvement. According to Sullivan, these quality standards should be enumerated in the development agreement in order to ensure that the land trust can actively protect its reputation and pursue its own goals (Sullivan, 2005). For example, Scenic Hudson evaluated whether the City of Beacon would be a good partner by requiring, at minimum, that the partnering city be financially and politically stable, accessible and cooperative (scenichudson.org, 2012). This is a good strategy since the entire reason for partnering with a stakeholder is to increase the conservancy's stability, expertise and resources, not to burden itself with turbulent politics or another stakeholder's financial instability. The land trust should use its minimum standards to decide whether to even embark on a project and which stakeholders to partner with.

As previously mentioned, fostering a positive, responsible and involved local reputation is important because the feasibility of a limited development project often depends upon sharing expertise, available finances and work load between stakeholders. Trust is needed between stakeholders since, as recommended by McMahon, if the land 
trust is the initiating organization, it should set the project's context by drafting its initial vision statement based on its own minimum standards (2010). Examples of vision statements provided by McMahon include: "Protect critical habitat for salamanders" or "Incorporate a diversity of voices from across the community" $(2010,80)$. The project initiator should then invite project partners to refine its initial project vision and goals based upon the conservancy's initial direction (McMahon, 2010). McMahon recommends compiling a list of desirable site characteristics and features and then ranking these in order of importance and feasibility $(2010,82)$. However, potential partners may find it intimidating to enter into a project with a pre-determined ecological focus unless the conservancy has established a reputation for flexibility, successful projects and collaborative business partnerships. Land trusts must make sure potential partners are confident that a partnership will not result in too many limitations or costs (McMahon, 2010). While the project's vision is intended to keep the project focused on its original intent, the vision must be flexible enough to suit the needs, schedule and budget of the land trust's partners. This progression from vision statement to goals to project design encourages organized and fact-based negotiation and a narrow scope.

In limited development projects, conservancies may assume many different kinds of partnerships with stakeholders with varying levels of responsibility and involvement. Stakeholder collaboration in limited development often takes the form of four different models as enumerated by Jeffrey Milder (2006). These models include the "Buy, Restrict, Sell" model which requires the land trust to purchase the entire property, place a conservation easement on a strategic area with particular conservation values and hire consultants to conduct permitting, appraisal, subdivision, and infrastructure installation 
on the portion to be developed (Milder, 2006, 15). A land trust may have difficulty conducting the project on its own if it lacks development expertise and finances. To avoid costly redesigns, before pursuing this model, a land trust should determine local priorities by examining recent development and conservation projects, the typical level of public participation and the types of obstacles encountered. In addition, the land trust should have established a good reputation so that the community is clear on its priorities.

In Milder's “Work with the Landowner" model, the land trust approaches a landowner that is willing to preserve part of the land in order to reclaim a portion of its worth (Milder, 2006). In this model, the land trust leaves the landowner to develop the property and, instead, takes the landowner's wishes into consideration as it composes a site plan for the conservation area that prioritizes the site's ecology, protects sensitive habitat areas and locates public access in less-sensitive or more abundant habitat areas (Milder, 2006). This model requires that the land trust use data as the basis for its design decisions. It also requires that the landowner and land trust be willing to compromise and collaborate to define objectives for the project that meet both stakeholders' needs.

Even an unofficial agreement between the landowner and the land trust to conserve a property can be very valuable. According to McMahon, the Guilford Land Trust demonstrated for a landowner who was, initially, not interested in conserving his land that his property's value would increase if it were conserved (2010). The owner agreed to sign a letter of intent, which would not be legally-binding, pledging to sell his land to the conservancy when he was ready to put it on the market (McMahon, 2010). The landowner initially wished to sell the developable portion of the property and conserve the wetland, but during a meeting with the land trust, he decided to donate the 
entire property (McMahon, 2010). While an informal letter of intent may seem insufficient for a land trust to base its long-term plans upon, such a letter functions as a promise that the landowner will remain in dialogue with the land conservancy.

In the "Partner with a Developer" model, the developer buys the land and accepts all of the risks and profits of its sale, but it asks the land trust to conduct the ecological site design early in the process (Milder, 2006). Just as in the "Work with a Landowner" model, the land trust assumes an advisory role, helping the developer compose the conservation easement and decide the least impactful locations for conservation areas, development and public access (Milder, 2006). Negotiation and accommodation are important since each stakeholder's goals for the project may be very different.

In this model, the conserved portion and the developed portion may be treated either as one large project with the developer and land trust incorporating compatible elements into each system, or as completely separate projects, with the land trust and the developer each having little input in each entity's designs. The latter approach was used in the Eagle Ranch Project, a detailed discussion of which may be found in the Case Study section of this report. The Eagle Ranch property was divided into two separate projects: the agricultural easement protecting a cattle ranch owned by the Smith family and the development area annexed to the City of Atascadero. The Land Conservancy of San Luis Obispo County assumed less involvement because the Smith family initiated the project and hired its own designer. Since most designers prefer to work with just one client (New England EFC, 2003), the Conservancy had to leave site design in the hands of RRM Design and the City of Atascadero and undertake the task of negotiating the terms of the agricultural easement with the Smith family (Harrison, pers. com., 2012). If 
a conservancy wants to have a greater role in design, it must initiate the project and hire the developer itself. Sometimes, the most appropriate role for a land trust is a more passive one, ensuring that the easement provisions are of sufficient quality.

If project success depends upon compatibility between the developed and conserved portions, the land trust and developer, in the Milder's Work with the Developer model, may wish to treat the conserved and developed portions as one project and pursue joint ownership of the project (McMahon, 2010). The land trust and the developer must be willing to negotiate problems, use their individual expertise to solve these problems and incorporate solutions into the final design with minimal disagreement (Sullivan, 2005). In a joint ownership project, design must often be altered to accommodate the needs of the developer. For instance, the developer may request placing drainage areas or public trails in conservation areas for convenience or marketability (McMahon, 2010). Land trusts must use their discretion in determining whether the developer's proposals will achieve project goals. Land trusts must also understand that when they deny a developer's financially-efficient requests, such as increasing density or building on flat land in conservation areas, they put an additional financial burden on the developer. When making alternative design suggestions, the land trust must balance marketability and quality conservation and should brainstorm ways of mitigating developers' income loss as a result of the alteration. Joint ownership projects require greater negotiation but allow the conservancy greater control over project design. An example of an effective joint ownership agreement is provided by the Long Dock Beacon project, in which the conservancy posted a Request for Qualifications and then assembled a community advisory committee to evaluate whether developer 
applications fulfilled several criteria (Sullivan, 2005). Detailed Request for Qualification interviews help the conservancy determine its compatibility with the developer. Scenic Hudson's criteria required that the developer uphold and practice the trust's "core principles," and evaluated the developer's reputation, inclusion of the public, prior experience with, and support for, conservation and green design and its experience with assembling funding from a variety of sources (Sullivan, 2005, 96). These criteria were previously mentioned in this report as essential goals for land conservancies to incorporate into their mission statements. I recommend that the land trust also ask developers how they would handle likely situations such as citizen opposition or insufficient funding. After reviewing applications, Scenic Hudson and the community advisory committee selected Foss Group Beacon as the project's developer and all three collaborated to select architects that would compose the master plan and project designs (Sullivan, 2005). In this project, each stakeholder had to be willing to cede some authority to achieve designs that benefited everyone.

Whether establishing a joint ownership agreement or simply partnering with a developer, it is important to define, in writing, each party's responsibilities. Scenic Hudson, the land conservancy, and Foss Group Beacon, the developer, negotiated a development agreement which ensured that Scenic Hudson would still retain ownership and use of its land if the project failed (Sullivan, 2005). The development agreement also safeguarded the land conservancy's nonprofit status despite its engagement in a profitable project (Sullivan, 2005). Development agreements are intended to unite the very different priorities of project partners, are created through the process of negotiation and ascertain a commitment from all parties to the specified priorities and quality standards. 
The last of Milder's limited development models is called the "Conservation Investors" model. Conservation investors are entities that are willing to fund a portion of a conservation project in exchange for a percentage of the profit, private use of the property or the project's tax incentives (Milder, 2006). In this model, the land trust and investors collaboratively buy the land, design a site plan, and designate the area to be conserved (Milder, 2006). Costs are often shared and there may be numerous investors. The conservancy must be able to demonstrate its experience and the project's marketability to ensure investors feel confident in the project. In the Long Dock Beacon project, investor confidence was earned through Scenic Hudson's management of several large conservation projects which required handling substantial sums of money and addressing local concerns (Sullivan, 2005). Additionally, if there is demand for commercial and residential space, landlords can ask higher rents and home prices can be higher (Sullivan, 2005). Investors perceive that a strong market for tenant space is indicative of a low investment risk, and according to Miles et al., they "are willing to pay a higher price for a less-volatile income stream" $(2007,150)$. Provided that a conservancy can prove to investors that the project will have a stable market, the investor may be willing to provide a larger investment.

It is important that conservancies evaluate their compatibility with investors before agreeing to partner with them since they must make major project decisions with investors' input. Sometimes, investors may even wish to be involved in land purchase, site design, the designation of conservation areas or the sale of subdivided properties (Milder, 2006). Sullivan recommends asking the developer for his or her recommendations for potential "equity investors" that have good reputations and goals 
that are similar to those of the project $(2005,100)$. Just as choosing a developer requires careful consideration of compatibility and values, so too does requesting potential investors since their investment makes them equal partners in the project.

I would also add to Milder's models, an option to work with a local municipality. Limited development projects can be initiated, not only by land trusts, but by local governments that acquire a property that they want to conserve. However, in order for a city or county to be willing to spend public money on the maintenance of a project or portion of a project, it must directly contribute to achieving a policy or goal in its General Plan. Collaboration with the city can be advantageous since the city can pay to maintain a portion of the project, enforce conservation goals and offer incentives for developers to adopt conservation priorities. These may include allowing the transfer or purchase of development rights, waiving fees, offering tax credits, offering density bonuses or expediting the permit process (McMahon, 2005, 52; New England EFC). Finally, a city can also put pressure on developers to pursue limited development by imposing impact fees (McMahon, 2005). The conservancy should first determine whether tailoring its project to accomplish a municipal initiative would alter its original mission and goals.

After considering each of these limited development models, a land trust should pursue the model that is most likely to succeed in its locality. A land trust should evaluate the potential successfulness of a project based on its own minimum project standards, its compatibility with stakeholders, the local response to the proposed project, its own resources and the resources that other stakeholders can contribute. After forming a partnership, the land trust must then collaborate effectively with its new partner, seeking mutual benefits and jointly defining the project's vision and goals. 


\section{Valuable Stakeholder Behaviors and Roles}

After selecting project partners, initial stakeholder meetings in the limited development process are held to evaluate whether the project is likely to be viable and profitable and whether stakeholder goals are compatible. Similar goals and perceptions of what is possible enable easier negotiation and collaboration between project partners and greater willingness to remove barriers for one another. A 2003 study by the New England Environmental Finance Center recounts a round table discussion between eleven professionals including developers, land trust employees, and city planners that had been involved in limited development projects. The topic of the meeting was "Innovative Approaches to Land Conservation and Smart Growth" and its purpose was to determine whether there is a correlation between financial benefits and trust-building between stakeholders (New England EFC, 2003). The participants were asked to describe key moments in the project that involved financial loss or gain and the behaviors that each exhibited that either facilitated or hindered trust-building (EFC, 2003).

According to the New England EFC's report, developers were appreciated for their willingness to cooperate, negotiate and rally potential supporters (2003). Since developers must advocate for project feasibility and marketability, they often do not prioritize collaboration (New England EFC, 2003). In limited development, the land purchase and construction loans are often expensive since they fund the purchase of large tracts of land as well as the construction of public amenities, such as trails, that generate no income. This financial burden entails a greater risk for developers than conventional development since they must hold the construction and land purchase loans until the 
negotiation process, municipal reviews, public feedback, construction and home sales are completed (New England EFC, 2003). Developers must then assume more risks when they prioritize ecological standards which conflict with their own perfected strategies for cost-effectiveness and project marketing. It is fair to say that limited development puts developers through greater financial risk than would a standard development simply because they are not in control of the project's cost, timeline or contents. Project partners should relieve this burden whenever possible (New England EFC, 2003).

In exchange for higher-risk, conservation-oriented development, a developer's project partners might offer financial assistance, expedited design review, permission to increase density or permission to include marketable amenities (McMahon, 2010, 52; New England EFC, 2003). As demonstrated by the New England EFC's study, other stakeholders appreciate when the developer is tolerant of the flexibility of limited development projects (2003). However, it is crucial that this flexibility does not overwhelm the developer and that project partners recognize that some project aspects that require large risks are often not negotiable. I advise that if the developer feels confident in the project, he may be more inclined to accomplish the last of the EFC's supportive actions: marshaling support from local architects or construction agencies, bringing resources to the project that other stakeholders cannot access (2003).

Provided that the risk is low enough, developers are likely to find conservation and limited development appealing since the proximity of open space raises the sales prices of homes and the project's marketability (New England EFC, 2003). In addition, limited development can benefit the public reputation of developers, since they will be engaging residents and businesses in discussion, determining local preferences and 
incorporating these faithfully into the project (Miles, 2007, McMahon, 2010).

Additionally, if trust is built between project partners, the developer may decide that there is a good likelihood that its fees will be waived or its permitting process expedited (New England EFC, 2003). Finally, the land trust can assume some time-consuming tasks or offer advice regarding site design, ecological feasibility, mitigation measures and outreach to potential clients (McMahon, 2010) or solicit public input. According to the New England EFC, project partners should depend upon the developer's sense of reasonable project costs and pacing in order to gauge whether the limited development project is reasonable as well (2003). Thus, a limited development partnership offers numerous benefits to both the developer and the conservancy. The objections of either party should not be an obstacle, but the catalyst for a needed discussion of larger, looming project issues. To better support the developer, the land trust should encourage stakeholders to share and negotiate issues and depend upon collective expertise to identify and circumvent impending problems.

The land trust can also provide necessary support to project partners. According to the New England EFC, stakeholders appreciate when the land trust: contributes ecological expertise, strives to balance development and conservation, consults them when drafting the site plan, accommodates their needs, and coordinates in-person public outreach or communications such as email, phone or mail (2003). Clearly, stakeholders want the land trust to work with them as a team, respecting stakeholders' needs rather than only its own conservation agenda. Stakeholders can then rely on the land trust's professional advice knowing that if land trust staff suggests a design change that could, potentially, be a hardship, they will not do it lightly and will offer support. 
A land trust should repay sacrifices made by other stakeholders by offering additional staff or funding. This assures stakeholders that they will be supported when they take risks to achieve project goals. Finally, if the land trust has been involved in community projects, I agree with the New England EFC's and Sullivan's stance that the land trust is ideal for community outreach since it is a public-serving entity $(2003,2005)$. To promote a project, I recommend that a land trust make the public aware of the project's quality by maintaining public visibility. In an article for the American Water Works Association titled Key Steps to Effective Public Outreach, Patricia Tennyson recommends speaking to local newspapers, giving tours of completed projects or providing information at community events and schools (2012). Thus, while a conservancy's project partners coordinate the site's development, the land trust can conduct outreach with residents.

When a stakeholder proposes partnership or requests that a conservancy hold an easement, the trust should first evaluate the quality of the preserved land (Sullivan, 2005), the types of existing habitat values and the degree to which the land's preservation would serve the public. The land trust's degree of involvement may vary depending on the model of limited development used. As previously mentioned, both the Land Trust Alliance and Perlman and Milder recommend that land trusts, before selling a property to developers, at minimum, compose the site plan by identifying important, sensitive or unique features, in both the preservation and development areas, that development should avoid $(2004,11 ; 2005)$. If the land trust is not given input in the project's design or if the project does not meet its quality standards, it should use caution, adhering strictly to its mission when evaluating whether stewarding the land could be mutually beneficial. 
McMahon argues that imperfect projects can still provide very advantageous amenities and services to nearby communities such as access to the natural environment, improved water quality, improved property values and better marketability (2010). The land trust must evaluate the project's potential to last and its total benefits in order to protect its reputation lest it become known for supporting projects with no real conservation value.

Greater involvement by land conservancies is needed in limited development to ensure habitat quality. This is demonstrated by a 2010 study of land planning ordinances in 414 counties of the western United States conducted by conservation biologist Sarah Reed (Wortman-Wunder, 2012). According to Reed, though more than a third of the counties supported conservation and limited development, only $13 \%$ required a site observation to identify sensitive ecological features, while the majority of counties were even less likely to protect critical habitat (Wortman-Wunder, 2012). A conservancy can help developers decide which site evaluations are necessary and how to connect with ecological consultants. It is thus important that conservancies understand local ecological processes and wildlife needs so that they can recommend good ecological practices to developers. Though conservancies may not be able to enforce their recommendations, they can encourage developers to adopt their proposed guidelines by initiating the site inventory and composing the site plan according to conservancy standards.

Cities are another important collaborator in the limited development process. The New England EFC states that cities want, at minimum, projects that: use comprehensive feedback from the public, minimize public opposition or the likelihood of litigation, do not require frequent city intervention, reduce needed infrastructure, offer higher property 
taxes due to proximity to open space, meet and adhere to quality standards and development and conservation goals regardless of outside pressures (2003).

Municipalities are often less-flexible than private organizations because they must adhere to their zoning code and must evaluate all proposed projects fairly (New England EFC, 2003). In order to decrease municipal skepticism, McMahon recommends demonstrating the potential rewards of clustered development and citing successful limited development projects in other cities (2010). Limited development is often financially advantageous for cities since most projects are density-neutral and so will garner the same amount of property taxes as standard development (New England, EFC, 2003). Provided that a project fulfills the basic tenets of the city's General Plan, it is important that cities ensure that existing zoning and development regulations such as use, lot size or density restrictions, do not become a barrier to non-standard limited development projects (New England EFC, 2003). However, a city will want to know that the project will directly benefit residents since tax money will be spent to maintain the site's public spaces and utilities (McMahon, 2005). It is strategic for stakeholders to reduce the city's risk and increase trust by using the project to address local needs, which, in turn, encourages the city to fairly evaluate nonconventional limited development projects based on their overall benefits and not on narrow building codes and regulations.

According to the New England EFC, behaviors and actions exhibited by municipalities that are valued by other stakeholders include: publicly endorsing the project and refraining from setting unreasonable requirements or demanding additional contributions from project partners simply because the project deviates from the norm (2003). Since the city is risking its reputation in offering expedited permitting and 
variances, it will be much more willing to exhibit these good behaviors if it can trust that project partners will defend the long-term quality and sustainability of the site. In fact, if designers incorporate city input and public feedback and try to use the project to decrease costs to all, the city may agree to publicly promote the project, encourage businesses to locate there, or even to purchase and maintain the project (New England EFC, 2003). Finally, if project partners use public feedback to make changes to the project before the city has to request changes, the city council often appreciates not needing to act as an enforcer (New England EFC, 2003) and risk altering the project's original intent. Cities must be flexible since the regulations they enforce automatically make them project partners in this negotiation-dependent process.

At times, earning the support of all core stakeholders is difficult. Rocking K. Ranch in Pima County, Arizona was a project that, at first, met opposition from local residents and even the National Park Service, which wanted the land to remain undisturbed (McMahon, 2010). Tough negotiation was required to achieve a compromise that was both feasible and satisfactory to all parties. In order to encourage stakeholder negotiation in spite of opposition, limited development was chosen and development was reduced and clustered and 2,000 of the total 6,000 acres were donated to the National Park Service for conservation (McMahon, 2010). Rincon Institute, a stewardship organization, was established using resident fees in order maintain the property and encourage community participation (McMahon, 2010). In this way, the final design met each stakeholder's needs. The developer profited from selling its land to the National Park Service and homebuyers, concerned citizens benefitted from reduced density and lessened project impact and the National Park Service, after advocating for its 
own data, was successful in proving that conservation was critical to replenishing the water table and protecting species (McMahon, 2010). Thus, limited development can even move forward despite contention since these projects address multiple needs and provide the option to compromise and avoid city council debates.

In more congenial limited development projects, limited development is advantageous because greater risks can be taken if project partners can depend upon one another to remove barriers or waive fees. In the Acadia Woods project in Bar Harbor, Maine, the developer, the Lyme Timber Company, formed a partnership with the Maine Coast Heritage Trust to pursue a limited development project on a 380-acre foreclosed property (Sullivan 2005). In light of input from the National Parks Service, Bar Harbor city officials, and the community, the Lyme Timber Company made the risky decision to develop only half of the lots allowed by the zoning code (Sullivan, 2005). The Lyme Timber Company deemed this decision feasible because the costs of paving and land clearing would be decreased and the negative impacts on the community and ecosystem would be lessened (Sullivan, 2005). To relieve some of the developer's cost burden, state and local officials reduced development fees and expedited permitting (Sullivan, 2005). Limited development stakeholders should consider preemptively offering support to stakeholders that assume greater risk.

Thus, for land conservancies interested in partnering with a stakeholder, there is a necessary progression from developing a positive reputation to effectively communicating with compatible partners to anticipating needs and being willing to take risks based on confidence in the support of project partners. While trust is not completely necessary due to the potential for successful compromises in limited development, trust, 
good communication and removing barriers, nevertheless, decreases the project's risk and allows the project to meet multiple needs at once. Limited development depends upon supportive behaviors between stakeholders such as sharing expertise and local connections, thus helping to ensure that risk does not outweigh the potential benefits.

\section{Stakeholder Collaboration Strategies}

One of the challenges of limited development is that the project must be put to the service of very diverse stakeholders with very different values and objectives. With so many stakeholders, equal collaboration is a challenge and if a land trust wishes to solicit greater public participation, it must include community members early in project design. Henry Sanoff proposes two very useful collaboration techniques that seek to bring diverse groups to consensus about the project's context, objectives and approach. The first is called Action Planning which always seeks concrete results such as a prioritized list, written or verbal feedback or alternatives that address this feedback (Sanoff, 2000). The other collaboration method is called Participatory Action Research which involves all stakeholders in project research, dialogue, information-sharing and direction-setting in order to achieve consensus about the facts and context of the project (Sanoff, 2000). According to Sanoff, these approaches can be used to resolve disputes, replace preconceptions with fact and provide project partners with data to support their decisions (2000). Note that consensus, here, means a group's final collective decision resulting from the organic process of discussion, debate and negotiation where, according to Sanoff, "differences are creatively explored" $(2010,18)$. Sanoff states that consensus should not "inhibit the argumentative process" or "silence those who are marginalized," 
and Myatt agrees that groupthink "stifles innovation, discourages candor, disdains dissenting opinions, and mutes the truth" if not arrived at organically $(2010,2012)$. I agree that consensus in limited development should be the end result, perhaps in the form of a site plan, of a collaboration process that fully assist the creative exploration of feasibility, priorities and use of the project to meet multiple needs.

Since Sanoff's collaboration approaches are intended for use in community, rather than professional, meetings, and since they give primary control of project design to the public, only certain aspects may be suitable for professional collaboration in limited development. When applying these models to professional stakeholder meetings, negotiation should move toward action, expertise should be shared and stakeholders should remove barriers for one another. When applying these models to public meetings, meeting organizers should solicit local preferences, educate residents about project goals and, in turn, allow residents to educate designers about how the site is used.

Whether using Participatory Action Research with community or professional stakeholders, there are several consensus-building principles that help form a team dynamic. For instance, all project partners should contribute their ideas, have access to detailed project information and benefit from the collaborative research process (Ramasubramanian, 1994, in Sanoff, 2000). Since the achievement of consensus provides a solid foundation from which to begin the project, one of the first data collection endeavors should be conducting "awareness walks" on the property to ensure all agree upon the existing conditions of the site (Sanoff, 2000). According to Sanoff, awareness walks "allow participants to "learn a common language and bond through a shared experience of the physical reality and through each other's experiences" (2000, 
62). I argue that even professional stakeholders can benefit from on-site discussion and should heed Sanoff's advice to record site observations on a worksheet that poses questions about possible project impacts, existing site hazards and unique features that could be protected (2000). After the awareness walk, stakeholders should meet and discuss whether a formal collaboration agreement is feasible and, if so, should identify project objectives and needed data and assign project responsibilities (Sanoff, 2000). Thus, this collaboration technique gives each stakeholder equal expertise regarding the project's baseline data by involving all stakeholders in its collection using research, surveys, and site observations. In addition, Participatory Action Research makes the process of researching into an opportunity for discussion and evaluation of priorities and compatibility between stakeholders. To qualify as true Participatory Action Research, however, Sanoff specifies that the public must be included in research-collection and goal-setting because they are the project's users (2000).

In order to avoid costly project redesigns, community design should be considered if the project's initial goals agree with community priorities, if the project will significantly impact or serve the public, if there is opposition to the project, if residents can offer valuable insight into the use or conditions of the site or if the necessary funding is available. For instance, if the primary concern is the local character or community amenities, such as low-income housing or public schools, residents should be allowed to shape project design. According to McMahon, "a local culture of mistrust" is created when citizens are left out of the decision-making process, resulting in opposition and, consequently, stricter development policies (McMahon, 2010, 52). While Tennyson warns that managers and engineers may prefer to "do their homework" before inviting 
public involvement $(2012,77-78)$, I argue that many project impacts can be addressed and mitigated if public input is solicited early in project design and used to gauge project feasibility. Thus, this report argues that early public involvement can help proposed projects be viewed as opportunities rather than impositions.

Early public participation does not, however, mean yielding all control of design over to the public. Public involvement should be sought in a way that also safeguards existing design guidelines. Tennyson provides an example of a project in which existing goals and designs were protected from alteration by requiring community members to adhere to specific criteria when submitting their own designs (2012). The proposed project could not be made smaller, the budget could not be changed and participants had to submit their recommendations by a certain date (Tennyson, 2012, 78). This gave residents control over the project's design while keeping community proposals within the realm of feasibility by preventing deal-breaking issues from being incorporated.

In truth, public participation is not always needed when a project cannot provide a community service, or if it must meet complex conservation goals, municipal requirements or financial needs. For instance, a project on private property that will not provide public access will only require a public-comment period assessing final designs and will focus, instead, on meeting ecological and municipal needs. In projects such as these, the project manager hires the developer and designs the project based upon market analysis rather than community input. However, since, the project will usually impact neighboring residents, according to McMahon, it may be advantageous to meet with any directly-impacted, neighboring landowners before finalizing designs to determine if 
mitigation measures are needed to offset impacts (2010). Thus, the circumstances of the project should determine the level of public outreach necessary.

Tennyson emphasizes that competently addressing public criticism is important and advises adhering to a specific public message that focuses on achieving a positive goal (2012). I recommend that this message be the project's central vision. If this vision is challenged by the public, the land trust should make note of this feedback for later consideration while explaining and defending the project's original vision. Stakeholders should make clear to participants that the purpose of public meetings is to solicit public responses and explain the project, not to negotiate large project alterations. Project partners should demonstrate that their research gives them a bird's- eye-view of project feasibility, enabling them to propose wise solutions that fulfill an array of needs.

Public workshops should be used to address public criticism and prevent negative publicity. According to Tennyson, at public workshops, information should be presented clearly, without jargon $(2013,68)$. McMahon recommends using visioning exercises, consumer preference surveys, mapping exercises and summarizing for the community all local workshops and community plans $(2010,77)$. These workshop activities give community members the project's facts, an idea of the project's complexity and involvement in brainstorming and merging their design ideas. McMahon recommends using build-out maps that illustrate how the land would look when fully-developed if the existing zoning codes and land use policies were followed (2010). By filling in all vacant space according to its proper zoning, residents can see the flaws of existing zoning and are invited to use the project to create alternate uses for the land. 
Another collaboration technique involves participants in what Henry Sanoff calls “design games" which are brainstorming activities that use small objectives to determine a group's preferences regarding the project's aesthetic, budget and site design (2000). Since surveying residents requires little discussion, it is ideal to use when quick feedback is needed. For greater discussion, Henry Sanoff suggests a variety of design games ranging from providing participants with stickers printed with icons so they may decide their configuration in the design area, to brainstorming activities that encourage participants to draw inspiration from the suggestions of other group members as they list and rank as many ideas as possible (2000). The objective of each "game" is to restrict critique until after participants have generated an abundance of project ideas thus ensuring that stakeholders' opposing viewpoints do not prevent discussion. When brainstorming, Gregory and Keeney recommend dividing the group's objectives into “means objectives," which are smaller, contributing objectives and "fundamental objectives" which are the project's overall goals, and then ranking them according to desirability and feasibility (1994). This report argues that this prioritization of ideas is the key to stakeholder agreement and the ability to put these ideas into action.

When disagreement arises, I recommend using Sanoff”s “Group Process” brainstorming method to establish rules that allow only specific kinds of feedback to be given as participants propose their ideas (2000). This collaboration technique allows each person of the group to present an idea without interruption for a certain amount of time (Sanoff, 2000). After the speaker is finished, the group's responses must be constructive, for instance, Sanoff gives the example of stating: "If I were you, I would..." $(2000,73)$. The presenter must write down each recommendation and may not respond 
to critiques until all participants have responded (Sanoff, 2000). This model limits participants' ability to respond negatively, instead, encouraging them to consider each proposal and offer improvements. This technique may be used with either the public or professionals in order to resolve conflict since it creates an environment in which participants may share and discuss their ideas.

Finally, after the conclusion of the project, it is important to extend gratitude and share credit with project partners for making a successful and locally-important project. Tennyson reminds project managers that they should celebrate the completion of the project with the other stakeholders and the role that each played in shaping and enhancing the quality of work $(2012,77)$. It is important that communication is continued between a conservancy and a developer to keep open opportunities to partner on future limited development opportunities. 


\section{Chapter 9: Eagle Ranch Case Study}

The two case studies that follow in Chapters 9 and 10 were chosen on the basis of the differing approaches to conservation and limited development employed by each. An analysis will be conducted of these projects' successes, failures, and the way that their contexts and conditions affect each land trust's approach to the project. For both case studies, an interview was conducted with an official involved in the project. A full transcript of interviews and interview questions is provided in Appendices A and B.

The first case study to be examined is the Eagle Ranch limited development project in Atascadero, California. Eagle Ranch is a 6,500-acre cattle ranch owned by the Smith family, originally subdivided into private lots offering no public open space. The purpose of this project is to place an agricultural easement on half of the property, preserving it as a working cattle ranch for use by the Smith family. The remaining portion will be annexed to the City of Atascadero and developed as an environmentallysensitive residential and commercial project utilizing clustered development to maximize public open space. This case study will examine the strategy behind the Land Conservancy of San Luis Obispo County's decision to assume a limited role in this project, instead, negotiating and enforcing the easement's terms. Analysis of the Eagle Ranch project provides an accurate depiction of the context, interest groups, stakeholder collaboration methods and public reception that may be expected for limited development projects in San Luis Obispo County. The purpose of this case study is to provide an example of roles that land conservancies can assume in limited development projects.

To gain an understanding of a designer's role and concerns in a limited development project, an interview was conducted for this Professional Project with 
Victor Montgomery, a principle designer in the Eagle Ranch Project and the former president and CEO of RRM Design. In my in-person interview with him, Montgomery describes the environmentally-oriented development process used on the Eagle Ranch project and his experience working with stakeholders such as the public and the city. Montgomery also discusses some of the successes and challenges encountered by RRM Design and its clients, the Smith family.

\section{Eagle Ranch Project Description}

The developed portion of the Eagle Ranch project is 3,430 acres and will be annexed to the city while an agricultural easement will cover the remaining 3,100 acres and will continue to be used as a cattle ranch by the Smith family (V. Montgomery, personal communication, May 22, 2012). The Smith family has signed a "Right to Negotiate" with the Land Conservancy of San Luis Obispo County, giving the Conservancy the "exclusive right" to possess the agricultural easement (V. Montgomery, personal communication, May 22, 2012). It is the conservancy's duty to ensure the easement meets their minimum quality standards and to hold and monitor the easement.

The project will contain clustered, single-family and multi-family lots that will range from .5 acres to more than 5 acres (DRC Powerpoint presentation 2-1, January 31, 2013). Due to public critique of the initial development proposals, the number of lots was reduced from 650 to 494 and more multifamily units were added to accommodate a variety of incomes, resulting in 93 units total with 47 of these units dedicated to senior housing (DRC Powerpoint presentation 2-1, January 31, 2013). The portion to be annexed will contain a village center with commercial buildings, parks, open space, an 
equestrian center, pedestrian and equestrian trails, a hotel and, possibly, a school (V. Montgomery, personal communication, May 22, 2012; theeagleranch.com, 2012).

\section{The Role of the Land Trust in Project Design}

This project is complex: it must comply with the city's General Plan, it must be affordable and feasible for the developer, it must meet conservancy standards and it must be compatible with the Smith family's adjacent ranch. The Land Conservancy of San Luis Obispo County assumed a less-involved role for several reasons: first and foremost, the City of Atascadero's General Plan required that clustered, environmentallycompatible development become mandatory in all rural areas and that open space in these areas be maximized (Eagle Ranch Specific Plan, 2010). This shifted the burden of project initiation and design from the Conservancy to the developer and landowner. Second, since the easement-protected land held by the Conservancy would remain a private ranch and provide no public access or critical habitat, it would not require ridged maintenance standards. And third, in the developed portion of the project, since RRM Design expressed its commitment to mitigating impacts as they were discovered and since both the designers and the city hired their own environmental consultants, (Eagle Ranch Specific Plan, 2010), the Conservancy's guidance was not needed.

Relieved of its project design duties, the Conservancy's primary role became negotiating with the Smith family the agricultural easement's restrictions and allowances and holding and enforcing the easement to ensure the land's quality (theeagleranch.com, 2012). I advise that if limited development is made mandatory throughout the county, the conservancy may then coordinate with county officials to compose objectives for the 
county's limited development policies, such as strategic locations, designs catered to specific species and means of ensuring that these policies are feasible for developers to fulfill. Finally, I argue that, even in a limited role, a conservancy may still attend City Council meetings and offer design recommendations or support for certain designs.

Thus, a conservancy should assume a limited role in a limited development project if it lacks the staff time to initiate these projects. To remedy this, a conservancy should help compose objectives for a county's General Plan requiring the use of environmentally-sensitive, clustered development in rural areas. Additionally, when numerous stakeholders' priorities threaten to make a project overly-complex, I argue that a conservancy should ensure that the project meets their minimum quality standards, but refrain from requiring unnecessarily complex project alterations. Finally, a conservancy should take a less-involved role when the land will remain in private ownership, if there will be no public access, or if it feels the environmental analysis is adequate.

\section{Designing the Project Concurrently with the Environmental Impact Report}

In the Eagle Ranch project, the Land Conservancy of San Luis Obispo County was not involved in identifying sensitive areas in the site for conservation. Instead, the Smith family and RRM Design agreed to design the project while conducting the constraints analysis, spurred by financial incentives, the requirement so Atascadero's General Plan and the Smith family's wishes for a self-mitigating project (Eagle Ranch Specific Plan, 2010). This unique approach allowed RRM to mitigate negative impacts as they were discovered, lessening the expensive changes that could be requested later in the project by the city council (Eagle Ranch Specific Plan, 2010). RRM Design decided 
to hire its own consultants, in addition to the city's, so that it could substantiate its design decisions and negotiate development requirements with the city (V. Montgomery, personal communication, May 22, 2012; theeagleranch.com, 2012). However, the City of Atascadero and RRM then had the challenge of reconciling two sets of impact analyses and postponing design work until both findings were given fair consideration. I argue that hiring one's own consultants might be worth the cost if analyses may be conducted more quickly or if the designer feels at a disadvantage using the city's findings.

Design costs were also raised by tailoring the project to the site's ecology and concealing it from view which required building on difficult terrain (V. Montgomery, personal communication, May 22, 2012; theeagleranch.com, 2012). According to Victor Montgomery, Environmental Impact Report (EIR) documents often cost \$1 million or more and "every addition or change to the project results in a re-draft of a portion of the EIR, as well as the costly studies to support it" and "the creation of new impacts" (personal communication, May 22, 2012). Thus, I argue that, despite the up-front cost, it is advantageous to use EIR studies to identify the project's largest impacts and incorporate reasonable mitigation practices into project design. Designing the project to decrease impacts may preclude expensive design changes, demonstrate the project's quality to local jurisdictions and enable the project to function compatibly with adjacent natural habitat. Although concurrent design succeeded in mitigating environmental issues, community issues, such as the project's traffic generation, persisted.

\section{Stakeholder Negotiations}

RRM Design encountered some issues with public outreach and had to make improvements to the project with which it did not agree to accommodate community 
needs. Despite monthly meetings and impact mitigation, RRM had to include public trails, paths through the ranch connecting to the national forest, traffic analyses and affordable and senior housing as requested at the February 26, 2013 Atascadero Joint City Council and Planning Commission meeting (2013). RRM Design opted for the Atascadero City Council to settle the disagreement, but they ruled in Atascadero's favor. According to Montgomery, the City Council, is "the final authority over the developed portion of the project," since the Specific Plan produced by RRM Design belongs to the City of Atascadero (personal communication, May 22, 2012). Thus, it is often fruitless to resolve disputes through direct confrontation with city councils (V. Montgomery, personal communication, May 22, 2012). I argue that a city may begin to view a project as desirable, even necessary, if project partners engage in dialogue early in design and strive to understand municipal priorities. As RRM Design learned, if a developer hopes for project approval, it must incorporate features that help municipalities accomplish their General Plan goals. Finally, developers should remind city councils that if the development that funds the project is reduced, the preserved area must also be reduced.

In regard to public outreach, commendably, the core stakeholders including RRM Design, the city council, the planning commission and the design review committee were accessible to the public to explain project details and answer questions (V. Montgomery, personal communication, May 22, 2012). For instance, in order to introduce residents to the project applicant, the Smith Family, and to showcase preliminary project designs, RRM Design, the Smith family and city representatives conducted an open house on January 17, 2008 (Eagle Ranch RFQ, 2010, 7). To date, a total of 25 public meetings have been conducted including workshops, neighborhood group meetings and 
professional joint study sessions (theeagleranch.com, Community Outreach, 2014). In addition to these meetings, the Smith family has taken an active role and has mailed information to neighbors, granted interviews to reporters, replied to emails and provided a website and project phone line (theeagleranch.com, Community Outreach, 2014). According to the Community Outreach portion of the Eagle Ranch website, conducting this amount of community outreach before filing an application for a development permit is rare (2014). RRM Design's public outreach process entailed seeking initial public input, beginning project design, seeking numerous follow-up public and small group neighborhood meetings once specific issues have been identified.

Weekly meetings were held with the client, the Smith family, to ensure project compatibility and to include their feedback on designs (V. Montgomery, personal communication, May 22, 2012). However, according to Victor Montgomery, design by the public was deemed to be infeasible (personal communication, May 22, 2012). Since the portion of the project offering public access is in the City of Atascadero's jurisdiction, it was assumed to be the city's responsibility to advocate for the needs of the public or to coordinate public design. The designers were responsible for taking public and private feedback and making design decisions. Soliciting periodic public involvement yet leaving ultimate project design in the hands of designers can be beneficial and result in a shorter design phase, less expense and more-focused project goals since there are fewer designers complicating and slowing the process.

However, one critique of Eagle Ranch's public involvement is that, at some initial meetings, public engagement was overly-simplified. At the first public meeting, held on September 25, 2008, the public took part in an "instant poll" survey that used visuals 
shown on a projector to illustrate each choice and "hand-held electronic devices" to cast a vote (theeagleranch.com, 2012). The survey asked residents to identify the most appropriate types of roads, land uses and open space as well as the importance of protecting the view shed (Eagle Meeting 1 Response Report, 2008). However, since they lacked a complete understanding of the effect each choice, residents could only answer these questions based upon their own assumptions. For instance, according to the Eagle Ranch Meeting 1 Response Report, $88 \%$ of residents expressed their opinion that country or rural roads were most appropriate to connect to the project, yet the question did not provide any context about the anticipated traffic density illustrating whether rural roads actually could be used (2008). The survey allowed residents to think that all of the options they had chosen could be implemented while, in reality, some options superseded others. Since the designers prioritized the options chosen by the community, the community could not specify, for instance, whether they preferred hiking trails and greater project density or fewer public trails and a less-dense project. Instead, the purpose of initial public meetings was to clarify information and solicit input about already-completed designs only. I argue that the community should be given meaningful participation debating and prioritizing preferred options and suggesting alternatives.

In the third public meeting held on November 16, 2011, designs were shown to the public; however, designs were met with defensiveness and disappointment from members of the public because they were intimidated by the seeming inalterability of the project's designs. Residents at this meeting still wished to offer input and negotiate the contents of the project, as exemplified by Atascadero resident Dennis Derickson's request: "If you could at least taper [the density] down as you're going into the 
development," (Young, 2011). According to Montgomery, the density, visibility and proximity of the proposed project were "hugely contentious," among the large-lot landowners (personal communication, May 22, 2012). In an article in the Atascadero News, one resident, Matt Gillette, stated, "With the current lot sizes, many residents... don't see other homes from the property, but with the proposed development, there will likely be 50 to 100 homes visible" (Young, 2011). Atascadero resident Diana Larsen also stated: "I kind of feel it's a bait-and-switch," stating that she thought 300 homes were going to be built rather than 800 (Young, 2011). Residents did not feel that the designs reflected the results of the survey conducted in the first meeting. Eighty-seven percent of participants had rated "maintaining the Atascadero rural look and feel" as "important or very important” (Eagle Meeting 1 Response Report, 2008). If constructive criticism, rather than skepticism, is desired from the public, actual discussions should be held early in the process to make project partners aware of public design priorities.

Since the public was not included in defining design priorities, they were not clear about the reasoning behind designers' decisions. Increasing project density was necessary to close the "public value gap" (Sullivan 2005) that was created when the nonrevenue-generating amenities requested by the public exceeded the resources available to construct them (previously discussed in the Construction Costs subsection of this report). For instance, Option E for the San Rafael neighborhood would have made the project more difficult since it would have added equestrian trails yet reduced the total number of lots by 60 , "the sale of which makes the project financially feasible" (V. Montgomery, personal communication, May 22, 2012). Additionally, according to Victor Montgomery, "there is flat ground that is prime area for development;" however, this 
area "is within view of several two-acre lots," and so, in order to protect the view shed, it cannot be developed (personal communication, May 22, 2012). However, "locating development on hilly, sloping ground causes more impacts" and greater grading expenses (V. Montgomery, personal communication, May 22, 2012). Montgomery is quoted in an Atascadero News article, stating that the project's density was increased to "have enough units to cover the cost of developing the ranch" (Young, 2011). However, I would add to this that if residents had been involved in prioritizing options and choosing alternatives and if a true dialogue could be had to facilitate mutual understanding of each party's priorities and needs, residents may be less apt to defend infeasible requests.

After initial negative feedback from the community and requirements by the Atascadero City Council to address traffic impacts, RRM Design took a different approach to public outreach. Individual meetings with neighborhoods were held to address specific traffic issues that would affect each neighborhood differently (V. Montgomery, personal communication, May 22, 2012). This enabled RRM Design to address objections regarding project road location and allowed residents to brainstorm solutions, rank their priorities and identify a consensus in a small-group. I argue that waiting until an issue arose and then addressing it, in-detail, with workshops and meetings allowed costs to be targeted to remedy specific issues, decreasing upfront project costs and complexity. A community advisory committee, recommended by Sullivan and established at the beginning of the design phase, would fulfill the same function (2005). In exchange, Sullivan states that this committee must accommodate the needs of professional stakeholders as well as their own and resolve public value gaps (2005). By arranging small-group meetings to be composed only of immediately- 
involved individuals, RRM Design helped residents distill their concerns, come to a consensus and streamline what would have been a cacophony of concerns. According to Montgomery, this was still a challenge since "each neighborhood wanted to push traffic density toward a different neighborhood" (personal communication, May 22, 2012). Finally, core stakeholders should be warned that, if residents are excluded from project design and priority-setting, costs and complexity later in the project may rise due to public criticism or unrealistic requests.

In final preparation for public meetings, if negative press is anticipated, project partners may wish to submit their own press release in the local paper to present the facts, remind residents of an upcoming meeting's purpose, reassure the community about the measures that designers are already taking to address anticipated problems. When RRM Design released a report ahead of a joint city council and planning commission meeting describing the project proposal, this report gave rise to an opinion piece in the local newspaper titled "Questions about Eagle Ranch remain unanswered." The opinion piece, written by a resident on behalf of several concerned landowners, questions the location of roads, the possibility of drainage problems, the feasibility and cost of additional fire and police coverage, the potential for a decrease in property values and the cost of project maintenance (2012). Reviewing news articles such as this one can be useful for project partners to prepare responses for how they will address project issues. Provided that project partners are willing to follow-through with commitments made at these meetings, addressing problems during meetings may encourage positive press and an attitude of cooperation between the public and core stakeholders. 
There are multiple opportunities for the Land Conservancy of San Luis Obispo County to have a greater degree of involvement in development. Sullivan suggests that since the Conservancy is a nonprofit organization dedicated to serving public needs, its opinion is generally trusted and could act as a mediator during these projects (2005). In future projects, the Conservancy may use this public trust to its advantage and offer its support to various project stakeholders in exchange for the inclusion of design features that meet Conservancy standards (Sullivan, 2005). I would also add that the conservancy can use its good reputation to bring the focus of municipalities to services the project will provide and vouch for their quality. The Conservancy should assume the level of involvement that it deems appropriate, ranging from hiring the designer and initiating the project to simply acting as an environmental design consultant. The Conservancy can also encourage cities to incorporate limited development into their General Plans. In future projects, the Conservancy can encourage designers to conduct their environmental analysis and project design simultaneously to minimize impacts. Finally, if the Conservancy deems it appropriate, it can encourage core project partners to include residents in project design and priority-setting from the beginning to discourage public criticism or unrealistic requests bred from defensiveness. Thus, despite the Conservancy's limited role, the Eagle Ranch limited development project provides useful lessons for conducting limited development in San Luis Obispo County. If a conservancy is flexible, well-informed, opportunistic and willing to fill a role at any level of involvement, it can facilitate limited development projects. 


\section{Chapter 10: Galisteo Basin Preserve Case Study}

This next case study provides an analysis of the benefits and challenges faced by conservancies when they assume a high degree of involvement in a limited development project. Unlike Eagle Ranch, Commonweal Conservancy was established specifically to oversee Galisteo Basin Preserve and thus, did not need to divide its attention between its new project and its past projects. It is important to analyze the conservancy's role as it transformed from project initiator to developer, partnered with land buyers and sellers in risky, but profitable, finance strategies and used green building and community design to achieve compatibility between the developed and conserved portions of the project.

\section{Project Description}

Galisteo Basin Preserve is a 13,522-acre conservation development that contains a mixed-use village center and four luxury communities (McMahon, 2010). The village center will contain 965 of the total 1,015 residences, a post office, chapel, offices and a school (McMahon, 2010). This project protects Commonweal Conservancy's reputation since, according to McMahon, it ensures the conservation of 13,090 acres, or 96.8\% of the site, while developing only 277 acres (2010). The project conserves space by clustering most development in the village portion which has an average density of 3.2 units per acre (McMahon, 2010). Four additional luxury communities, called 'homestead communities,' are located on larger properties surrounded by scenic, rural landscape.

The Thornton family who initiated the project, at first, only wished to preserve 1,400 acres of their 13,522-acre ranch (T. Harrison, personal communication, May 5, 2012). The Trust for Public Land had agreed to hold the easement for, and maintain, the conservation area in order to protect the site's geologic, archaeological and cultural 
landmarks of importance (McMahon, 2010). However, Santa Fe County's Planning Director expressed some concern that preserving this small amount of land would only illustrate "what the landscape used to look like" (McMahon, 2010, 136) and asked if the Trust for Public Land could preserve a larger portion using limited development ( $\mathrm{T}$. Harrison, personal communication, May 5, 2012). Ted Harrison, who was, at the time, the Southwest Regional Director of the Trust for Public Land, states that Santa Fe County's proposition "prompted me to reimagine the need and importance of community-building in a comprehensive, integrative, humanist approach to park-making and land conservation" (McMahon, 2010, 136). Since the Trust for Public Land did not possess the necessary expertise and did not want to lose the trust of its investors, it was not able to take part in a limited development project (T. Harrison, personal communication, May 5, 2012). As a result, Ted Harrison left the Trust for Public Land and founded Commonweal Conservancy, assuming the role of President and leading the efforts to purchase the property and pursue a conservation and limited development project (McMahon, 2010). Thus, in this project, limited development enabled a much larger conservation project than would have been otherwise possible.

\section{Project Demographics}

This project offers property buyers varying levels of affordability and luxury. This increases the entire project's stability and likelihood of success since the project can fill a greater variety of niches and survive if one of its markets disappears. Lower-priced properties are achieved by decreasing their lot size and clustering them, offering instead, common greens and natural open space for public use. The project's Village includes 
rental studios and townhouses ranging in size from 750 to 1,350 square feet and costing between $\$ 200,000$ and $\$ 325,000$ (McMahon, 2010, 146). Tract homes in the Village are 1,300 to 2,400 square-feet for $\$ 350,000$ to $\$ 450,000$ and larger custom homes cost between $\$ 500,000$ and $\$ 1,200,000$ (McMahon, 2010). These custom homes cater to wealthy individuals and ranchers and are located in the project's "ranch homesteads," which consist of: four properties in the West Basin neighborhood ranging from 32 to185 acres, 20 properties in the New Moon Overlook neighborhood ranging from 13 to 52 acres, and 22 properties in the Southern Crescent neighborhood of 3 to 9 acres (McMahon, 2010, 138). These luxury communities expand the project's market to wealthy individuals seeking larger, private properties and more space between homes (.23-.73 acres in Southern Crescent for instance). This project demonstrates that ranchettes may be offered in an environmentally-sensitive project if there are proportionately few of them and if they are clustered to limit disturbance.

Commonweal also had the difficult task of complying with Santa Fe County's requirement that $30 \%$ of project residences must be affordable to lower-income residents in four different income brackets ranging from those who earn the area median income to those who earn $50 \%$ of the area median income (Briefing Book, 2011). This is a challenge since land near open space has a higher value and so cannot be sold as cheaply to buyers. It is estimated that Commonweal Conservancy's affordable housing will cost between $\$ 122,000$ and $\$ 202,800$ (McMahon, 2010). According to the 2007-2011 American Community Survey (ACS), the median value of homes in Santa Fe County is $\$ 293,900$ and the mean, or average, income of Santa Fe County’s residents is $\$ 75,815$ (2007-2011). Thus, the average resident of Santa Fe County would be able to purchase, 
in installments, the affordable housing offered by Galisteo Basin Preserve. Even residents from the neighboring community of Galisteo which has a lower average income of $\$ 48,100$ (ACS, 2007-2011) would be able to afford the project's affordable housing.

\section{Mission and Goals of the Project}

Harrison and his staff used ecosystem needs and community character to create criteria for determining the most appropriate uses for the land (McMahon, 2010). If a conservancy expects its project design criteria to be adopted by a developer or municipality, the criteria must meet their minimum needs, be financially feasible and agree with their values. Design criteria are important because they untether project stakeholders from typical development concerns and direct their priorities toward other initiatives such as preserving Santa Fe County's desert landscape, protecting Native American landmarks and sustaining the renowned art community. According to McMahon (2010, 139), Galisteo Basin's project design goals are the following:

- "Love for the Galisteo Basin's precious scenic resources

- Deference to the Galisteo Basin's cultural history

- Stewardship of the region's animal, plant, soil, and water resources

- Respect for the complexity and creativity of social organizations"

This project's criteria are worded to specify that nature should be given priority over man-made landscapes. For instance, in describing landscape areas that reflect Galisteo Basin's cultural history, the word 'deference' is used which means "respect and esteem due a superior or an elder," indicating that landscapes should be allowed to shape project design (Merriam-Webster's Dictionary, 2013). A goal then puts this criterion into 
action establishing that "artists, educators, healthcare professionals, scientists, and community-service professionals" are knowledgeable and valuable project consultants that possess "unique knowledge, skills, and creativity" (Galisteo Briefing Book, 2011, 4). An example of how deference to the landscape and community preferences was applied in the project may be seen in the Village houses which reflect the "cultural, ethnic, and social diversity" of the community (Galisteo Briefing Book, 2011, 4). Thus, design criteria should clearly define priorities and give direction, but should also be general and depend on goals and objectives to make priorities actionable.

\section{Stakeholder Collaboration}

Conservancies may have greater negotiating power, though not necessarily shorter negotiations, in communities with which they have built familiarity and trust. Before beginning the Galisteo Basin Preserve project, Ted Harrison had demonstrated his reliability to the local community by acting as the Southwest Regional Director of the Trust for Public Land, for 15 years (T. Harrison, personal communication, May 5, 2012). According to Harrison, he was familiar with the priorities and needs of the eight upperclass, large-lot, residents of the small community adjacent to the project, enabling him to better understand issues as they arose in public meetings (personal communication, May 5, 2012). Three years were devoted to several phases of outreach to neighborhood associations within the adjacent rural bedroom community (T. Harrison, personal communication, May 5, 2012). This ongoing dialogue helped project designers adapt the project to the local character and held Commonweal accountable to its commitments.

Galisteo Basin Preserve's marketability and reputation benefitted from local organizations and community groups that were willing to associate their names with the 
project and attest to its quality. In addition, by coordinating with other nonprofit organizations and governments, Commonweal was able to pursue mutually-beneficial initiatives that would not have been accessible to it otherwise. For instance, when the Santa Fe Earth Works Institute partnered with Commonweal Conservancy, they qualified for a \$75,000 grant from the New Mexico Environmental Department to restore riparian land in the project (Harrison, Integrative Conservation, 2009). This funding was valuable to Commonweal since it would not have had the time to pursue the grant on its own.

The Galisteo Basin Preserve and Eagle Ranch projects exhibit very different approaches to public outreach. In the Eagle Ranch project, public outreach lasted longer than five years (beginning in 2008 and continuing into 2015) in order to address public complaints about density, traffic generation and visibility. This was the result of designs that were created based on too-general public input, project partners' priorities and indepth public input only in the face of a difficult issue. This approach cost Eagle Ranch the trust of some members of the public because community members were forced to act as their own advocates, scrutinize project designs and voice their objections to the city council. As can be learned from the Eagle Ranch project, public skepticism regarding the designer's proposals can result in longer, less-productive negotiations.

Conversely, Commonweal Conservancy proactively approached landowners so that disputes and concerns did not have to be debated before the city council. Trust was built through the conservancy's long-term demonstration of its approachability, familiarity with local culture and attentiveness to community needs. Harrison recommends making the development process "transparent and inclusive" to all (personal communication, May 5, 2012). Commonweal's fulfillment of commitments that it made 
during its three years of public meetings structured its strong relationship with the public (personal communication, May 5, 2010). These commitments included personally overseeing impact studies costing "hundreds of thousands of dollars" to ensure they addressed traffic, water availability, light pollution, project visibility, slope, and solar orientation (T. Harrison, personal communication, May 5, 2012; Briefing Book, 2011). In this way, the public was able to trust that designers would serve as their advocate. If a conservancy or designer not only allows the public meaningful involvement but also acts as an advocate for the community, these actions build trust and put the focus of project design on opportunities and mutual benefits rather than the threat of change.

In both the Galisteo Basin Preserve and the Eagle Ranch projects, design was tailored to the needs of the primarily client (McMahon, 2010). For Eagle Ranch, this was the City of Atascadero and the Smith family and for Commonweal, this was the existing community. According to Harrison of Commonweal Conservancy, "public values are the first filter that is applied when we first approach a project" (personal communication, May 5, 2012). It is important to choose a primary client that will be impacted by the project so that the project may serve specific needs. Since this project had fewer stakeholders, Commonweal chose the community, the project's primary user, as its client. Harrison states that it was challenging for Commonweal Conservancy to find a balance between the different goals of very diverse community groups (personal communication, May 5, 2012). Similar to the Eagle Ranch project, existing community members did not want new residents in the area, valued the seclusion of their homes and feared that the project would cause traffic and burden fire and police services ( $\mathrm{T}$. Harrison, personal communication, May 5, 2012; McMahon, 2010). However, unlike 
Eagle Ranch, criticism by the public peaked early and then waned due to community members' meaningful participation in project design which spared Commonweal from a long approval process and expensive design alterations. In fact, in one public meeting, only three residents criticized the project's impact report findings while 25 others spoke in support of the project (T. Harrison, personal communication, May 5, 2012). After three years of discussing the project's intent and design, listening to feedback and demonstrating potential benefits, the project was finally approved (McMahon, 2010). According to Harrison, at the 2007 master plan approval hearing before the County Board of Commissioners, 50 people attended and the plan was approved without a single objection (McMahon, 2010). I argue that, provided that the conservancy has sufficient resources, an extended negotiation process is preferable to an extended approval process which would entail defending against resident objections in front of the City Council and explaining why the project cannot mitigate certain impacts or meet certain needs.

Despite the community trust that Commonweal had fostered, developers did not have confidence in the conservancy due to its lack of experience with large development projects and limited development's questionable marketability (McMahon, 2010). Developers from outside of the county also declined involvement, saying that they were unfamiliar with the market in Santa Fe (T. Harrison, personal communication, May 5, 2012). Commonweal then had to decide whether to assume the heavy burden of development. Harrison states that it was a "somewhat terrifying threshold" (McMahon, 2010, 138). At stake was the conservancy's reputation for quality habitat protection. As the developer, the conservancy hired its own contractors, including archaeologists, "landscape architects, land planners, GIS professionals, engineers, architects, ecologists, 
and hydrologists," conducted the constraints analysis and took out a construction loan (McMahon, 2010, 138; T. Harrison, personal communication, May 5, 2012). Before beginning a project, a conservancy should ensure that local developers have experience with limited development.

Though the conservancy's inability to hire a developer required it to assume the burden of development, the end result was a strong working relationship between Commonweal and the community. If Commonweal had passed the project to a developer, it would have been, according to Ted Harrison, "a terrible violation of trust" (McMahon, 2010, 144). However, not all conservancies have the financial or technical resources to manage the development process, including permitting and hiring contractors, while continuing normal conservation duties. Hiring a developer need not be a betrayal of trust if the developer is willing to respect community needs and if the conservancy will continue acting as a community advocate.

Once Commonweal became the developer, it could freely make decisions and prioritize impact reduction when designing the project's lot configuration, roads and storm water management infrastructure (T. Harrison, personal communication, May 5, 2012). For instance designing homes to achieve a LEED Gold rating, incorporating solar photovoltaic and water heating, passive heating and cooling, rainwater collection, lowimpact development, electricity-efficient appliances, and reused lumber and materials (Galisteo website, Homes of the Preserve, 2014). The conservancy also decided that the design of the project's village would be influenced by the layout of traditional New Mexico towns and public input (Project Briefing Book, 2011). As a developer, the 
conservancy has the luxury of incorporating exactly the features that will carry out its community-approved vision.

\section{The Role of Amenities in Galisteo Basin Preserve}

In the Galisteo Basin Preserve project, the types of amenities, home prices, lot sizes and presence or absence of private or communal property structure the way in which the community is able to coalesce. If the project includes unique amenities and high-quality features that promote a particular lifestyle, demand for the project can stretch far outside the immediate region, widening the market. However, the inclusion of numerous, unusual project features and amenities, requires the project team to commit greater: time, finances, and faithfulness to the project's original intent.

The amenities and features of Galisteo Basin Preserve do adhere to the project's original intent because they seek to build connections between: neighborhoods, residents and the land, residents and one another, project design and cultural history and the landscape and development. The project's neighborhoods are connected by parks and walking paths that join fifty miles of hiking trails, interspersed with signs that explain natural processes and local history (Galisteo Project Briefing Book, 2011). A bus system and a train station are also planned to give residents access to other cities (2011).

In regard to connecting community members to the land, the Village portion was designed to create an "intimate, enlivening, deeply knowledgeable, and active stewardship community" (McMahon, 2010, 138). The planned elementary school and outdoor-oriented charter school will, according to Harrison, "anchor the community's sense of ownership and commitment to place" and may "supercharge the flow of the daytime population and enhance the viability of...commercial enterprises" (McMahon, 
2010, 139-140). An environmental education center was included for residents to learn about ecologically-beneficial practices to follow on their own properties (McMahon, 2010). A community stewardship organization, called "Friends of the Preserve," was also established to handle small management duties and coordinate community activities such as trail-building workshops, bird counts and landscape maintenance (Galisteo Basin website, 2013; McMahon, 2010). This stewardship organization includes county and municipal officials as members so that the project's land management might complement regional programs (McMahon, 2010). All of these amenities and programs seek to foster community investment in the open space and to allow the project to meet regional needs.

Galisteo Basin Preserve also emphasized connections in its marketing by completing the construction of 15 miles of trails before any other structures and then inviting buyers and community members to an open house to use the trails and experience the beautiful scenery (McMahon, 2010). Beyond encouraging property sales, this open house helped the project gain support among community members, which would be needed during the project's approval hearing. The project's man-made amenities were designed to highlight the beauty of the site's natural features to encourage the public's connection with the landscape. Amenities that connect the project to the landscape, community and larger region encourage its stability and relevance.

This project's amenities also support a variety of lifestyles ranging from rustic to luxurious for a variety of ages and incomes. To this end, the project includes: affordable housing, housing for elderly citizens, in-home business space and 25 to 35 cohousing units (McMahon, 2010). Cohousing units are located in neighborhoods that are designed and managed by their residents to focus on community-building and often contain 
communal areas or communally-accessible houses (Cohousing.org, 2013). The project will contain a community-run farm and orchard, greenhouses, a cattle pasture, community gardens and row crops (McMahon, 2010, 142). Harrison asserts that the farm will demonstrate the importance of "bringing our food sources closer and making their production more visible" (McMahon, 2010, 142). In addition, a 5-acre "green" cemetery will provide low-impact, headstone-free burial (McMahon, 2010). Finally, as previously mentioned, a charter high school will provide students with a hands-on, outdoor curriculum using the project's open space (McMahon, 2010). By including a wide variety of amenities, Commonweal sought to expand the project's market; however, it also ran the risk of appealing only to a small portion of the community. Commonweal dealt with this risk by introducing each amenity gradually as the demand arose.

Choosing which land uses and amenities to include is a challenge since some buyers may not want the peculiar mix of rural and luxury living offered by limited development. For instance, Bob Baldwin Jr., the director of Bundoran Farms, in Virginia, reflects on a failed sale in which a potential buyer, a business executive, expressed his distaste for allowing his neighbor's cattle to graze in his yard as part of a communal pasture (McMahon, 2010). Prospective buyers must be willing to play their small part in upholding the project's goals. While ranchers may more readily tolerate the use of their properties as a communal pasture, this may be too small of a market. Since the project's core philosophy was of communication and collaboration between neighbors rather than exclusion from private property, Baldwin would not negotiate and, unfortunately, lost the sale (McMahon, 2010). As Baldwin states, "It can be hard to stick by your principles when someone is ready to write a million-dollar check" (McMahon, 
2010, 129). Since limited development often has ideologies as its goals, such as conservation and community-building, stakeholders must ensure that these philosophies complement one another and are viewed as luxury features by the project's target market. According to Ted Harrison, “This isn’t about private open space, golf courses, or lavish amenity packages. It's about...being deeply-connected to the earth in a way that allows people to celebrate the pure and simple beauty of the place we call home" (McMahon, 2010, 142). Thus, some amenities are common to both Eagle Ranch and Galisteo Basin Preserve including clustered housing, affordable and elderly housing, green space, a village center, trails and a community stewardship center. Even if the inclusion of unusual project amenities and programs is deemed too risky or expensive, project partners should include the above-listed basic features because they appeal to a wide audience and help connect and reconcile a project's, otherwise, disparate parts.

\section{Project Finance}

As discussed in the Finance section, funding for the purchase of the entire Galisteo Basin Preserve and the composition of the site's master plan (McMahon, 2010) was derived both from the landowner's agreement to sell the property as a half-priced "bargain sale," as well as from the full-priced sale of subdivided properties to buyers that promise to place an easement on the land after its purchase (T. Harrison, personal communication, May 5, 2012). The project had to contain enough lots for their sale to offset the $\$ 19,833,000$ bargain sale price of the land (McMahon, 2010). As previously mentioned, in response to the decline of the housing market and resulting slow property sales, Commonweal sacrificed conservation land and repurposed it into undeveloped "ranch homestead" lots as the need for additional property sales arose (T. Harrison, 
personal communication, May 5, 2012). The sale of these homestead lots enabled Commonweal to repay its land purchase loan and construction costs (T. Harrison, personal communication, May 5, 2012). This approach may be conducted cheaply by the conservancy since the burden of development is on the buyer.

Other sources of funding for the project include a low income housing grant provided by the State Housing Authority and a $\$ 75,000$ grant to rehabilitate riparian land from the New Mexico Environmental Department (T. Harrison, personal communication, May 5, 2012; Harrison, 2009). Additionally, real estate transfer fees funded the longterm management of the education center and the community stewardship organization (McMahon, 2010). This project's transfer fees were implemented before the FHFA's 2011 rule that transfer fees may only be used to directly and exclusively benefit the donated property and its users (LTA, 2012). Commonweal's transfer fees may remain in effect since they were implemented before the FHFA's rule and since the education center and stewardship organization directly serve the residents of the project. See the Finance section of this report for an in-depth analysis of bargain sales, the sale of subdivided properties at full-price and the new rules governing transfer fees.

Despite initial slow property sales and a delay in the development of the project's Village due to the absence of grants and loans, as of 2012, the project has had greater sales success (T. Harrison, personal communication, May 5, 2012). The Galisteo Basin Preserve was developed in small phases to test whether the market would absorb the project and to lessen the impact of declining sales. The Tryon Farm limited development project in Indiana was also constructed in phases to avoid the large, upfront infrastructure costs (McMahon, 2010). Moving forward, Commonweal will conduct a market study to 
determine demand for the project and will watch how foreclosed properties sell to gauge banks' willingness to provide loans (T. Harrison, personal communication, May 5, 2012).

\section{Environmental Design}

The ecological goals for the preserved portion of the Galisteo Basin Preserve are to improve native wildlife and plant diversity and to preserve and protect archaeological and historic sites (Galisteo Preserve Vision, 2013). The Preserve's two main ecological goals for the developed portion are: to employ "regenerative land development" which focuses on healing the land and restoring damaged habitats, and second, to establish a “resource-efficient development plan" (McMahon, 2010, 134, 137). Commonweal Conservancy encourages regenerative land development by placing conservation easements on most properties, adapting their "covenants and restrictions" to suit each neighborhood's environmental conditions (Galisteo Preserve Vision, 2013). Easements provide the necessary level of control over individual properties since some may be located near to sensitive habitat and require specific mitigation measures.

Limited development projects require efficient resource management since both the ecological and the developed portions are unable to function as they would normally. Galisteo Basin Preserve achieved resource efficiency in several ways. First, materials already in the site were reused to construct new roads, thus lowering costs (McMahon, 2010). Second, due to the proximity of state highway 285 , Commonweal had to install a traffic light to slow traffic and lessen its impact, as negotiated with the New Mexico Department of Transportation (Master Plan, 2006). Third, all houses were positioned to utilize passive heating and cooling, wind protection and the use of solar panels (Galisteo Preserve Vision, 2013). According to Galisteo Basin's website, the project has achieved 
"net zero energy consumption" and is able to produce more electricity than it consumes by burning biomass (organic materials such as tree trimmings or livestock waste) (2013). The efficient use of the site's solar and wind resources entices new buyers with the promise of lower utility bills. Furthermore, it offsets the cost of environmental design by eliminating the need to install heating or cooling systems for each property.

Galisteo Basin Preserve provides a good example of efficient resource management because it strives to maintain a delicate balance between the urban and rural systems and between resource inputs and outputs. However, maintaining this balance does not necessarily eliminate negative impacts entirely. For example, while the project's grassland and community farm create organic waste which is then used to generate electricity, if the generator must consume more biomass than the available surplus, it can burn debris that would otherwise decay and replenish nutrients in the soil (Galisteo Basin website, 2013). In addition, Commonweal's “quick-rotation grazing program" was implemented to manage grass levels and reduce the risk of fire; however, conservationists argued it would disturb sensitive species (McMahon, 2010, 142). Commonweal reasoned that grazing created less impact than mowing or using herbicide and promised to introduce grazing slowly and in such a way that replicated the "history and ecology" of the site (McMahon, 2010, 142). While impacts to the site are often unavoidable, effective resource management clearly involves attempting to replicate the natural functioning of the systems, establishing the level of impact that is acceptable, introducing changes by small degrees, and correcting surpluses and deficits of resources.

Since a regional water system was not yet available when the project was being constructed, the project had to depend solely on well water and Commonweal had to 
demonstrate that the project would not deplete the underground aquifer (McMahon, 2010). Citizens also criticized constructing a community farm, fearing that it would use a large amount of water for irrigation (McMahon, 2010). The conservancy proposed designs that collect grey water for irrigation and discourage runoff, retaining water onsite to replenish the underground aquifer (Galisteo Preserve, Vision, 2013). The conservancy purchased ground water rights after well studies demonstrated that, with these design alterations, the water supply could support the project and that the project would use only .16 acre feet per year while the county average is .25 (Project Briefing Book, 2011). I argue that depending on well water was a risk in an arid region requiring expensive well studies and an analysis of past droughts. I advise that conservancies choose amenities that are compatible with fluctuations of the site's resources.

At all times, the conservancy must balance ecological need, project feasibility, marketability, public input, available finances and the impacts to the site resulting from these decisions. Not only is this balancing necessities difficult for a conservancy to do while still adhering to its mission, each task is extremely time-consuming and expensive because each requires negotiation, feasibility studies, public outreach, hiring a contractor, municipal approval and making necessary alterations to design. Commonweal's involvement in this project represents a very high degree of involvement in limited development, one that most conservancies do not have the resources to undertake. This case study demonstrates that to assume a high or even moderate degree of involvement in a project, the minutiae of each step must be addressed and coordinated with the project's mission to foster a lifestyle for residents that celebrates the local landscape. 


\section{Chapter 11: Conclusions}

As illustrated by this report's numerous approaches to limited development, the most appropriate approach and level of involvement is dependent upon stakeholder and project needs. This report argues that a conservancy must first decide whether limited development clashes with its conservation goals and Strategic Plan. If limited development is deemed an acceptable approach to conservation, the conservancy should decide the appropriate level of involvement based on its experience, finances and conservation initiatives such as water quality preservation. Overall, the conservancy must be flexible and willing to assume any role necessary to support limited development and these conservation initiatives. Furthermore, this report argues that success in these projects is dependent upon stakeholder actions that increase project feasibility and assemble necessary resources. These actions include: establishing connections and trust between stakeholders (New England EFC, 2003), using resourcefulness in land acquisition, employing green design, using finances strategically, and initiating early dialogue with the community. Additionally, no limited development strategy should be adopted without altering it to match the local market, regulations, political climate and ecology (McMahon, 2010). Although one jurisdiction's exact approach will not apply to another jurisdiction, designers may wish to emulate the mission or goals of an exemplary project, devising their own process to achieve those results.

Thus, a project's success should be evaluated based upon how well it fulfills its own mission and goals rather than how it performs in comparison to another project. For instance, the Eagle Ranch project was not initiated by a conservancy, like a typical limited development project, but by the policies of the City of Atascadero's General Plan, 
the landowners' wishes and RRM Design's willingness to pursue a conservation project. As a result, these stakeholders' needs were prioritized and the public was not involved until after the drafting of initial project designs. By contrast, in the Galisteo Basin Preserve project, since Commonweal Conservancy acted as its own developer, the conservancy chose the public as its client and allowed the land's ecology and the community's needs to drive the project's design. Both projects had difficulties and successes and each achieved its, very different, priorities. Thus, different approaches to limited development are necessary and unique challenges will occur in relation to a conservancy's chosen approach.

This is not to say that it is impossible to define general best practices for limited development. For instance, this report argues that after joining a project, conservancies must be willing to make decisions as part of a team and use the project's ecological design to accomplish, not only conservation, but the needs of multiple groups. Conservancies should act as an advocate for the site's ecology, but should also have an understanding of the development process and be willing to let the project's funding, feasibility, marketability and timeline take priority over conservation when necessary. Conservancies must decide the degree to which they are willing to accommodate nonecological needs such as financial feasibility or public preferences. This report argues that the project's primary users should meaningfully contribute to prioritizing these needs. There is, however, some risk in involving numerous stakeholders since the project's goals can proliferate and its focus can be lost. The Eagle Ranch and Galisteo Basin projects remained focused on core objectives despite revisions because their missions and goals were formulated early in the process. Thus, if project designers 
adhere to goals, preferably created by the project's future users, the project's direction is less likely to be altered by the cacophony of stakeholder input that will occur later on.

This project illustrates the wide variety of roles that a conservancy can assume in limited development including: project initiator, property purchaser, designer or, of course, conservancy. These roles range from a minimal to a high degree of project involvement. Milder's four limited development models ("Buy, Restrict Sell," "Work with a Landowner," "Partner with a Developer," and "Conservation Investors") require the conservancy to form a formal partnership with a stakeholder and assume a higher level of involvement (2006); however, the conservancy may also play a less-involved, yet proactive role in the development process without forming a partnership. Roles that require minimal involvement include: advocating for the incorporation of limited development into municipal General Plans, raising awareness among developers and landowners, coordinating public participation, acting as a consultant, acting as a mediator, advocating for a particular stakeholder or acting strictly as a conservancy. Consequently, conservancies that pursue limited development must be flexible and willing to fill either passive or proactive roles to accomplish conservation initiatives.

It may be difficult for a conservancy to take an active role in local development since this requires development experience, financial investment, public and professional trust and compliance with complex municipal requirements. Ted Harrison states that an effective limited development project inspires professionals within the industry to trust and adopt limited development (McMahon, 2010, 144). This report demonstrates that the best way for a land conservancy to participate in the development process is by tailoring a project's goals and quality standards to serve local needs. This project supports the 
recommendation of the Land Trust Alliance (LTA, 2004, 11) and Perlman and Milder (2005) that, at minimum, land trusts should identify critical conservation values in the site and compose the conservation agreement to protect these resources. In Milder's "Partner with a Developer" strategy, developers may hire a conservancy to help them satisfy municipal development requirements or tailor their project to the land's ecology and raise the land's value (McMahon, 2010). A developer may also ask a conservancy to publicly support a project before a city council. The conservancy should ensure that any project it agrees to support meets its environmental quality criteria, especially if the conservancy did not design the project. This report agrees that once conservancies have gained the necessary experience with limited development, they should assume an advisory role since this easily complements a conservation mission.

This project has also illustrated that, while the conservation and limited development approach is largely successful at preserving land while meeting stakeholder needs, it does have some characteristics that weaken its effectiveness. It is important to address Wartman-Wunder's critique that the projects that most successfully preserve habitat quality are, very often, well-funded, large projects occupying thousands of acres (2012). In fact, all but three of the projects mentioned in this report are larger than 1,000 acres, the largest being Santa Lucia Conservancy which is 20,000 acres. A question for further research is: since few projects have this much land available, can smaller limited development projects accomplish the same objectives as larger projects without degrading overall project quality? This report agrees that it may be challenging for designers of small projects to prevent development from impacting small swaths of conservation land, especially since sensitive animal species often require large ranges. 
However, this report argues that if strict conservation is not the only goal, preserved open space may be used for public recreation and, according to Sauvajot et. al. (1998), habitat for species that can tolerate disturbance. Small conservation projects can serve a variety of ecological and community uses successfully.

Three key principles, offered by Jeffrey Milder, that define success in a limited development project are the following: preservation of "key conservation values" in the site, provision of a sufficient profit margin to the conservancy, developer and investors and, finally, consideration of the local community's needs and character (2006, 14-15). These principles should serve as a conservancy's objectives; however, this report argues that Milder inadvertently illustrates a tension between these objectives when he contradicts himself in defining the appropriate use of limited development. Milder at first states that limited development need not only be used as a "last resort" since it provides landowners with "financially attractive" conservation opportunities and enables conservancies to "target high-priority lands" $(2006,14)$. However, later in his paper, Milder states that limited development projects "are beneficial only when the resource is under foreseeable threat of development" (2006, 14-15). In fact, Milder warns that if limited development is used in lieu of full preservation, it "may serve only to introduce negative impacts" (2006, 14-15). This tension between Milder's key indicators of project success means that the accomplishment of one often detracts from the quality of the others, making it very difficult for the conservancy to support all three. This report argues that rather than balancing the project's necessary components, the project's primary users must prioritize the components, accomplishing some to a greater degree and some to a lesser degree. 
This report draws upon the recommendations, case studies and analyses offered by many leading authors and experts in order to form a basic picture of the entire process. It argues that the individual components of limited development may best be understood when viewed as a whole. This report shares many of the views of limited development professionals including Milder's (2006) models of limited development, Arendt's (1998) conservation design principles and McMahon's (2010) confidence in the potential for harmony between development and conservation land. However, this report adds to these analyses its own interpretation of limited development.

This report provides a particular interpretation of the conservation and limited development approach. Despite the risks of pursuing limited development, this report asserts that these projects are worth the risk since they allow a conservancy to deviate from normal conservation procedures, pursue a formerly-unobtainable ecological objective by removing barriers and force parties to meet and negotiate the project's ecological priorities. This professional project recommends using limited development when a stakeholder has a specific, concrete vision for an available property that would be difficult to accomplish without additional expertise, funding or maintenance. If a project is not governed by a vision and goals, it can easily become directionless. This report interprets limited development as a participant-structured process that can help stakeholders realize a local vision for the land. It is a collaboration in which the land's ecological health may be prioritized due to comprehensive support from project partners. Limited development is also a conservation initiative that expands a land conservancy's ability to conserve using the profits derived from development. This report envisions the ideal limited development process as one in which: a specific goal is pursued, 
conservation is prioritized, affected stakeholders define remaining project priorities and project partners collaborate to increase the project's stability.

The intent of this report has been to provide interested conservancies, including the Land Conservancy of San Luis Obispo County, with an illustration of the components of limited development, how these fit together and the amount of involvement required to pursue a role in this worthwhile conservation strategy. In order to begin to define specific roles for itself, the Land Conservancy of San Luis Obispo County could, for example, state in its Strategic Plan that it will pursue a specific role in the Bob Jones Bike trail construction project. Such a development project is small and environmentallyfocused, yet it also requires balancing a budget, seeking funding sources, conducting an environmental impact report, composing an environmental site plan and working with municipal and county planners. The Conservancy need not assume a managerial role unless this is the level of involvement it wishes to pursue in future limited development projects. It would be wise for the Conservancy to establish a relationship with a local developer that is open to working collaboratively on limited development projects.

While there is already an abundance of open space in San Luis Obispo County, there are many other reasons the Land Conservancy may want to use limited development. First, limited development may be used to purchase key properties that connect existing conservation land. Second, since the people of San Luis Obispo County are very protective of the scenic views of surrounding hills, limited development can provide the necessary public engagement and flexibility to diffuse tensions. Third, the Conservancy can use limited development to mitigate land purchase costs since properties in San Luis Obispo County are expensive. Fourth, the Conservancy may 
continue to maintain its existing land holdings while using limited development to establish new open space supported by residents' homeowners' association fees. Finally, San Luis Obispo County is an advantageous location for limited development. According to Ted Harrison, "the only way that a landowner would want to pay a premium for land in exchange for conservation" is if the location possessed "a wealthy class, a beautiful landscape, people who are already in place on the land, scenic conservation values, (and) good climate" (personal communication, May 5, 2012, parentheses mine). This report proposes that limited development is likely to be marketable in San Luis Obispo County due to the land's beautiful scenery, mild climate and reputation as a tourist destination. Thus, limited development offers San Luis Obispo County a promising land preservation approach as well as a proactive and financiallyefficient land acquisition and maintenance strategy. If successful in these ventures, the Conservancy can develop the expertise to initiate and lead limited development projects of its own. The Land Conservancy of San Luis Obispo County may then begin to determine the role that conservation and limited development may play in its community to encourage high-quality, targeted and locally-oriented land conservation. 


\section{References}

U.S. Department of Agriculture. Agricultural soil survey: San Luis Obispo County (u.d.). Retrieved from http://www.hughpitts.com/properties/Adelaida\%20Rd\%208225\%20Hayley/Web Webs\%20Maps/AdelaidaSoilsSurvey.pdf

American Community Survey. Santa Fe Selected housing Characteristics 2007-2011. Santa Fe County Selected Home Value 2007-2011 American Community Survey 5-Year Estimates. Galisteo Selected Home Value 2007-2011 American Community Survey 5-Year Estimates. American Fact Finder. Retrieved from http://factfinder2.census.gov

Appelbaum, J., Brown, E., Forsyth, S., Kashiwase, \& Murray, D. (2010). Development of conceptual models and ecological baselines to support the creation of an adaptive management plan for Tejon Ranch, California. Bren School of Environmental Science and Management. University of California Santa Barbara. Retrieved from http://www.bren.ucsb.edu/research/documents/TEJON_FinalReport.pdf

Arendt, R.G., Brabec, E.A., Dodson, H.L., Reid, C., Yaro, R.D. (1994). Rural by design. Lincoln Institute of Land Policy, Environmental Law Foundation, Center for Rural Massachusetts. American Planning Association Planners Press, Chicago, Illinois.

Arendt, R.G. (1996). Conservation design for subdivisions. Washington, DC: Island Press.

Burger, J.C. (n.d.). An efficient monitoring framework and methodologies for adaptively managing human access on NCCP lands and other reserves in Southern California. Irvine Ranch Conservancy. California Department of Fish and Wildlife. Retrieved from https://nrm.dfg.ca.gov/FileHandler.ashx?DocumentID=46787\&inline=1

California Air Resources Board. (2014). CoolCalifornia.org Next 10. Renewable and Appropriate Energy Laboratory. Retrieved from http://www.coolcalifornia.org/funding-wizard\#wizard

California Council of Land Trusts. Conservation easement provisions in the Pension Protection Act of 2006. (2013). in Research and Information. Retrieved from http://www.calandtrusts.org/download.cfm? ID=15933

California Department of Fish and Wildlife. (2013). Natural community conservation planning (NCCP): Grants for NCCPs and HCPs. Retrieved from http://www.dfg.ca.gov/habcon/nccp/grants.html 
Cal Fire, San Luis Obispo County Fire Department. (2011). Standard 4 access roads and driveways. Retrieved from

http://calfireslo.org/Documents/Prevention/Standards\&Exhibits/2011\%20Standar d\%204-\%20Access\%20Roads\%20\&\%20Driveways.pdf

The City of Atascadero. Eagle Ranch joint city council and planning commission meeting summary. (2013). Retrieved from

http://www.atascadero.org/index.php?option=com_content\&view=category \&id=1 $37 \&$ Itemid $=1161$

Cohousing.org. What is cohousing? (2013). Retrieved from http://www.cohousing.org/what_is_cohousing

Commonweal Conservancy. Who we are. (2012). Retrieved from http://www.commonwealconservancy.org/whoweare.php

Community Development Financial Institutions Fund. (2011). Treasury announces $\$ 3.5$ billion in awards for economic development and community revitalization. United States Department of the Treasury. Retrieved from http://www.cdfifund.gov/news_events/Treasury-Announces-3.5-Billion-inAwards-For-Economic-Development-and-Community-Revitalization.asp

County of San Luis Obispo, Department of Planning and Building. (2014). Permit View. Map Data OpenStreetMap contributors. CC-By-SA. Retrieved from: http://www.sloplanning.org/PermitView/MapSearch

Dechant, J.A., Sondreal, M.L., Johnson, D.H., Igl, L.D., Goldade, C.M., Nenneman, M.P., and Euliss, B.R. (2003). Effects of management practices on grassland birds: Northern Harrier. Northern Prairie Wildlife Research Center Online. Northern Prairie Wildlife Research Center, Jamestown, ND. Retrieved from http://www.npwrc.usgs.gov/resource/literatr/grasbird/noha/noha.htm

Doscher, P. and Masland, T.N. Esq. (2011). Conservation stewardship transfer fees. Society for the Protection of New Hampshire Forests. Retrieved from http://clca.forestsociety.org/pdf/conservation-stewardship-transfer-fees.pdf

Eagle Ranch Meeting 1 Response Report, 2008. Pp. 1-18. Retrieved from http://theeagleranch.com/pdfs/CPSMeetingResponseReport.pdf

Eagle Ranch Specific Plan EIR RFQ. (2010). October 8. Atascadero Community Development Department. Retrieved from http://www.atascadero.org/files/CD/Eagle\%20Ranch\%20RFQ.revised\%2010.11.1 0.pd

Eagle Ranch Specific Plan (2010). August 10. Atascadero City Council Staff Report. Community Development Department. Retrieved from 
http://www.atascadero.org/index.php?option=com_wrapper\&view=wrapper\&Ite $\operatorname{mid}=1634$

Forever Forests, LLC. (2010). Benefits of a conservation easement. Retrieved from http://foreverforests.net/conservation-benefits/

Franklin Land Trust. (2012). Retrieved from http://www.franklinlandtrust.org.

Commonweal Conservancy. (2011). Galisteo Basin Preserve Project Briefing Book. http://www.galisteobasinpreserve.com/pdf/Briefing\%20Book\%202011.pdf

Galisteo Basin Preserve. Lot Pricing and Availability for Conservation Ranches and East Preserve. (2013). Retrieved from http://www.galisteobasinpreserve.com/properties/ranches_lotpricing.php

Galisteo Basin Preserve. (2013). Vision. Retrieved from http://www.galisteobasinpreserve.com/vision/conservationdev.php

Gregory, R. and Keeney R. L. (1994). Creating policy alternatives using stakeholder values. Management Science. 40 (8). 1034-1048. Retrieved from http://www.jstor.org/stable/2633092

Harrison, T.O. (2009). Integrative conservation: Steps toward a practice of stewardshipbased community development. 1-17. Retrieved from http://www.galisteobasinpreserve.com/pdf/Integrative_Conservation_Harrison.pd $\mathrm{f}$

Heesh, R. (2012). Questions about Eagle Ranch remain unanswered. Opinion piece. Cal Coastal News. March 29. Retrieved from http://calcoastnews.com/2012/03/questions-about-eagle-ranch-remainunanswered/

Hoffman, M. (2012). Bargain sales. National Publication. Planned Giving Design Center. Accessed 2014. Retrieved from http://www.pgdc.com/pgdc/bargain-sales

The Land Conservancy of San Luis Obispo County 2013-2018 Strategic Plan. (2013). Retrieved from http://www.lcslo.org/wp-content/uploads/2013/11/2013-18Strategic-Plan_web-low-res.pdf

The Land Trust Alliance. (2004). Land trust standards and practices. Retrieved from http://www.landtrustalliance.org/training/sp/lt-standards-practices07.pdf

The Land Trust Alliance. (2012). Prohibition on Fannie and Freddie lending on property with transfer fees. April 18. Retrieved from https://www.landtrustalliance.org/conservation/conservation- 
defense/conservation-defense-news/prohibition-on-fannie-and-freddie-lendingon-property-with-transfer-fees

The Land Trust Alliance. (2013). Conservation donation rules. Retrieved from http://www.landtrustalliance.org/policy/tax-matters/rules/conservation-donationrules

The Land Trust Alliance. (2013). State and local tax incentives. Retrieved from http://www.landtrustalliance.org/policy/tax-matters/campaigns/state-taxincentives

McMahon, E.T., (2010). Conservation communities: Creating value with nature, open space, and agriculture. Washington, DC: Urban Land Institute.

Meadows, D. (2008). Thinking in systems: A primer. Vermont: Chelsea Green Publishing Company.

Merriam-Webster's Dictionary. (2013). Deference. Retrieved from http://www.merriamwebster.com/dictionary/deference

Milder, J.C. (2006). Using limited development to conserve land and natural resources. Exchange. Land Trust Alliance. Spring ed. (14-19).

Miles, M.E., Berens, G.L., Eppli, M.J., Weiss, M.A. (2007). Real estate development principles and process, fourth edition. Urban Land Institute, Washington D.C.

Myatt, M. (2012). Consensus-team building's silent killer. Forbes. April 19. Retrieved from http://www.forbes.com/sites/mikemyatt/2012/04/19/consensus-teambuildings-silent-killer/

New England Environmental Finance Center. (2003). Trust, collaboration and financial return in conservation/development partnerships. December. Edmund S. Muskie School of Public Service. Retrieved from http://efc.muskie.usm.maine.edu/pages/pubs_trust_and_risk.htm

Noss, R. F., O’Connell, M.A., Murphy, D. D (1997). The Science of conservation planning: Habitat conservation under the endangered species act. World Wildlife Fund. Washington, DC: Island Press.

Parker, D.P. (2002). Cost-effective strategies for preserving private land: An economic analysis for land trusts and policy makers. October. Retrieved from http://www.perc.org/pdf/land_trusts_02.pdf

Pennsylvania Land Trust Association. (2012). Legal considerations for stewardship funding arrangements. Conservation Tools.org. <http://s3.amazonaws.com/conservationtools/s3_files/1305/CT_SFA- 
Legal_120814.pdf?AWSAccessKeyId=1NXAG53SXSSG82H0V902\&Expires=1 368221136\&Signature $=9 \mathrm{fKlt} 4 \mathrm{~K} 033 \mathrm{nX} \% 2 \mathrm{FPPOUBUKjNWi810} \% 3 \mathrm{D}>$.

Perlman, D.L., \& Milder, J.C. (2005). Practical ecology for planners, developers, and citizens. Lincoln Institute of Land Policy. Washington: Island Press.

Sauvajot, R.M., Buechner, M., Kamradt, D.A., Schonewald, C.M. (Dec. 1998). Urban Ecosystems. Vol. 2.4: 279-297.

Rockwell Institute. (2012). Secondary markets won't allow private transfer fees. Retrieved from http://realestateschoolwire.com/post/3068749/secondary-marketswon-t-allow-private-transfer-fees

San Luis Bay Area Plan. (2009). Land Use and Circulation Elements of the San Luis Obispo County General Plan. Retrieved from http://www.slocounty.ca.gov/Assets/PL/Area+Plans/San+Luis+Bay+Coastal+Are a+PlaP.pdf

Sanoff, H. (2000). Community participation methods in design and planning. New York: John Wiley \& Sons, Inc.

Sanoff, H. (2010). Multiple views of participatory design. Focus. Vol. VII. (11-21). Retrieved from http://digitalcommons.calpoly.edu/cgi/viewcontent.cgi article $=1182 \&$ context $=$ foc us

Santa Lucia Land Conservancy.org (2012). Retrieved from http://www.slconservancy.org

Sbranti, J.N. (2013). Merced County is sinking; researchers blame over-pumping of groundwater. The Modesto Bee. November 21. Retrieved from http://www.modbee.com/2013/11/21/3044724/merced-county-is-sinkingresearchers.html

Scenic Hudson. (2012). Our work in Beacon. Retrieved from http://www.scenichudson.org/whatwedo/backyardcampaigns/beacon

Shandon Community Plan. (2012). Land Use and Circulation Elements of the San Luis Obispo County General Plan. Retrieved from http://www.slocounty.ca.gov/planning/General_Plan_Ordinances_and_Elements /Plans_in_Process_and_Draft_Plans/Shandon_Community_Plan_Information/sha ndon.htm

SLO Data Finder. (2010). Robert E. Kennedy Library. http://lib.calpoly.edu/gis/ 
Small, S.J. Esq. (2006). Test your knowledge of conservation purposes. The Private Landowner Network Article Library. Retrieved from http://www.privatelandownernetwork.org/library/article.aspx?id=180

Sullivan, N.; Rosenberg, S. (2005). Chapter 6: Employing limited development strategies to finance land conservation and community-based development projects. From Walden to Wall Street: Frontiers of conservation finance. J.N. Levitt (Ed.). Lincoln Institute of Land Policy. Washington: Island Press.

Tennyson, P. (2012). Key steps to effective public outreach. American Water Works Association. Retrieved from http://www.katzandassociates.com/2012/04/126/

Wortman-Wunder, E. (2012). Do subdivisions designed for conservation actually help wildlife? High Country News. Retrieved from https://www.hcn.org/issues/44.9/do-subdivisions-designed-for-conservationactually-help-wildlife/article_view?b_start:int $=0$

Young, H. (2011). Eagle Ranch gets public input. Atascadero News. Nov. 17. Retrieved from http://www.atascaderonews.com/v2_news_articles.php?heading=0\&page=72\&sto ry_id=4447 


\section{Appendix A Interview Transcript: Victor Montgomery, RRM Design}

To compose the case study for the Eagle Ranch limited development project, Victor Montgomery, a principle designer on the project and the former president and CEO of RRM Design, granted me an-in person interview at his office in San Luis Obispo, CA. The interview was conducted on Tuesday May 22, 2012.

1. Catherine: Your website stated that you were working closely with city biologists to mitigate the project's EIR findings. Is this still occurring? How does this communication best occur so that costly redesign of the project can be avoided?

Victor Montgomery: The existing county EIR review process is inefficient because an EIR document costs on average $\$ 1$ million. Every addition or change to the project results in a redraft of a portion of the EIR as well as the costly studies to support it. In addition, each change to the EIR potentially results in the creation of new impacts.

RRM instead wants to hire the EIR consultants at the front end. So the city hires their own EIR consultants and they pay to conduct the constraints analysis and other studies such as geological survey or archaeological survey which is a huge issue in SLO County. Eagle Ranch, the city and the county enthusiastically agreed that this was much more efficient. So the city's biologists surveyed in the field for 2 months and recorded their findings. However, when RRM's own consultants conducted work they discovered different findings. They are still constructing the constraints analysis and so they are having conversations with city biologists. They will eventually use this data to design the project. 
2. Catherine: Are there any mitigation measures that need to be implemented to protect agricultural land from the proposed development?

Victor Montgomery: The Smith Family, the owners, want to continue grazing part of the land. 3,400 acres will be annexed and of those, 1,000 will be suitable for grazing. There is a small amount of class 1 agricultural land on the ranch-soils are high-quality. But the constraints analysis has found that development will not cause it a significant impact.

3. Catherine: What will be your approach in addressing criticisms of the project by neighbors in regard to the project's size, visibility and traffic generation? What will be your approach to addressing criticisms of the project by the Atascadero City Council in regard to the city's responsibility for providing fire and police coverage?

Victor Montgomery: RRM Design has conducted individual neighborhood meetings. Traffic is a huge issue and so this is why they decided to speak to individual neighborhoods. Each neighborhood wants to push traffic density toward a different neighborhood.

Another main issue is that there is flat ground that is prime area for development that is within view of several two-acre lots.

We also conduct public workshops with the city council, the design review committee and planning commission and joint planning commission and city council 
workshops. All of these are open community workshops and not charrettes since allowing the community to design these would be infeasible in a project such as this.

4. Catherine: In collaborating with project stakeholders how often did you meet? Did meetings involve brainstorming or simply reporting on progress?

Victor Montgomery: RRM has a regularly scheduled monthly meeting with the city of Atascadero. They also have a weekly project team meeting which the Smith family takes part in. In fact, RRM is in contact with the Smith family, our client, even more frequently. About four times per week I communicate with them.

5. Catherine: Who had final authority over the project?

Victor Montgomery: The total Eagle Ranch property is 6,500 acres. 3,400 acres will be annexed to the city. 3,100 acres will remain in the county with an easement donated by the Smith family to the Land Conservancy of San Luis Obispo County. The two projects are totally separate and this is how the Smith family can receive tax incentives for their donation of the easement. Between the Smith family and the Land Conservancy, a Right to Negotiate has been signed. This says that the Conservancy of SLO County has the exclusive right to obtain the easement from the Smith family for the 3,100 acres of land. The 1000 acres that is in the city's jurisdiction is still owned by the Smith family.

6. Catherine: How were disagreements handled? 
Victor Montgomery: There haven't been any disagreements between RRM and their client, the Smith family. There have been disagreements between the City of Atascadero and RRM/the Smith family. The city wants the project to make improvements that RRM doesn't want to make. Disagreements go to the city council which then decides the issue. The City Council is the final authority over the developed portion of the project since the Specific plan that RRM has to create for the project which is the final planning document, belongs to the City.

7. Catherine: Based on articles in the news, project option E, which limits the development to 700 homes with larger lots facing existing houses, sounds like it is most supported by residents. What will be the challenges in enabling this option to be financially feasible?

Victor Montgomery: Option E is the solution to lot size problems for just one single neighborhood: the San Rafael neighborhood. The current entire project has 650 lots and 50 multifamily lots. Option E makes it a more difficult project since they are losing the total number of houses, the sale of which makes the project financially feasible. If residents want parks and other amenities, then they need higher density lots. In addition, locating development on hilly, sloping ground causes more impacts but obscures the development from the view of neighbors [V. Montgomery, personal communication, 2012].

\section{End of Interview}




\section{Appendix B Interview Transcript: Ted Harrison, Commonweal Conservancy}

To compose the case study for the Galisteo Basin Preserve limited development project, Ted Harrison, the President and founder of Commonweal Conservancy in Santa Fe, New Mexico, granted me a phone interview. Mr. Harrison was kind enough to answer my questions regarding the Conservancy's role and approach to initiating and leading a limited development project. The half-hour phone interview was conducted on Tuesday May 5, 2012.

1. Catherine: How has your conservancy managed to balance public outreach and community design with stewardship and existing responsibilities?

Ted Harrison: "The Trust for Public Land had been involved primarily. We had been asked by [Santa Fe] County to steward 1,400 acres of a total 15,000- acre ranch. To begin the project, the Trust would have to enter into negotiation with the family that owned the 15,000-acre ranch, who was currently working with the county. The county asked whether the Trust for Public Land would be interested in limited development. This project incubated Commonweal Conservancy.

However, the Trust for Public Land was dealing with the recession, and they thought it would be confusing for their donors if they became involved in a limited development project. In addition, this kind of project would require a, special skill set that the organization didn't have then. And so, a small group of us spun off into Commonweal Conservancy to handle the county's acquisition. I was familiar with the 
people and proposed a plan because of [the site's] proximity to existing utilities and services like water and sewer and school service areas.

In designing the project, Commonweal Conservancy conducted outreach to neighborhood associations. There was concern for any kind of change. The area was, geographically, a plateau that had developed into a small bedroom community. Typical large-lot development came to the edge of the plateau and was owned by wealthy residents. Eight large landowners controlled 100, 000 acres. And so, Commonweal Conservancy described an alternative approach. We designed a proposal that depicted how just one of the properties might be preserved. It showed, among other design features, how wildlife corridors might be incorporated. The question was: Would they be accepting of this large development?

2. Catherine: During the project's three years of public dialogue, what was your method of communication with other stakeholders? How often did you meet? Did meetings involve brainstorming or simply reporting on progress? Were they receptive to community input?

Ted Harrison: Many discussions commenced. The first two years were spent in meetings with community groups, answering questions and incorporating community members' input. This was an iterative approach to their community engagement. I had been in the community for 15 years, and had earned credibility and trust from community members. In meetings, they discussed what they will put as their priorities-they wanted a balance. For Commonweal, public values are the first filter that they apply when they 
first approach a project. Amenities to be included in the Village development included: Affordable housing which would provide a new resource for people, commercial space and gallery, and a public school. The project would concentrate development in 300 acres of the larger 13, 000 acres.

3. Catherine: How were disagreements handled? Have there been problems that have resulted from the location of development near open space areas and what actions have you taken?

Ted Harrison: There was a small handful that didn't want outsiders coming in. NIMBY-["Not in my backyard"] spirited outsiders viewed the land as their hidden home. The project would cause some impact including night sky pollution, water use, and traffic problems. It would impact the nearby river and water wells. Commonweal Conservancy had to spend many hundreds of thousands of dollars to study wells, conduct traffic studies, and conduct view shed studies to insure that these resources were not harmed by the project as it was built. We did this independently from the City or County biologists. Culturally, we thought it was important to be visible in the community.

4. Catherine: Who had final authority over the project?

Ted Harrison: We are the developer in this. We brought in a team of architects, planners, engineers, archaeologists and, hydrologists. We had originally intended to bring developers on board after conducting the public outreach. We conducted outreach 
with [specific] developers; however, they said they didn't know the Santa Fe market and so couldn't accept the position.

5. Catherine: How was the project financed?

Ted Harrison: We had financing from the State Housing Authority. We went through the whole master plan approval process. Three years of documentation. At the end of the process, there was no public opposition. We won master plan approval. We planned the preliminary plat and laid out the lots, roads and storm water [infrastructure] that would be part of the construction. The development was 37,000 square feet. When designing the plat, three people showed up that didn't believe the hydrologists, but 25 people spoke in favor of it.

6. Catherine: Your article states that the Commonweal Conservancy's vision of the developed community includes public participation in "plant and animal species inventories, grassland and riparian restoration initiatives, cultural resource conservation programs, energy and water modeling and monitoring, way finding, animal husbandry, trail maintenance, and interpretive education." Has this vision taken shape and what are the most successful aspects? How are you evaluating the success of these? (Harrison, 2009, 11).

Ted Harrison: Since 2010, we haven't brought the village forward due to the recession. The project contains a lot of green building and design and, right now, there is so little 
financing and capacity for home buying in this market. Santa Fe has suffered. We are watching how the bank-owned properties that were foreclosed upon sell. The short sale of these homes serves as an indicator of how favorable the market is in Santa Fe for new development. It is easier and cheaper to buy existing foreclosed homes. We are looking to complete the final plat in the next 15 months. We get lots of emails indicating enthusiasm, but we need a larger market study that shows capacity. We want banks to be more secure in their lending capacity before we proceed with the development of the project.

7. Catherine: In this difficult economy, what have you found to be successful methods of project financing?

Ted Harrison: In this tough economic climate, we are surviving from the sale of larger parcels-the conservation ranches on the west side of project. This was going to be part of the public open space. We are marketing homes on larger lots to buyers so that the land would be preserved but sold, unencumbered, to these land owners at full market value. This arrangement is strategic, but risky for the conservancy because we only agree to the sale if the potential buyer makes an informal promise to overlay it with an easement after purchase so that it can be preserved. The informal agreement is necessary since a formal agreement to preserve it would cost the landowners their charitable donation tax deduction. The conservancy has to make sure that folks interested in purchasing any of their project offerings are deeply committed to conservation. In this way, Commonweal Conservancy can make money from its land holdings while, through some risk, putting 
the land in the hands of individual landowners who agree to put an easement on it soon after its sale.

8. Catherine: Were any of the partners able to receive federal property tax exemptions or tax credits as incentives to encumbering the land? Or have you found that most are out of reach for limited development projects?

Ted Harrison: We can't document it [the placement of an easement] formally, because then the donor intent is lost. There is an uncertainty. We have to trust them that they will advance the mission of the larger project. Every land owner has followed through so far. But the Conservancy may be fooled. If there is a requirement that is contractual in the sale that that they have to put an easement on the property, it legally defeats the donative intent. It is not freely giving and thus does not merit a tax deduction because you're just performing to what you agreed to. As long as there is a risk that it the easement won't be made, that period of risk is the donative intent. This is too much for some land trusts and is not an approach that works in all cases.

A bargain sale: The 1,300 acres of land that the Conservancy bought from a longtime landowner is being sold in small phases to landowners that will, hopefully, put an easement on it. To make a profit, Commonweal Conservancy is buying land at $50 \%$ of its fair market value from sentimental landowners who have owned the property for 70 years and who want to see it conserved. However, when the conservancy sells the property, we do not put an easement on it and so it is priced it at its fair market value. This is accomplished without risking private inurement. The family that had owned the 
land was able to benefit from the tax savings since they sold their land to the conservancy at $50 \%$ of its normal price. They receive a tax write off for the charitable donation of half of the price of the property.

This method of conservation does require a mix of players. You need a seller that is willing to make a significant concession and one that is conscious of their role in the larger community to advance the protective objective of the community. The land trust can take a discount on the lots it sells such that it makes a profit just over the acquisition costs.

Most people underestimate the expense. It can take longer to sell lots. If the market goes away, we could be stuck with the land and with development costs. However this is a worse problem if the land has an easement on it, since land sales are discounted as a result of conservation easements. The net between your purchase cost and your sales revenue, helps fund the maintenance of the site and offsets the cost of the land.

It's a high-touch endeavor. [It is] accessible, transparent, and inclusive, to both the folks worried about our work, as well as those in favor of the project. It is important to know what their concerns are, be forthright in explaining plans, and be forthright with how the project is evolving. The pure project design has been compromised. We've had to take a more traditional project approach. The budget has been tight.

9. Catherine: Do you have any other comments? 
Ted Harrison: For land trusts in general, this approach may not apply. To use this method of financing and land acquisition, a conservancy needs a highly amenitized [sic.] landscape, meaning a wealthy class, a beautiful landscape, people who are already in place on the land, scenic land values, and a good climate. The location has to have features that draw people to buy property. These amenities draw individuals from the wealthy class that value scenic landscapes and nature and communities that want to tell the story that 'we are outside the norm.' You need a community that wants to put its wealth to good purposes. This is the only way that the landowner would want to pay a premium for land in exchange for conservation.

Book recommendations: Lost Landscapes Failed Economies by Power [Thomas Michael Power, 1998] speaks to issue of communities that are struggling with 'Should we open up timbering and natural resources development or is the short-term benefit higher than long term? Or should we prioritize long-term? Is it going to add value? He argues that the resource-protecting strategy is better longer-term.

Also, Conservation Communities by the Urban Land Institute and McMahon [2010]. The Sonoran Institute advocates for limited development. [They are] involved in projects in the Urban Land Institute. They wrote a book with sixteen case studies." [Harrison, personal communication, May 5, 2012, brackets mine].

\section{End of Interview}




\section{Appendix C Best Practices}

A distillation of the report's discussions may be found in this summary list of best practices that can serve as a straightforward guide to limited development for conservancies. I have included my own recommendations along with those of the authors and professionals.

\section{Introduction}

- Conservation and limited development is primarily a conservation tool.

- Occurs when a small, less-critical, portion of a property is developed in order to fund the preservation of the larger, more environmentally- sensitive, portion.

- Conservancies may initiate and pursue conservation projects by making competitive bids on available properties (Milder, 2006)

- The site's existing features determine where development is located.

- All stakeholders must be willing to collaborate to reconcile their different goals.

\section{Challenges in Implementing Limited Development}

To handle challenges when pursuing limited development, the conservancy should:

- Take precautions not to lose its nonprofit status (LTA, 2004).

- Set standards for project and habitat quality (Sullivan, 2005).

- Using easements to conduct conservation in limited development requires expensive negotiation and is not convenient Parker argues (2002).

- Understand that though they are expensive and labor intensive, easements allow specific features to be conserved and provide the necessary strictures to ensure that conservation land may be placed next to development without concern that one will negatively impact the other. 
- Pursue risk reduction strategies such as community trust-building, early involvement of the public in project design, investment of time and finances in project quality or the use of an easement to share the cost burden with a stakeholder.

\section{The Role of the Conservancy in a Limited Development Project}

The conservancy may pursue a variety of roles in limited development including:

- Acting as a conservation advisor and ecological advocate, coordinating ecological grant funding, advocating for certain projects and removing barriers for stakeholders.

- Community outreach specialist due to its good reputation and connection to the community (Sullivan, 2005).

- Be prepared to assume any role that cannot be filled in order to make these multifaceted projects feasible.

- Project manager, provided it has the funding and staff resources.

\section{Drafting a Mission Statement and Goals that Encourage Limited Development}

To encourage limited development, a conservancy's mission statement and goals should:

- Specify the minimum and maximum participation that the conservancy desires and the circumstances under which limited development should be used, based on its expertise, reputation, finances, staff and investor expectations (Sullivan, 2005).

- Identify the conservancy's priorities, resources to conserve, minimum quality standards and standards for fair collaboration measures (Sullivan, 2005; McMahon, 2010).

- Protect the land trust's conservation purpose, reputation and nonprofit status.

- Consider supporting community and municipal plans (McMahon, 2010).

- Identify a variety of funding sources (Sullivan, 2005).

- Employ commonly-accepted practices even if some data is unavailable (Noss, 1997).

- Prepare the conservancy to, at minimum, analyze the site, identify important conservation features, create the site plan and negotiate the easement's terms (LTA, 2004; Perlman \& Milder, 2005). 
- Encourage meetings with core stakeholders to exchange information and expertise (Sullivan, 2005).

- Increase community visibility to strengthen its influence.

- Evaluate how limited development may help the conservancy implement its mission and goals.

\section{The Site as a System}

In designing the conservation area site plan, land trusts should:

- Understand how the site functions without development to evaluate how the site will function after the project is built.

- Understand that a system is a group of elements that are "interconnected in such a way that they produce their own pattern of behavior over time" (Meadows, 2008).

- Protect critical flows that support the system's natural processes and stability (Meadows, 2008).

- Balance and direct flows of water, vegetation, pollinators, predators, organisms and people using natural and man-made design features.

- Focus stakeholders on the compatibility of adjoining systems (Meadows, 2008).

- Advocate for the inclusion of additional feedback loops to strengthen the lessresilient ecological system against harmful urban flows (Meadows, 2008).

- Hire biologists and ecologists to tailor mitigation to the local landscape.

- Use buildings as barriers to prevent public access to habitat since, in Sauvajot's (1998) study, development causes fewer disturbances than roads or paths.

- Advocate for management that can be adapted to control seasonal hazards (Meadows, 2008).

- Use fire-resistant buildings and designs since the developed portion will be located in or near dry, grassy areas (Perlman \& Milder, 2005).

- Use city or county GIS data to determine non-visible site hazards (Permit View, sloplanning.org, 2014).

- Buffer conservation areas at risk for flood or fire using watered sports fields, gardens with native plants, streams or watered farmland. 
- Prevent erosion in San Luis Obispo County

- Analyze how a project impacts, or is impacted by regional flows.

- Design the site's uses and features to mimic the site's historic inputs and outputs.

- Avoid drainage ponds unless they can be stocked with fish to control mosquitoes and maintained to be an attractive feature of the community (Arendt, 1994).

- Avoid using drainage pipes that empty into sensitive habitat areas.

- Use rain gardens, permeable pavement, bioswales, and planters with droughttolerant native vegetation (McMahon, 2010).

\section{Balancing Human Impact with Human Access}

To design the site to balance human impact with human access, the land trust should:

- Prioritize the preservation of sensitive areas.

- Build trails in large, common or resilient environments to minimize disturbance (Perlman \& Milder, 2005).

- Allow access to scenic, even sensitive, areas if required to access desirable hiking destinations that define the local character (Perlman \& Milder, 2005).

- Locate roads and trails to accommodate existing site flows.

- Avoid sensitive habitat by building trails on an overpass or bridge and using barriers to prevent access and ensure that hikers will not stray from the trail (Perlman \& Milder, 2005)

- Determine the minimum amount of restoration necessary to sustain a particular use.

- Encourage disturbance species since they can substitute as a food source if native prey species disappear (Sauvajot et. al., 1998).

- In San Luis Obispo County, use grassland ecosystems, which recover quickly, as buffers between sensitive habitat and development (Perlman \& Milder, 2005).

\section{Landscape Analysis}

In composing the project's landscape analysis, the conservancy should: 
- Use the site analysis to compose a site plan that tailors development to the landscape, preserving existing habitats and ecological processes.

- Refer to the developer or city's EIR Initial Study in place of a landscape analysis to save time and money (Perlman \& Milder, 2005).

- Record how animals, plants and humans use and migrate through the site to inform how conservation areas should be connected.

- Use the site analysis as a baseline for existing conditions to gauge the project's impacts on the environment (theeagleranch.com, 2014).

- Consider designing the project to mitigate impacts as they are found (theeagleranch.com, 2014).

- Identify and connect habitat areas that are a source or sink of population (Perlman $\&$ Milder, 2005).

- Use the site analysis to inform its composition of the site plan.

\section{Conservation Area Site Planning and Design}

In designing the configuration of the conservation area, the land trust should:

- Evaluate whether the site requires rehabilitation, buffering, incorporation of recreation trails or location of migration routes.

- Tailor the site to a single species or interdependent species (Sauvajot, et. al., 1998) by consulting local biologists to determine migration or habitat needs, ecologists to determine how species might interact, the Initial Study of the city's General Plan, the city's Local Coastal Program, a jurisdiction's GIS maps or the Northern Prairie Wildlife Research Center's wildlife distribution maps.

- If there is a lack of information about how species move in the site, preserve an example of each type of habitat and connect them with green corridors (Perlman \& Milder, 2005).

- Ensure that habitat areas accommodate the ranges of species. For non-native species, 12 acres or less are adequate. For edge-sensitive, native bird species, 15 to 25 acres of forested land is needed. Sensitive native species require at least 100 acres of core habitat (Perlman \& Milder, 2005). 
- Keep larger patches in-tact to prevent a natural disaster from devastating the entire population (Perlman \& Milder, 2005).

- When large habitats are not possible, install migration corridors connecting all small patches of habitat in the site to form a large habitat area, forming numerous of Meadows's (2008) feedback loops that stabilize the system enabling migration and interbreeding.

- Connect habitat to state or national conservation areas (Perlman \& Milder, 2005).

- Consider a variety of migration corridors to meet specific species' needs including riparian corridors, culverts, foothills, bioswales, pedestrian trails or even expensive overpasses with plant-covered walkways or animal walkways that are built into the ground (McMahon, 2010; Perlman \& Milder).

- Consider partnering with nearby jurisdictions to construct and maintain the, often expensive, migration corridors (Perlman \& Milder, 2005).

- Use Perlman \& Milder's “Aggregate with Outliers" model by combining isolated parcels to form a larger habitat area and by encouraging residents to plant small habitat areas with native vegetation in the urban portion (2005).

- Offer to certify residential yards that comply with the land trust's ecological guidelines (Perlman \& Milder, 2005).

- Create habitat with uneven boundaries to encourage animals to cross into new habitat and to guide them away from dangerous urban areas (McMahon, 2010).

- Begin with a border that juts or dips just 10 or 12 feet to avoid adding to the edge.

- Compose a green print specifying the exact layout, number and species of native plants that will be included in each habitat area (Perlman \& Milder, 2005).

- Ensure that the landscape contains "complete vegetation" including grasses and shrubs, and understory, mid-story and canopy trees (Perlman \& Milder, 2005).

\section{Development Area Site Planning and Design}

When designing the site plant for the developed portion, the land trust should:

- Consult the local jurisdiction's GIS data detailing flood plains, geography, land slope and zoning. 
- Consider existing and past uses of the site (McMahon, 2010).

- Consult the project's vision and goals to order to incorporate the community's input into site design.

- Locate development so that it is feasible, marketable and ecologically-beneficial.

- Use limited development as a buffer between cities and open space (McMahon, 2010).

- Locate development near existing transit and development, but far enough away that the ambiance or property values will not be affected (McMahon, 2010).

- Encourage the community to spend time and money in the project by including unique amenities that serve the project's target market such as outdoor education schools, retail, restaurants and outdoor recreation.

- Use the project's land uses and public spaces to build community relationships and celebrate, rather than compensate for, the rural nature of the project.

- Minimize impacts by using buffers between incompatible uses.

- Examine how site conditions such as wind direction and runoff will affect the project.

- Limit lot size to one acre or smaller, providing easement-protected public open space instead (Arendt, 1994).

- Compensate for the proximity of homes by providing each with a view of open space and conceal development from view among trees or hills; however, this can be very costly, requiring the extension of infrastructure or additional grading to situate homes on sloping ground (McMahon, 2010).

- Minimize disturbance by clustering development and constructing smaller parking lots and narrower streets (Perlman \& Milder, 2005).

- Lower infrastructure costs and thus, the price of homes by refraining from using curbs, provided that runoff amounts are not significant (Arendt, 1994).

- Negotiate with local jurisdictions to alter design guidelines as needed and to make decisions based on the landscape rather than on policies and building standards.

- Weigh the high danger of fire in San Luis Obispo County against the need to reduce paved surfaces and maximize green space. 
- Consider assigning Cal Fire's standard road width of 24 feet with 2-foot wide shoulders to roads with high volumes of traffic while negotiating with Cal Fire to allow 18 to 19-foot road widths on smaller streets, provided these allow emergency vehicle access (Arendt, 1994).

- Design roads, in dense areas, with a width of 26-28 feet for parking on one side of the street and a road width of 32-36 feet for parking on both sides (Arendt, 1994).

- For reluctant jurisdictions, make the project a planned unit development with its own zoning and building standards, use performance zoning to control negative impacts, or compose a yield plan which estimates the minimum number of lots feasible in light of compliance with local design guidelines (Arendt, 1996; McMahon, 2010).

\section{Defining the Direction of Development}

In order to exercise greater control over development, the land trust must:

- Nonetheless depend on both staff and consultant expertise to navigate the development process and meet its overall goals and mission statement.

- Decide if it has the resources and time to manage the project or whether it must hire a developer to manage the project.

- Hire specialized experts onto staff positions only if organization goals and mission statements require the use of specialized skills on a weekly basis.

- Negotiate greater involvement as a condition for holding the project's easement.

- At minimum, compose the project's site plan advising the developer about the least impactful location for development and the location of critical habitat areas (LTA, 2004) (Perlman \& Milder, 2005).

- Ensure the site plan is based on sound data and accommodates the developer.

- Respect developers' concerns and project critiques as an assessment of market demand, cost of materials, availability of employees and many other factors (McMahon, 2010). 


\section{Marketability and Market Analysis}

In creating a site that appeals to key buyers, the land trust should:

- Meet with prospective lenders and buyers and conduct a feasibility study before taking out a construction- or land purchase loan (Miles et. al., 2007).

- Analyze the sales price of local non-conservation projects and how long a property stays on the market to gauge potential success (Harrison, 2012).

- Protect marketable features that embody the site's history, culture and ecology.

- Construct homes that complement the project's vision and minimize impacts.

- Use the project's amenities, size, uses, housing costs and proximity to urban areas to attract the target market, demonstrate its marketability, facilitate community-building and support the site's ecology.

- Offset the costs of amenity installation by increasing development density.

- Consider offering a share in the entire project rather than ownership of a property, reinforcing the project's focus on the community as used in the Tryon Farm limited development project (McMahon, 2010).

- Consider inviting a few potential buyers to a formal tour of the property or openhouse to listen to their concerns and solve design issues (McMahon, 2010).

- If a bank refuses to provide a loan, consider pre-selling lots to fund construction, and demonstrate the project's marketability as used in the Dewes Island limited development project (McMahon, 2010).

- Advertise to target audiences using venues that support similar values such as environmental magazines, country clubs, or farmer's markets (McMahon, 2010).

- Establish a website that summarizes the project to decrease public opposition and provide evidence of the project's quality (McMahon, 2010).

\section{Land Trust Involvement in Long-Term Land Management}

To determine its level of involvement in land management, the land trust should:

- Alongside other management entities, craft the management strategies of the long-term management plan contained in the easement agreement. 
- Ensure that management practices accommodate the needs, cultural values and environmental goals of all stakeholders that will be impacted (McMahon, 2010).

- Consider establishing a homeowner's association to handle vegetation management, mitigation, resident needs and adaptive management provisions.

- Consider establishing a homeowner's association if: the land trust requires resident fees to manage the land, a "restrictive conveyance" may dictate house size, building density, land uses, building design or type of vegetation, if residential issues are anticipated to be a significant part of long-term management or if the project's developer is willing to establish the homeowners' association (McMahon, 2010).

- Consider establishing a cooperative agreement with a jurisdiction if the project will directly benefit it enough to warrant maintaining it (Sullivan, 2005).

- Consider leasing the land to private landowners to use for farming, logging, grazing or conducting research. Rent from each tenant pays for maintenance (McMahon, 2010).

- Consider selling the land to a national conservation organization such as the Trust for Public Land or the Nature Conservancy if it can afford to provide a maintenance endowment for the property, if the property is high-quality and rare, and if it cannot afford to maintain the property itself (McMahon, 2010).

- Reduce homeowner's association fees in exchange for community participation in maintaining trails, reinforcing embankments or operating a community ranch as seen in the San Creek Ranch limited development project (McMahon, 2010).

- Ensure that easement restrictions remain flexible to adapt over time McMahon, 2010).

- Consider establishing several land management entities (such as a visitor's center, HOA and community recreation activity center) if a project has numerous objectives to accomplish.

- Consider managing the project itself if it has the resources to handle long-term burdens and if it feels it is the only entity that can realize long-term project goals.

- Evaluate whether it can handle: limited involvement in land management in which it might provide initial, occasional advice to the homeowner's association, 
or a moderate to high level of involvement in which it might monitor and adapt land management in light of findings or act as an ecological advisor or researcher.

- Evaluate whether it can handle a moderate to high level of involvement in public outreach holding community events, educating the public and involving residents in species counts, tree-planting or weed-pulling or whether it can only handle limited involvement implementing a few targeted programs (McMahon, 2010).

\section{Long-Term Adaptive Management}

To encourage the use of adaptive management, the land trust should:

- Pursue it to ensure that development will not impact the conservation area over time.

- Break project goals into management objectives and tasks that accomplish them, ensuring that each may be realistically achieved (Perlman and Milder, 2005).

- Monitor indicators of the achievement of these objectives or missing organisms in the ecosystem using wildlife cameras or species counts. (Perlman \& Milder, 2005; Burger, no date given). If these objectives are not met, adapt management to restore balance.

- Be willing to negotiate the land's management with landowners that wish to continue to use a property long-term.

- Designate fire-danger reduction as an important long-term maintenance goal since fire danger in San Luis Obispo County's chaparral environment is high.

- For wildfire adaptive management: restrict public access for one season to any burned area (Burger, no date given, 101). Reach out to homeowners, explaining the importance of controlled burns to ecosystem health (McMahon, 2010).

- Specify in the management plan vegetation management options, such as controlled burns, mowing or grazing, given the site's processes, tolerances of native species and proximity to residences.

- Ensure that adaptive management strategies are not overly-complicated (Noss, 1997) or time-consuming to amend and that strategies remain flexible enough for the managing entity to quickly solve changing issues (Parker, 2002). 
- Adapt land management to better achieve key project goals but adhere, without compromise, to these key project goals, unless criteria for changing them is met.

- Consider management alterations suggested by Burger, such as limiting public open space access to: a particular number of users, areas with resilient species, specific hours of the day, or certain days with at least three days between. (California Dept. of Fish and Wildlife, undated).

\section{Composing an Easement Agreement}

When placing an easement on a property to conserve it, the land trust should:

- Describe the baseline condition of the site, important species and processes and how these interact to form the system's sustaining feedback loops both regionally and locally (Parker, 2002).

- Include a general Statement of Purpose, the land's management plan outlining quality standards and indicators that trigger management changes (Burger).

- Set higher maintenance standards for habitat areas and more basic maintenance standards for areas that will be maintained by a homeowner's association.

- List and clearly define each stakeholder's responsibilities and authorities regarding maintenance, monitoring, development or community recreation to reduce confusion and ensure that all are working toward the same goals (Parker, 2002).

- State the maximum number of acres that may be developed (McMahon, 2010).

- Evaluate anticipated impact and consider restricting potentially disruptive uses such as feed lots, billboards, mining, fences, roads, logging and subdivision (Parker, 2002).

- Base site restrictions on overall project goals and the needs of species and people.

- Include procedures and cost allocation for dispute resolution, enforcement, litigation, distribution of information, enforcement, project approval, or amending or striking a clause from the easement agreement (Parker, 2002). 


\section{Easement Costs vs. Landownership Costs}

In order to evaluate the cost of land ownership as compared to the cost of placing an easement, land trusts should:

- Understand the costs associated with both of these conservation methods including monitoring, collecting baseline data (site's condition and zoning), appraising the land's value before and after easement placement and constructing additional amenities (Parker, 2002).

- Use an easement: if it cannot afford to purchase a property, if a landowner wishes to keep using the property, if a landowner wishes to conserve the property while selling a portion of it for a profit, if the land trust wishes to share land maintenance costs with other entities, if the land trust is willing to negotiate easement terms with the landowner, if land does not need complex conservation provisions or if a good relationship with the landowner or homeowner's association is anticipated (Parker, 2002).

- Specify both in the easement agreement and, verbally, to the landowner that the management of the land will change.

- Encourage the landowner and homeowner's association to participate in forming project goals.

- Expect a longer, more collaborative negotiation process (Parker, 2002).

- Benefit from using an easement since it provides a singular direction for stakeholders, enables land trusts to conserve properties out of their price range, provides property owners with a profit, allows more precise conservation and provides the conservancy with long-term maintenance support and allows development to be located next to conservation land with minimal impact.

- Consider using Parker's strategy of acquiring just the portion of the property that requires complex maintenance procedures (2002).

- Protect landowners' ability to qualify for an income tax deduction.

- Evaluate the additional costs of placing an easement including: hiring attorneys, mediators, surveyors, land managers or biologists, monitoring the site, adapting 
management techniques, buying materials for maintenance or restoration, evaluating baseline site conditions, or communicating with landowners (Parker, 2002).

- Evaluate the additional costs and risks of purchasing the entire property including: assuming a large initial risk, depending on the steady sale of development to pay back the land purchase loan, negotiating low-impact design standards with the developer, preparing the site for development and either conducting all maintenance or establish a homeowner's association.

- Anticipate greater monitoring maintenance and restoration expenses for limited development since there will be greater impacts and more complex easement provisions (Parker, 2002).

- Establish criteria for accepting easements that stipulate minimum land quality and require the estimation of yearly management costs (Parker, 2002).

- Use homeowners' association fees, fees from leasing the land, or the (taxed) proceeds from agricultural produce (McMahon, 2010) from the land to fund land maintenance.

\section{Long Term Maintenance Endowment Fund}

To fund the long-term maintenance of preservation land, the land trust can:

- Act as the land manager and receive an endowment from a landowner or developer, or act as the donor and, itself, provide the land manager with an endowment.

- Provide enough funding for the endowment that the interest that it accumulates will support annual maintenance (Doscher, 2011).

- Use a proforma to estimate the average annual cost of maintaining the easement and thus, the amount of the endowment (Sullivan, 2005).

- Base the endowment's final amount on anticipated profits from the project's development and the yearly cost of maintenance (Sullivan, 2005).

- Ensure that it can provide a sufficient endowment to achieve the level of maintenance that it deemed appropriate in the easement agreement. 
- If a developer established the conservancy originally, request that it provide greater long-term support and pay property taxes and assessments until the endowment is paid (Sullivan, 2005).

- Or, if lacking funds for the endowment, negotiate the developer's donation of a percentage of its profits from home sales (Sullivan, 2005) and specify this percentage in the development agreement.

- If it bought the land, sell the development area to the developer, but protect its nonprofit status.

\section{Land Appraisal}

To conduct the appraisal of the land, the conservancy should:

- Act as the project appraiser or hire an appraiser that understands that the project's value is inherent in the land's conservation potential (McMahon, 2010).

\section{Bargain Sale}

- Pursue this method if the seller is willing to make a large donation and contribute to local conservation.

- Inform interested landowners about income tax deductions for their bargain sale.

- Ideally, purchase cheaply from landowners that have actually lived on their property and are emotionally-connected to the community and their land (Ted Harrison, pers. com, 2012).

- Consider referring landowners to a tax consultant if needed (LTA, 2013).

\section{Full-Price Sale of Land and Protecting Landowner Tax Deductions}

- Preferably, use this technique in combination with a bargain sale.

- Use profits to pay the land purchase loan and fund land maintenance.

- Devote surplus money directly to a fund covering loan payment, land maintenance or even development costs, but never use it to raise staff salaries (Parker, 2003). 
- Educate potential donors about California's Natural Heritage Preservation Tax Credits and other state and federal income tax, property and estate tax deductions (LTA, 2004; Forever Forests, 2010).

- Be willing to risk selling the property without an easement to gain its full price. Then enable the buyer to pursue tax deductions by accepting an unenforceable, verbal promise that an easement will be placed on the land after its purchase (Harrison, pers. com., 2012).

- Aid landowners in meeting tax deduction criteria.

- Consult the "Conservation Donation Rules" (2013) page on the Land Trust Alliance's website.

- Get to know specific potential buyers and ascertain their level of commitment (Harrison, pers. com., 2012).

- Use this risky technique to preserve less-crucial areas of the property.

- Use this technique when clientele have the financial resources to purchase properties at full-price (Harrison, pers. com., 2012).

- Use this technique when there is a dependable market for the project, preferably when the area is scenic or desirable (Harrison, pers. com, 2012).

- Locate projects near enough to existing communities to ensure a market (Harrison, pers. com., 2012), but far enough away to avoid negative impacts to their property values.

- Use this funding method when the conservancy feels it can trust the client.

\section{Transfer Fees}

In light of the 2011 FHFA transfer fee rules, land conservancies should:

- Ensure that transfer fees take the form of homeowner's association or maintenance fees and directly benefit the users of the property.

- Ensure that transfer fees do not benefit the developer, investors or conservancy.

- Transfer fees are permitted in California provided that criteria are met (Pennsylvania Land Trust Association, 2012). 
- In states in which transfer fees are not allowed, consider, requiring that the land's donor, buyer or both contribute an annual amount to a maintenance endowment (LTA, 2004).

- Inform potential buyers that they must pay maintenance fees, but that these may only be a deductible for the original land donor and not a secondary owner (LTA, 2004).

- Due to the risk, only use transfer fees if homeowner's association fees or an endowment provided by the developer are not sufficient for maintenance.

\section{Grants}

When applying for conservation and limited development grants, the land trust should:

- Use CoolCalifornia.org as a source for state grants if located in California.

- Scrutinize the conditions of each grant before applying to determine if adhering to these conditions would drastically change the project's goals or objectives.

- Federal grants may require a demonstration that any fees or payments derived from the property's buyers or sellers will directly benefit only that property (LTA, 2004).

- Investigate the California Department of Fish and Wildlife's Natural Community Conservation Planning program for conservation development grants.

- For grants that do not allow other funding sources, such as the NCCP Local Assistance Grant, consider dividing the project into separate components.

\section{Loans}

To secure a bank loan for a limited development project, a conservancy may need to:

- Decrease banks' perceived risk by providing them with additional proof of project marketability and feasibility (McMahon, 2010).

- Reduce investment risk by making alterations to the project as requested by banks.

- Highlight the project's natural amenities and illustrate clearly the target audience. 


\section{Minimizing Construction Costs}

To encourage financially-efficient construction costs, a land conservancy should:

- Use green building and reduce the project's environmental impacts (McMahon, 2010).

- Allocate the funding saved via fewer material and construction costs to offset ecological design expenses such as maintenance of green infrastructure, restoration of degraded habitat, and mitigation of impacts (McMahon, 2010).

- Install project amenities for specific purposes, for instance, to attract the project's target audience, fulfill a project or community goal, complement the character of the project or gain public support (Sullivan, 2005).

- Apply amenities in an exact way to directly appeal to the project's target audience, fulfill a community goal, complement the character of the project or gain public support.

- Balance public amenities, habitat areas and profitable, developed parcels.

- Cluster residences, reuse materials, use pre-existing or narrower roads or replace gutters with bioswales to reduce infrastructure costs (McMahon, 2010).

- Ensure that long-term funding sources can provide the, larger-than-standard, amount of income needed to maintain the project's green infrastructure (McMahon, 2010).

\section{New Markets Tax Credits}

- If financial, staff and time resources are available, determine if the proposed project easily meets all criteria for securing New Markets Tax Credits, provided that the project provides low-income housing and is located in approved census tracts.

\section{Determining the Desired Type of Stakeholder Partnership}

In order to choose the best stakeholders to partner with, the land trust should:

- Use its minimum standards for quality and performance to evaluate potential partners (Sullivan, 2005). 
- If it is the initiating organization, compose the project's preliminary direction and vision statement based on its minimum standards and then describe this vision to stakeholders at the first meeting (McMahon, 2010).

- Pursue the "Buy, Restrict, Sell" model of limited development when: it can afford to purchase the property, staff has sufficient development expertise, it can manage a project on its own, it needs greater control of the project, or after fostering good relations with local entities and it understands local priorities and likely obstacles (Milder, 2006).

- Pursue the "Work with a Landowner" model: when desiring a property currently under private ownership, when complete authority over the project is not desired, if the conservancy can compose the easement terms and conservation area site plan, if it can collect the necessary facts and data to make design decisions, if it is willing to listen to landowner needs and compromise, or if the landowner promises to remain in dialogue with the land conservancy long-term (Milder, 2006).

- Pursue the "Partner with a Developer" model if the land trust lacks funding to acquire properties by itself, if the trust and developer are willing to remove barriers for, and accommodate, one another or if the land trust is willing to compensate for the income lost to the developer as a result of an alteration that it requested (Milder, 2006).

- Pursue joint ownership with a developer: if project success depends upon compatibility between the developed and conserved portions, if greater control over projects is desired, if both the land trust and developer use their individual expertise to solve problems early in project design and if both are willing to negotiate high-risk endeavors and alter project design to accommodate one another (McMahon, 2010; Sullivan, 2005).

- When making alternative design suggestions, brainstorm ways of mitigating developers' resulting income loss.

- Use the project to meet multiple needs and balance marketability and quality conservation.

- Include in the development agreement each party's responsibilities, clauses that protect the land conservancy's nonprofit status and reputation and which entities may 
associate their names with the completed project if it is successful and which will retain ownership if it fails (Parker, 2002).

- Pursue a Joint Ownership Agreement: to demonstrate the project's marketability, if

the conservancy wishes to have greater control over projects than an advisory role, if the developed and conservation areas are to be treated as one project, if the landowner has not already hired its own developer, if the developer is willing to uphold the land trust's principles, if the developer has experience with locating and managing finances, if the developer supports green design or if he has a good reputation (McMahon, 2010).

- Pursue the "Partner with a City" model if incentives (such as tax credits, density bonuses or expedited permit review) or enforceable consequences (such as impact fees) are needed to spur developers to adopt land trust conservation priorities (McMahon, 2010).

- Pursue the "Conservation Investors" model when the land trust lacks the funds to purchase land, when it can show investors evidence of the demand for the project, when it is willing to make important project decisions in partnership with investors, and when it has a developer's recommendation for investors that have good reputations and similar goals (Milder, 2006).

\section{Valuable Stakeholder Actions and Roles}

To encourage valuable or high-risk contributions from project partners, a land trust may:

- Encourage stakeholder behaviors described by the New England Environmental Finance Center that facilitate trust in the limited development process (2003).

- Decrease the developer's risk of adopting conservation-oriented goals in order to encourage good behaviors from developers including: collaborating and communicating with stakeholders, garnering support from development professionals or enabling stakeholders to access resources or grants, only available to the developer New England EFC, 2003). 
- Decrease the developer's risk by sharing the cost burden, waiving fees, expediting the permitting process and design review or granting permission to the developer to increase density or include marketable amenities (New England EFC, 2003).

- Highlight potential benefits such as increased land value, improved public reputation and the ability to delegate some project burdens to the conservancy.

- Depend on the developer's expertise about marketing, project costs and pacing to gauge whether the project is reasonable and composing the site plan according to conservancy standards (New England EFC, 2003).

- Remain visible in the community by speaking to local newspapers, giving tours of completed projects, providing information at community events and schools and thank supporters (Tennyson, 2012).

- Provide ecological advice, compose the site plan with stakeholder input, balance development and conservation, seek mutual benefits and accommodate project partners' needs (New England EFC, 2003).

- Ensure that all projects meet minimum quality standards, complement the conservancy's mission statement, provide benefits and are likely to last long-term.

- Be aware that cities want projects to: incorporate public input, be altered based on this input to decrease opposition and the threat of litigation, directly benefit residents, reduce the need for city intervention, reduce infrastructure, offer higher property taxes, meet and adhere to development and conservation goals (New England EFC, 2003).

- Encourage beneficial behaviors from cities such as: publicly endorsing the project, encouraging businesses to locate in the project, fair evaluation of nonconforming projects and refraining from levying additional fees on such projects (New England EFC, 2003).

- Remove barriers for and offer support to stakeholders that assume risks (New England EFC, 2003). 


\section{Stakeholder Collaboration Strategies}

When planning meetings with stakeholders, the land trust should:

- Decide if greater public participation is needed and if so, include community members in early project design.

- Use Action Planning, to resolve disputes, create a comfortable atmosphere for discussion or achieve concrete results such as a prioritized list (Sanoff, 2000).

- Use Participatory Action Research in order to achieve consensus about the project's context and facts, replace preconceptions and by involving all stakeholders in project research, dialogue between stakeholders, information-sharing and direction-setting (Sanoff, 2000).

- Using either model of participation, focus meetings with the public on providing designers with insight into local preferences, character and use of the land and on educating residents about the goals and facts of the project.

- Assemble a steering group to appoint tasks, prepare the project proposal, fundraise, conduct research, select architects, provide feedback on designs, orchestrate collaborative design and integrate stakeholders' ideas (Sanoff, 2000).

- Begin by collaboratively conducting research, "awareness walks" or surveys, the collection and analysis of which allows stakeholders to formulate ideas collaboratively, evaluate their compatibility, accumulate expertise, and reach a consensus on the project's context and priorities (Sanoff, 2000).

- Solicit less public participation when the project must meet complex conservation goals, financial needs, municipal zoning requirements or the client's needs. Invite greater and earlier public participation when the project will affect the community or when citizen objection is likely

- Protect existing design guidelines by requiring that community members adhere to specific criteria when submitting their own designs (Tennyson, 2012).

- Use public criticism to assess the feasibility of the project (Tennyson, 2012).

- Handle public criticism by stating the purpose of the public meeting and reminding attendants that the meeting is not for negotiating project changes (Tennyson, 2012). 
- Tennyson recommends adhering to a public message when facing criticism. This report recommends defending the project's original vision and goals (2012).

- Use build-out maps to illustrate problems with existing development patterns. Use brainstorming, surveys, mapping exercises and past workshop summaries to provide residents with a complete picture of the project (McMahon, 2010).

- Use design games to restrict critique until after participants have generated numerous project ideas. Use ranking surveys when little group discussion is needed, use the "Group Process" collaboration method of presenting ideas and allowing listeners to provide feedback without interruption to resolve conflicts, use stickers printed with icons when designing the site or use free-association brainstorming activities when many ideas are needed (Sanoff, 2000).

- To reach agreement despite very different priorities, compile the group's objectives, divide them into "means objectives," and "fundamental objectives" and rank them according to desirability and feasibility (Gregory and Keeney, 1994).

- Choose a facilitator that will encourage acceptance of diverse opinions, focus the group on mitigating problems, clearly articulate the project's risks but encourage participants to both take risks and reduce the risks of others by offering additional resources (Sanoff, 2000).

- Show appreciation for participants' help at the end of the project (Tennyson, 2012).

\section{Case Study: Eagle Ranch}

Lessons that conservancies may learn from the Eagle Ranch limited development project in Atascadero, CA are as follows:

- The conservancy took a limited role because it did not have to conduct site studies in the conserved portion, there would be no public access in its portion and there were already numerous agendas involved.

- Leaving project design in the hands of the designers can result in a shorter, lessexpensive design phase and more focused project goals because there are not too many designers complicating and slowing the process. 
- The City of Atascadero's General Plan requires that rural areas use clustered development and be compatible with open space, shifting the burden of project initiation and design from the Conservancy to the city and developers.

- RRM Design hired its own consultants and carried out project design concurrent with the constraints analysis, mitigating numerous negative impacts as they were discovered. The city council did not have to enforce quality standards, and the EIR did not have to be expensively revised.

- The core decision makers in the Eagle Ranch project were accessible to the public and 25 different types of public meetings have been offered.

- Individual meetings with neighborhoods were held when deemed necessary to address specific traffic issues. Waiting until something becomes an issue and then addressing it, in-detail, is an efficient way to reduce project costs and complexity.

- Meeting in small groups required residents to distill their concerns and come to a consensus, streamlining what would have been a cacophony of concerns.

- Since the initial project was conceptualized by professionals, some residents objected to the project's density and visibility, thinking the designs were inalterable.

- While only the designer and client should be included in the very earliest stages of design, invite input from the public at the start, giving them a sense of ownership over the project and a sense of the feasibility of their requests.

- Consider whether it wishes to reconcile two sets of impact analyses, the city's and its own, and carry its loans during this extended design process or whether it wishes to use the municipal constraints analysis instead.

- Ensure that public surveys are not overly-simplified, and that all of the options it presents are feasible. Ensure that participants are asked both their preferences and priorities. If the community is given participation, ensure it is meaningful.

\section{Case Study: Galisteo Basin Preserve}

As demonstrated in the Galisteo Basin Preserve limited development project in Santa Fe County, New Mexico a land trust should:

- Ensure that the project's approach is based on project priorities and goals. 
- If the project has few other stakeholders, choose community members, the primary users, as its client and allow them to set priorities.

- Establish long-term trust with a community through involvement in projects over time and demonstration of reliability.

- Conduct comprehensive outreach and act as the community's advocate by following through with the commitments it makes to the community.

- Give community members meaningful participation early in project design to encourage public criticism to peak early and then wane.

- Consider inviting community members to an open house to use the project's trails before the project is constructed to both sell homes and garner community support.

- Consider including both affordable housing and larger custom homes on large properties to include a variety of home types to allow the project to fill a variety of niches and to survive if one of its markets disappears.

- Consider reinforcing its stability and regional relevance by emphasizing connections between project uses and between community members.

- Consider using phased development was used to avoid large upfront infrastructure costs and to test whether the market will absorb the project.

- Consider deriving funding for land purchase and design from both a half-priced bargain sale of the land, as well as selling land at full price to landowners.

- If the land requires an easement, to avoid a decrease in the land's value and protect its profit, take a risk and ask each buyer to make an unofficial promise to place an easement on the purchased land. This protects the landowner's ability to receive a tax deduction for their donation of the easement since it is not an official agreement while also allowing the conservancy to sell the land at full price to pay off their loan.

- If properties sell slowly, consider sacrificing some conservation land to subdivide and sell as undeveloped lots, relying on the buyer to pay for the home's construction.

- Consider prioritizing impact mitigation and offering buyers lower energy bills by modeling homes according to the local setting, and constructing homes to have a zero net energy rating and to use recycled materials, incorporate photovoltaic panels, efficient appliances, passive heating and cooling, and rainwater harvesting. 
- Address developers' wariness of limited development by selling small portions to several developers so that no single developer would have had to assume the risk of investing in the entire project.

- Partner with a developer from the start if a conservancy knows that it cannot afford to develop the project on its own.

- Act as the community's advocate and ensure that the developer respects community needs.

- Include a variety of amenities to attract a particular market for the project. This project included affordable housing, housing for the elderly, cohousing, a "green," headstone-free cemetery, an outdoor-oriented charter high school and a communityrun farm. Even the expensive custom homes depend upon passive heating and cooling and solar power.

- However, ensure that amenities do not only appeal to a narrow market. Consider introducing each amenity gradually and specifying in its marketing and in its easement agreement that the project's homes and amenities should be low impact.

- Understand that limited development entails ideological components, such as luxury, conservation and community-orientation and ensure that these philosophies are compatible with the project's target market.

- Include several basic features because they appeal to a wide audience and help connect a project's, otherwise, disparate parts. These include: self-mitigating or low impact designs, clustered housing, affordable and elderly housing, public open space, a village center, trails and a community stewardship center.

- Ensure that not too many features require careful management since homeowners' associations are required to carry out routine maintenance.

- For every amenity and feature included, establish quality standards, monitor the results, introduce changes slowly and adapt management to meet these standards.

- Balance conservation with multiple concerns such as feasibility, marketability and public input.

- To act as the developer, address the minutiae of each step negotiation and coordinate them with the mission. These include feasibility studies, hiring contractors, seeking municipal approval and altering design. 


\section{Conclusions}

In conclusion, conservancies should:

- Assume any role necessary.

- Realize that success results from roles that increase feasibility such as risk-reducing collaboration (New England EFC, 2003), strategic land purchase and understanding how an ecological focus will impact the project's expense and feasibility.

- All projects must be adapted for the locality.

- The mission statement and goals anchor the project.

- The conservancy must be prepared to face challenges such as slow home sales (Harrison, 2012), disagreements over land management (Parker, 2002), or challenges in protecting an ecosystem's reinforcing structures (Meadows, 2008).

- Use the project to serve multiple functions.

- Determine whether it should seek greater and earlier public involvement since the public will be impacted by the project, or whether it may seek less public involvement since there will be no public access provided.

- Realize that there is a tension between Milder's three key priorities of limited development: the land's ecological values, a profit margin and community needs. This report argues that since accomplishing one of these detracts from the others, it is necessary to seek feedback, prioritize the feedback because not all of them can be accomplished and then ensure that the top priority is achieved by the project, yet the project is feasible.

- At minimum, identify conservation values in the site, compose the site plan and set easement standards (LTA, 2004; Perlman \& Milder, 2005).

- Gain experience with small development projects such as trails before pursuing limited development.

- This report's interpretation of limited development is that it is inherently collaborative.

- Limited development is a promising tool to accomplish conservation in San Luis Obispo County. 